Caroline de Gouveia Buff Passone

\title{
Tradução e validação do Diabetes Self-Management Profile (DSMP) para a Língua Portuguesa do Brasil: um instrumento para avaliar o autocuidado no diabetes tipo 1 numa população brasileira
}

Dissertação apresentada à Faculdade de Medicina da Universidade de São Paulo para obtenção do título de Mestre em Ciências;

Programa de Pediatria

Orientadora: Dra.Thais Della Manna

SÃO PAULO

2016 
Dados Internacionais de Catalogação na Publicação (CIP)

Preparada pela Biblioteca da

Faculdade de Medicina da Universidade de São Paulo

Creprodução autorizada pelo autor

\section{Passone, Caroline de Gouveia Buff}

Tradução e validação do Diabetes Self-Management Profile (DSMP) para a língua portuguesa do Brasil : um instrumento para avaliar o autocuidado no diabetes tipo 1 numa população brasileira / Caroline de Gouveia Buff Passone. -- São Paulo, 2016.

Dissertação(mestrado)--Faculdade de Medicina da Universidade de São Paulo Programa de Pediatria.

Orientador: Thais Della Manna.

Descritores: 1.Diabetes mellitus tipo 1 2.Autocuidado 3.Estudos de validação 4.Entrevista 5.Adesão à medicação 6.Criança 7.Adolescente 


\section{DEDICATÓRIA}

Dedico este trabalho a todos os pacientes com diabetes tipo 1 que passaram pela minha vida $e$, que lutam diariamente para acolher 0 momentâneo incurável, se cuidar a todo instante e, sobretudo, ser feliz. 


\section{AGRADECIMENTOS}

\section{À Deus}

Ao meu querido marido Thiago Passone e filho Matheus

Aos meus pais Selma e Jorge

Ao meus avós: Maria da Conceição, João Eugênio ( em memória), Walter ( em memória), Assunta ( em memória)

A minha família: Pammela, Luis, Nuno Felipe, Nayara, Fábio, Manuela, Maria José (Zeza) e Dinei

A minha orientadora e inspiradora Dra. Thais Della Manna

A minha querida amiga Lygia S Oliveira

As tradutoras: Mariana Paglione Vedana e Beatriz Leite

A todos os pacientes com diabetes tipo 1 e seus familiares

A todos que me deram suporte na realização do trabalho, em especial ao Thiago Mendonça (estatístico) e a Monica Souza.

A toda a equipe do Ambulatório de Diabetes do Instituto da Criança, em especial à Dra. Roberta Savoldelli, à nutricionista Larissa Baldini Mattar e à enfermeira Leila Ferreira Garcia

A equipe de Endocrinologia Pediátrica do Instituto da Criança, a todos os residentes e complementandos nestes anos de trabalho, aos queridos mestres Dr. Durval Damiani, Dr. Hilton Kuperman, Dr. Hamilton Menezes-Filho, Dra. Leandra Steinmetz, Dra. Louise Cominato, Dra. Ruth Rocha Franco, Dr. Vae Dichtchekenian, Dra. Nuvarte Setian. 
"Onde há amor e sabedoria, não tem temor e nem ignorância."

- Francisco de Assis

"O conhecimento do corpo para ser eficaz não é necessariamente o alto conhecimento científico do engenheiro, mas sim aquele, prático do operário.”

- Jigoro Kano 
Normalização adotada

\section{Padrão Vancouver}

Esta dissertação está de acordo com as seguintes normas, em vigor no momento desta publicação:

Referências: adaptado de International Committee of Medical Journals Editors (Vancouver).

Universidade de São Paulo. Faculdade de Medicina. Divisão de Biblioteca e Documentação. Guia de apresentação de dissertações, teses e monografias. Elaborado por Anneliese Carneiro da Cunha, Maria Julia de A. L. Freddi, Maria F. Crestana, Marinalva de Souza Aragão, Suely Campos Cardoso, Valéria Vilhena. 3a ed. São Paulo: Divisão de Biblioteca e Documentação; 2011.

Abreviaturas dos títulos dos periódicos de acordo com List of Journals Indexed in Index Medicus. 


\section{SUMÁRIO}

\section{LISTA DE ABREVIATURAS E SIGLAS}

\section{LISTA DE TABELA}

\section{LISTA DE FIGURAS}

RESUMO

SUMMARY

1 INTRODUÇÃO

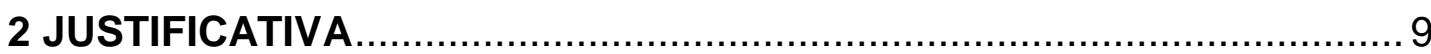

3 HIPÓTESE

4 OBJETIVOS

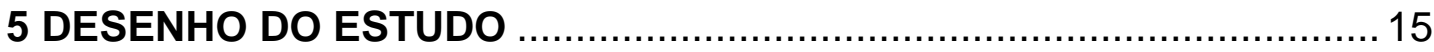

6 MÉTODOS

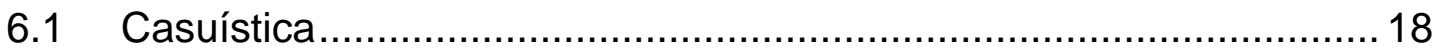

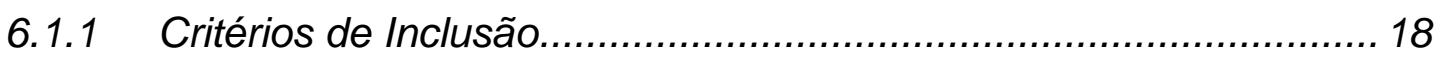

6.1.2 Critérios de Exclusão ................................................................ 18

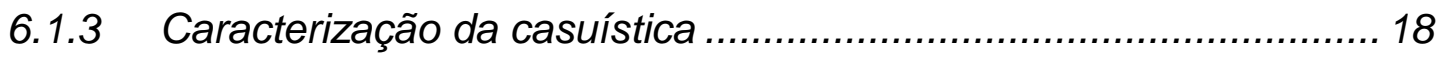

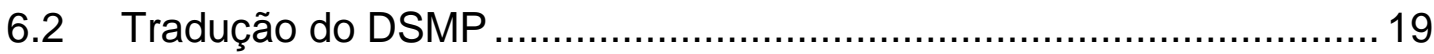

6.3 Aplicação do questionário traduzido ................................................. 20

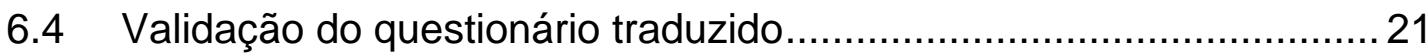

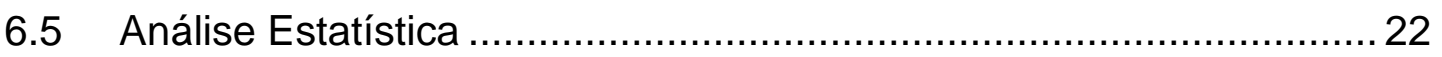

7 RESULTADOS

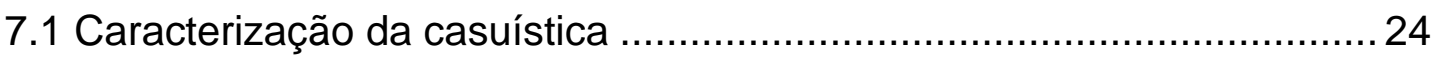

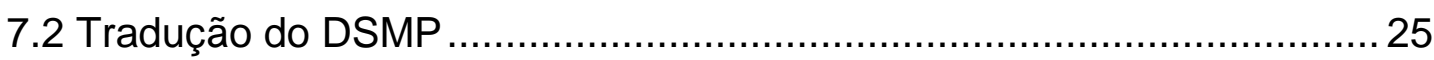

7.3 Pontuação do questionário traduzido: escore total e subescalas ............26

7.4 Comparação dos Escores por Idade, Sexo e Tipo de Regime de Insulina

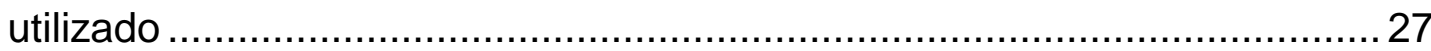

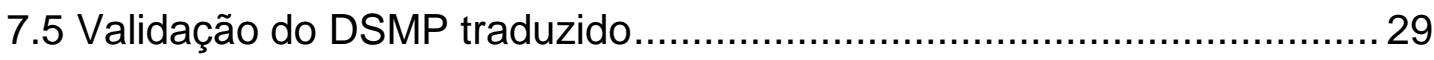

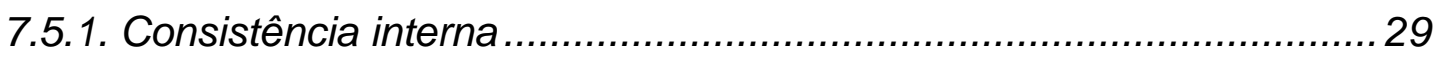

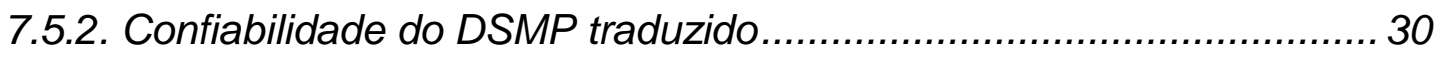

7.5.3. Validação concorrente do DSMP traduzido...................................... 31

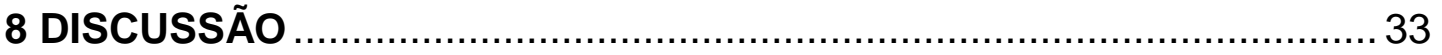


9 CONCLUSÕES

40

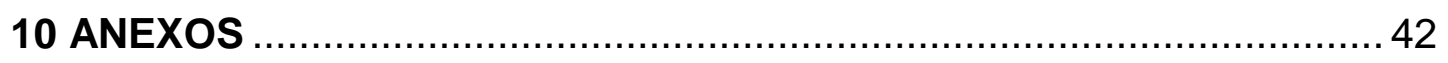

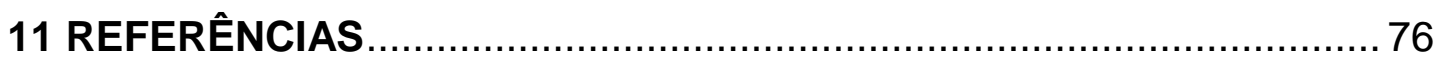




\section{LISTA DE ABREVIATURAS E SIGLAS}

\begin{tabular}{|c|c|}
\hline DM & - diabetes mellitus \\
\hline ADA & - Associação Americana de Diabetes \\
\hline DM1 & - diabetes mellitus tipo 1 \\
\hline DM2 & - diabetes mellitus tipo 2 \\
\hline DCV & - doenças cardiovasculares \\
\hline IDF & - Federação Internacional de Diabetes \\
\hline OMS & - Organização Mundial da Saúde \\
\hline SUS & - Sistema Único de Saúde \\
\hline DCCT & - Diabetes Control and Complications Trial \\
\hline DQol & - Quality of Life \\
\hline PedsQL & - Pediatric Quality of Life InventoryTM \\
\hline DSMP & - Diabetes Self-Management Profile \\
\hline SSCA-R & - Summary of Self-Care Activities Measure-Revised \\
\hline SMOD-A & - Self-Management of Type 1 Diabetes in Adolescents \\
\hline DQOL & - Quality of Life Scale for Children \\
\hline HC-FMUSP & $\begin{array}{l}\text { Hospital das Clinicas da Faculdade de Medicina da Universidade } \\
\text { de São Paulo }\end{array}$ \\
\hline DSMP & - Diabetes Self-Management Profile \\
\hline TCLE & - Termo de Consentimento Livre e Esclarecido \\
\hline $\mathrm{HbA} 1 \mathrm{c}$ & - Hemoglobina glicada \\
\hline ISPAD & - International Society for Pediatric and Adolescent Diabetes \\
\hline
\end{tabular}




\section{LISTA DE TABELA}

Tabela 1 - Caracterização clínica da casuística ............................................. 24

Tabela 2 - Caracterização socioeconômica.................................................. 25

Tabela 3 - Escore total e por subscalas do questionário traduzido .................. 26

Tabela 4 - Comparação entre o escore total e subescalas entre os pacientes

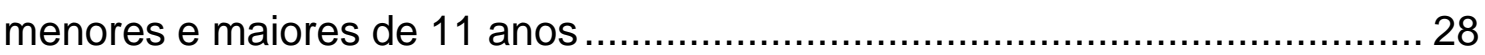

Tabela 5 - Comparação entre o escore total e subescalas entre os pacientes

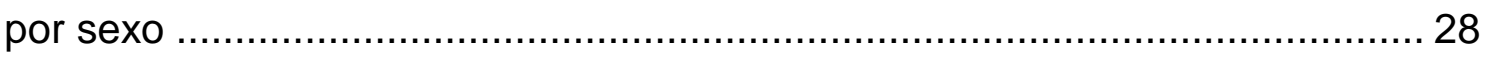

Tabela 6 - Comparação entre o escore total e subescalas para regime

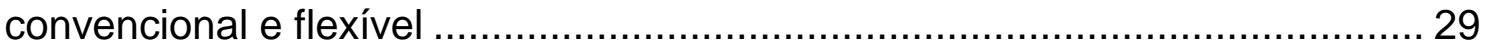

Tabela 7 - Consistência interna obtida através do valor alfa de Cronbach total e

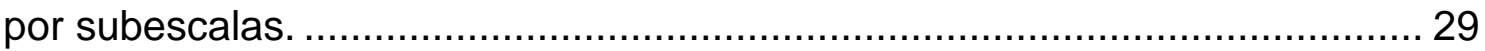

Tabela 8 - Correlação entre os valores alfa de Cronbach obtidos em cada subescala com o escore total ................................................................ 30

Tabela 9 - Confiabilidade intraobservador /teste-reteste ................................ 30

Tabela 10 - Confiabilidade interobservadores ................................................ 30

Tabela 11 - Correlação entre Hb1Ac média com o escore total e subescalas . 31

Tabela 12 - Comparação entre o escore total e das subescalas dos pacientes

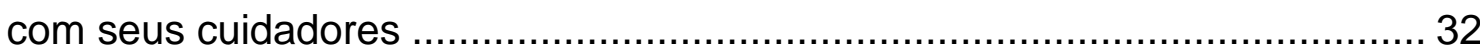




\section{LISTA DE FIGURAS}

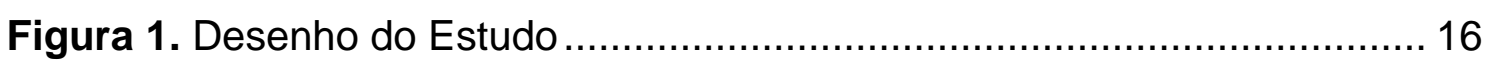

Figura 2. Correlação entre o escore total e a Hb1Ac média ............................... 31

Figura 3. Correlação escore total e percepção médica .................................. 32 


\section{RESUMO}

Passone CGB. Tradução e validação do Diabetes Self-Management Profile (DSMP) para a língua portuguesa do Brasil: um instrumento para avaliar o autocuidado no diabetes tipo 1 numa população brasileira [Dissertação]. São Paulo: Faculdade de Medicina, Universidade de São Paulo; 2016.

Objetivo: Traduzir e validar o instrumento Diabetes Self-Management Profile (DSMP)-Regime Convencional e Flexível para a língua portuguesa do Brasil, numa população pediátrica portadora de diabetes mellitus tipo 1 (DM1) e seus cuidadores, para avaliar a qualidade do autocuidado desta população.

Método: O DSMP é uma entrevista semiestruturada composta de 25 questões, dividida em 5 subscalas (exercício, hipoglicemia, alimentação, monitorização glicêmica e insulinoterapia). Foi administrado para pacientes com DM1 entre 6 e 18 anos $(n=102)$ e seus cuidadores. Crianças menores de 11 anos foram entrevistadas com os pais e as maiores separadamente. Os pacientes foram entrevistados duas vezes no intervalo de 3 meses pelo mesmo pesquisador, e estas entrevistas foram gravadas e avaliadas por um segundo pesquisador. A análise estatística para confiabilidade e validade incluiu a associação do escore com a Hb1Ac e um questionário de percepção medica.

Resultados: O escore do DSMP total mostrou adequada consistência interna (Cronbach $=0,79)$ e adequada confiabilidade inter $(r=0,38, p<000,1)$ e intraobservador $(0,43, p<000,1)$. $O$ escore total do DSMP e subscalas tiveram correlação negativa com a HbA1c $(r=-0.53, p<0.001)$ e positiva com a percepção médica do autocuidado $(r=0.67, p<0.001)$.

Conclusões: A versão traduzida do DSMP demonstrou que este é um instrumento confiável e válido para avaliar o autocuidado do DM1. O escore do DSMP foi correlacionado com HbA1c em nossa população brasileira, sendo agora é o primeiro instrumento de autocuidado validado em nossa língua para avaliar pacientes pediátricos.

Descritores: 1.Diabetes mellitus tipo 1 2.Autocuidado 3.Estudos de validação 4.Entrevista 5.Adesão à medicação 6.Criança 7.Adolescente. 


\section{SUMMARY}

Passone CGB. Translation and validation of Diabetes Self-Management Profile (DSMP) into Brazilian Portuguese language: first instrument to access type 1 diabetes self-management in a pediatric population. [Dissertation]. São Paulo: Faculdade de Medicina, Universidade de São Paulo; 2016.

Objective: To translate and validate the instrument DSMP-Conventional and Flexible Regimens into Brazilian Portuguese language in order to evaluate the quality of diabetes self-management in children and adolescents with type 1 diabetes and their caregivers.

Method: DSMP was translated into Brazilian Portuguese language by forward and back translation method and validated in a group of 102 type 1 diabetes youths between 6 and 18 years $(n=102)$ and their families by the analysis of its internal consistency, intra and interobserver reliability and concurrent correlation with $\mathrm{HbA} 1 \mathrm{c}$ and physician perception.

Results: DSMP total scores demonstrated adequate internal consistency (Cronbach's 0.79), 3-month test-retest reliability $(r=0.43)$, inter-interviewer agreement $(r=0.38)$. DSMP total scores and all subscales were significantly correlated to HbA1c $(r=-0.53, p<0,001)$, as well as physician perception $(r=0.67, p<0,001)$.

Conclusion: DSMP-translated version into Brazilian Portuguese language is a reliable and valid tool to assess diabetes self-management.

Keywords: 1.Type 1 diabetes. 2.Self-management 3.Validation 4.Interview 5. Adherence 6. Child 7. Adolescent. 
1 INTRODUÇÃO 
O diabetes mellitus (DM) é definido como um grupo de doenças metabólicas caracterizadas por hiperglicemia, resultante de defeitos na secreção de insulina e/ou em sua ação ${ }^{1}$. A classificação proposta pela Associação Americana de Diabetes (ADA) inclui 4 categorias'2: diabetes mellitus tipo 1 (DM1), diabetes mellitus tipo 2 (DM2), diabetes gestacional e outros tipos específicos de diabetes (monogênico, associado a outras doenças e a drogas). Ainda existem duas categorias, referidas como pré-diabetes, que são a glicemia de jejum alterada e a tolerância à glicose diminuída. Essas categorias não são entidades clínicas, mas fatores de risco para o desenvolvimento do DM e de doenças cardiovasculares (DCV) ${ }^{1-2}$.

O DM2 é a forma mais comum de diabetes, correspondendo a $90 \%$ dos casos, afetando indivíduos que têm resistência à insulina como também deficiência desta. Sua etiologia é heterogênea, sendo o risco de desenvolvimento diretamente proporcional ao aumento da idade, obesidade e falta de atividade física ${ }^{3}$.

O DM1, classe mais prevalente na infância, resulta da destruição das células beta do pâncreas, usualmente por processo autoimune (forma autoimune; tipo $1 \mathrm{~A}$ ) ou menos comumente de causa desconhecida (forma idiopática; tipo 1B). Os anticorpos estão presentes em $85-90 \%$ dos indivíduos quando a hiperglicemia é inicialmente detectada e incluem anticorpos antiinsulina, antidescarboxilase do ácido glutâmico, antiilhota, antitransportador do zinco 8 e antitirosino fosfatases ${ }^{3}$.

O atlas 2015 (sétima edição) da Federação Internacional de Diabetes (IDF) relatou que, anualmente, cerca de 86000 crianças menores de 15 anos desenvolvem DM1 no mundo ${ }^{4}$. Infelizmente, o diabetes diagnosticado na infância apresenta maior risco para complicações ainda numa fase precoce da vida, podendo implicar numa redução de 10 a 20 anos na expectativa média de vida, principalmente nos países em desenvolvimento ${ }^{4}$. Indivíduos diabéticos com menor acesso a educação em diabetes apresentam um aumento de $40 \%$ 
no risco de morte prematura comparado àquele de diabéticos altamente envolvidos em seus cuidados ${ }^{5}$.

De um total estimado de 542000 crianças com DM1, um quarto vive na Europa e um quinto na América do Norte e Caribe. Os países com as estimativas mais elevadas de casos são EUA (84100), Índia (70200) e Brasil $(30900)^{4}$. Consequentemente, podemos inferir que há um grande número de pessoas de língua portuguesa afetadas pelo DM1.

A Organização Mundial da Saúde (OMS) cita como referência brasileira, o estudo realizado em três cidades do estado de São Paulo (Bauru, Botucatu e Rio Claro) entre 1987 e 1991, relatando uma incidência anual média de 7,6 casos de DM1 por 100000 jovens menores de 15 anos $^{7}$. Um estudo que avaliou a variação temporal da incidência do DM1 na cidade de Bauru, entre 1986 e 2006, observou o surgimento de 179 casos novos no período, com uma incidência média de 10,4/100000, tendo havido uma variação de 9,6 vezes nesta incidência entre os anos de 1987 e $2002^{8}$.

A notificação do diabetes mellitus no Brasil pelo Sistema Único de Saúde (SUS) não está classificada em subtipos, o que acarreta uma carência de dados estatísticos sobre o DM1 no país. Através do sistema DATA-SUS, ocorreram 8.391internações em menores de 19 anos por diabetes mellitus no Brasil no ano de 2014, com 142 óbitos em 2013. Por outro lado, ocorreram 73.443 internações por asma e 17.169 internações por leucemia, com o número de óbitos de 117 e 892, respectivamente, em menores de 19 anos, nestes mesmos períodos ${ }^{9}$, o que sugere que a prevalência brasileira de DM1 na infância seja ainda inferior àquelas da asma e do câncer infantil.

$\mathrm{Na}$ última década, médicos e pesquisadores têm aumentado o interesse no autocuidado em crianças e adolescentes com DM1. Este conceito se tornou mais importante após a recomendação do regime de controle intensivo para tratamento do diabetes, em função das evidências clínicas observadas no estudo multicêntrico norte-americano Diabetes Control and Complications Trial $(\mathrm{DCCT})^{10}$, realizado entre 1983 e 1993, com 1441 pacientes portadores de DM1, que mostrou que manter os níveis glicêmicos o mais próximo do normal diminui a progressão para retinopatia, doença renal e neuropatia, em $76 \%$, $50 \%$ e $60 \%$, respectivamente ${ }^{10}$. 
O manejo do DM1 necessita da adoção de um complexo regime terapêutico pelo paciente e sua família. Diversos estudos mostraram que os pacientes têm muita dificuldade de atingir as expectativas da equipe de saúde e de adotar as medidas básicas do autocuidado em diabetes. Estima-se que a taxa de não aderentes varie entre 40 e $90 \%{ }^{11}$, estando relacionada com maus desfechos de saúde e custos elevados ${ }^{12-14}$.

Atualmente, o tratamento do diabetes tem enfocado a educação continuada dos pacientes e suas famílias, encorajando-os a modificar comportamentos diariamente, visando um melhor controle metabólico.

A educação em diabetes é definida como o processo de promoção de conhecimento sobre a doença, de facilitação da aprendizagem das técnicas e habilidades necessárias para o autocuidado, ao manejo das crises de descompensação e a mudanças de comportamento que conduzam ao bom controle do diabetes a longo prazo ${ }^{15}$. Com o objetivo de melhorar os desfechos clínicos, o estado de saúde e a qualidade de vida, a educação para o autocuidado visa: capacitar o paciente para a solução de problemas; ajudá-lo a identificar barreiras e a desenvolver habilidades de enfrentamento destas questões; promover a colaboração ativa com a equipe multiprofissional; fornecer orientação para o processo contínuo de decisão terapêutica ${ }^{16-17}$.

Para o profissional de saúde é importante avaliar a qualidade do autocuidado do paciente para o direcionamento de condutas e para 0 estabelecimento de estratégias e metas conjuntas com o paciente e sua família. A literatura especializada em DM1 em crianças e adolescentes busca, sistematicamente, instrumentos de avaliação da qualidade deste autocuidado que se diferencia da avaliação da qualidade de vida, que tem foco essencialmente psicossocial na doença. Para esta, existem alguns instrumentos já bem estabelecidos como o Diabetes Quality of Life (DQol) e o Pediatric Quality of Life Inventory ${ }^{T M}$ (PedsQL), sendo o primeiro já validado para a língua portuguesa ${ }^{18}$.

Por outro lado, para acessar a adesão e o autocuidado, várias estratégias já foram utilizadas como o atendimento telefônico 24 horas, diários escritos, monitores eletrônicos, além de questionários e entrevistas 
estruturadas; entretanto, inconsistências metodológicas e conceituais tem sido motivo de confusão ao longo das últimas décadas ${ }^{19}$.

A construção de instrumentos de avaliação da qualidade do autocuidado em diabetes apresenta algumas dificuldades intrínsecas. Primeiramente, 0 termo autocuidado tem muitas definições, atribuindo-se a ele três conceitos essenciais: processo, atividade e metas. Mais recentemente tem sido proposta a seguinte definição para o autocuidado: "É um processo ativo diário e flexível em que cuidadores e crianças dividem responsabilidades e tomam decisões para alcançar o controle da doença, saúde, bem-estar através de um grande número de atividades relacionadas à doença"20.

Para os autores de língua inglesa, há diferença de terminologia entre "self-care" e "self-management", sendo "self-care" associado ao cuidado do paciente consigo mesmo e "self-management" definido de forma mais ampla, envolvendo $o$ cuidado consigo $e$ as relações interpessoais ${ }^{20}$. No entanto, na tradução para a língua portuguesa, o termo "self-management" seria traduzido literalmente como "automanejo", uma expressão que não é aplicada na prática clínica pelas equipes multiprofissionais brasileiras especializadas em diabetes. Em nosso meio, utiliza-se 0 termo autocuidado, para se referir ao "self-management" e não em sua tradução literal. A construção de instrumentos de avaliação do autocuidado encontra algumas dificuldades, a começar pela discussão semântica existente sobre as terminologias complacência, adesão e autocuidado ${ }^{11}$. Os termos complacência e adesão são utilizados para avaliar se o comportamento do paciente coincide com a prescrição médica, porém evocam uma postura emocional negativa, de passividade do entrevistado, resultando em respostas inconsistentes. O termo autocuidado engloba os comportamentos do paciente e sua família e dos profissionais de saúde, assim como a manutenção e monitorização do controle do diabetes, prevenção e correção dos níveis glicêmicos. Portanto, o autocuidado enfatiza a quantidade, a precisão e a regularidade dos comportamentos, mais do que a distância que este comportamento está daquilo que foi prescrito ${ }^{11,20}$. A segunda barreira seria a questão da confiabilidade, uma vez que a precisão máxima exigiria um acompanhamento constante e ininterrupto do indivíduo por parte de um observador treinado, o 
que seria inviável na prática ${ }^{11}$. A terceira barreira seria o fato de que a maioria dos estudos não mostrou associação significativa entre adesão ao tratamento e controle do diabetes. A variabilidade glicêmica pode ocorrer em função de fatores genéticos, biológicos, demográficos, características farmacológicas das insulinas, da dieta e da atividade física.

Com a evolução do tratamento do diabetes, o autocuidado tem se tornado mais complexo e, além disso, modalidades terapêuticas mais recentes como o sistema de infusão e os novos análogos da insulina não foram avaliados pelos instrumentos de medida de adesão já publicados ${ }^{12}$.

Shilling et $a l^{20}$, em estudo de revisão sobre instrumentos de autocuidado validados na língua inglesa, destacam a importância da utilização dos instrumentos capazes de avaliar pacientes em regime flexível, já que se trata de uma importante opção de tratamento na atualidade. O regime flexível é aquele que utiliza o esquema de insulina basal/bolus, onde há uma dose de insulina basal (administrada com insulina lenta, ultralenta ou ultrarrápida pelo sistema de infusão contínua) e bolus de insulina para correção da hiperglicemia e também de acordo com a quantidade de carboidratos da dieta (insulina ultrarrápida). O regime basal/bolus pode ser administrado através da aplicação intermitente de múltiplas injeções de insulina, ou através da terapia com sistema de infusão contínua. Dentre os instrumentos analisados, somente o Diabetes Self-Management Profile (DSMP), o Summary of Self-Care Activities Measure-Revised (SSCA-R) e o Self-Management of Type 1 Diabetes in Adolescents (SMOD-A), publicado posteriormente ${ }^{21}$, avaliaram pacientes em terapia com sistema de infusão contínua; entretanto, esses dois últimos foram validados somente em adolescentes.

O instrumento $\mathrm{DSMP}^{11}$ é uma entrevista semi-estruturada, com 25 questões para acessar o autocuidado em crianças entre 6 a 18 anos nos últimos três meses, (Anexo 1). Este instrumento teve como base o Self-Care Adherence Inventory ${ }^{22}$, sendo capaz de acessar o desempenho e os ajustes nas atividades relacionadas ao diabetes, com bastante sensibilidade às variações existentes. Inclui um questionário para regime flexível e um para regime convencional para cuidadores e outro para as crianças. 
A pontuação desta entrevista é dada pela análise de cinco domínios ou subescalas num escore final (Anexo 2) que considera os seguintes escores máximos por subescalas: 12 pontos para atividade física, 11 pontos para hipoglicemia, 17 pontos para alimentação, 16 pontos para aplicação de insulina e 32 pontos para monitorização glicêmica.

A validação original feita por Harris et al. ${ }^{11}$, com 105 pacientes, mostrou adequadas consistência interna (alfa de Cronbach $=0,76$ para pais e adolescentes), confiabilidade intraobservador $(r=0,67)$ e interobservadores $(r=0,94)$ para o escore DSMP-Regime Convencional. No escore DSMP-Regime Flexível, realizado com 200 pacientes, no DirectNet Study Group ${ }^{23}$, foram encontradas adequadas consistência interna (alfa de Cronbach $=0,7$ para cuidadores e 0,65 para adolescentes) e confiabilidade inter e intraobservadores. Os escores do questionário DSMP, tanto regime convencional quanto regime flexível, apresentaram relação significativamente negativa com os níveis da hemoglobina glicada (convencional $r=-0,28$ ); flexível $r=-0,2$ ). Foi encontrada correlação significativa entre os escores do Quality of Life Scale for Children (DQOL) e os escores do DSMP para adolescentes e mães. Em 2006, lanotti $^{24}$ validou o DSMP em uma forma modificada, com resultados semelhantes, a qual não foi utilizada em nosso estudo. Em 2010, o instrumento em regime convencional e flexível foi revalidado com aumento da casuística para sexo e idade, inclusão de adolescentes e realização de comparações independentes entre pais e crianças e grupos por idade ${ }^{11,25}$. Neste estudo, participaram 275 crianças com DM1, e 444 cuidadores (nome usado para pais ou cuidador legal). A validação original incluiu crianças entre 6,1 a 15,8 anos, sendo ampliada para até 18 anos posteriormente. As crianças menores de 11 anos foram entrevistadas junto aos seus cuidadores ${ }^{25}$.

Em 2010, o instrumento para cuidadores foi validado para a língua espanhola e foi correlacionado com a hemoglobina glicada e com a percepção do médico em relação ao paciente, através de um escore que demonstrou boa consistência interna (alfa de Cronbach $=0,95)^{26}$. Também, o instrumento foi convertido em forma de autorrelato e validado em língua inglesa ${ }^{27}$.

Recentemente, o DSMP foi validado para a língua portuguesa em 75 pacientes, na faixa etária acima de 11 anos (média de 34,9 $\pm 13,7$ anos), com 
longo tempo de duração do diabetes (média 18,1 $\pm 11,8$ ). Nesta população, foi encontrada correlação negativa do escore total do instrumento com a hemoglobina glicada $(r=-0,46, P<0,01)$ e positiva com 0 instrumento de aderência $S \mathrm{Cl}-\mathrm{R}(\mathrm{r}=0,88, \mathrm{P}<0,01)$, também validado neste estudo ${ }^{28}$.

Após a análise dos diversos instrumentos, optamos pelo DSMP pelas seguintes vantagens: maior abrangência quanto à faixa etária, maior correlação com a hemoglobina glicada, correlação com a qualidade de vida de mães e crianças (mostrando que o autocuidado está relacionado à qualidade de vida) e sensibilidade à variação das atividades globais do controle do diabetes, praticidade, avaliação de autocuidado e não somente adesão, avaliação de pacientes em regime flexível (insulina no esquema basal/bolus ou sistema de infusão contínua). Entre as desvantagens encontra-se a necessidade de ser aplicado por uma pessoa treinada e de existir somente uma pergunta sobre colaboração dos profissionais de saúde e nenhuma sobre metas de autocuidado. 
2 JUSTIFICATIVA 
Com a finalidade de promover melhora do controle metabólico e do estado de saúde das crianças e adolescentes atendidos no Ambulatório de Diabetes do Instituto da Criança HC-FMUSP, planejamos implantar um programa de educação continuada em diabetes voltado ao paciente e seus cuidadores; dessa forma, um instrumento de avaliação do autocuidado será necessário tanto para o diagnóstico das necessidades educativas dessa população antes do início do programa, quanto para a avaliação de sua eficácia a curto e médio prazo, viabilizando assim constantes modificações do conteúdo educativo.

Em revisão da literatura, não foram encontrados questionários em língua portuguesa para avaliação do autocuidado para DM1 na faixa etária pediátrica. Assim, por se tratar de um instrumento para avaliação do autocuidado em crianças e adolescentes portadores de DM1 em língua portuguesa do Brasil, buscou-se um questionário com maior aplicabilidade, abrangência e confiabilidade, como o instrumento DSMP. Após a obtenção da autorização dos autores $^{11}$, procedemos à sua tradução e validação. 
3 HIPÓTESE 
Analisar se o questionário DSMP é capaz de avaliar o autocuidado numa população brasileira de pacientes entre 6 e 18 anos portadores de diabetes mellitus tipo 1. 
4 OBJETIVOS 


\section{Objetivos Principais}

Os objetivos deste estudo foram:

- traduzir o instrumento DSMP (Diabetes Self-Management Profile) Regime Convencional e Regime Flexível para a língua portuguesa do Brasil, de maneira que fosse equivalente à versão original, de forma clara e de fácil entendimento;

- validá-lo para uma população brasileira de crianças e adolescentes portadores de DM1 e seus cuidadores, possibilitando a avaliação da qualidade de seu autocuidado.

\section{Objetivo específicos}

- Avaliar a consistência interna da versão do DSMP traduzida para o português através da determinação da correlação interitens, como também de sua confiabilidade intra e interobservadores.

- Determinar o escore total e das subescalas do questionário traduzido;

- Verificar a existência de correlação do escore obtido no questionário com um parâmetro consagrado de controle metabólico (hemoglobina glicada) e também com a percepção médica da qualidade de autocuidado do paciente.

- Comparar o escore obtido entre os subgrupos por idade, regime de insulina utilizado, sexo e avaliações dos pacientes e seus cuidadores. 
5 DESENHO DO ESTUDO 
Foi realizado um estudo transversal, quantitativo, descritivo e analítico de tradução e validação do instrumento DSMP para a língua portuguesa do Brasil, na seguinte sequência: tradução-retroversão, aplicação do questionário numa amostra de indivíduos e sua validação através da análise dos resultados (Figura 1).

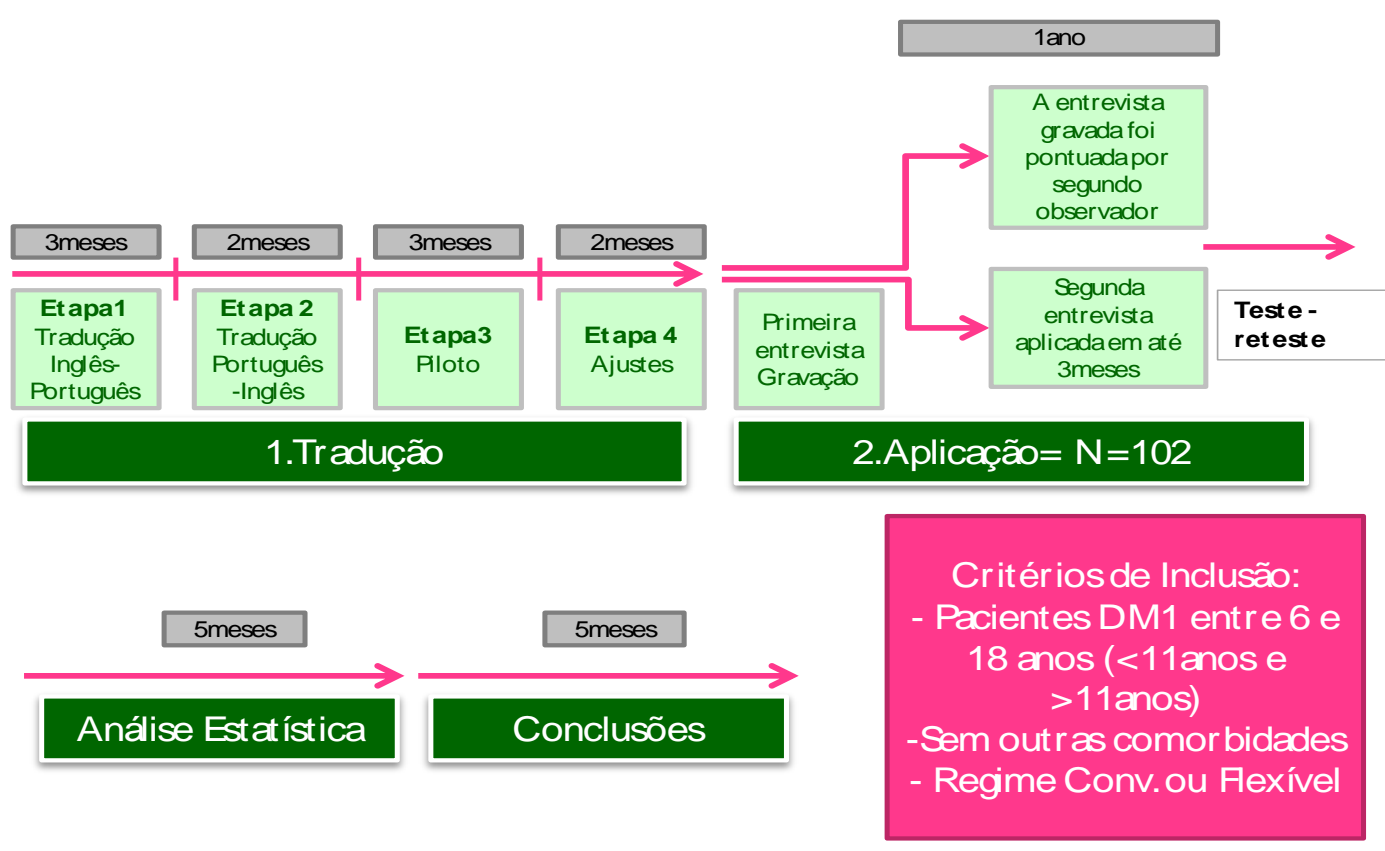

Figura 1. Desenho do Estudo 
6 MÉTODOS 


\subsection{Casuística}

Foram recrutados para o estudo, pacientes com diagnóstico de DM1 entre 6 e 18 anos de idade, acompanhados regularmente no Ambulatório de Diabetes do Instituto da Criança HC-FMUSP, no período de 2012 a 2013, com o objetivo de compor uma população amostral de 100 pacientes e 100 cuidadores (um por paciente), sendo 50 pacientes menores de 11 anos, que foram entrevistados juntamente com seus cuidadores, e 50 maiores de 11 anos, que foram entrevistados separadamente de seus cuidadores. Sendo metade destes em regime flexível.

\subsubsection{Critérios de Inclusão}

- Diagnóstico de DM1 por mais de 1 ano.

- Estar acompanhado por pelo menos um cuidador no dia da entrevista.

\subsubsection{Critérios de Exclusão}

- Apresentar outras comorbidades físicas e/ou mentais.

- Dose de insulina total diária menor que $0,5 \mathrm{U} / \mathrm{kg} / \mathrm{dia}$.

Após explicação verbal detalhada da pesquisa, o Termo de Consentimento Livre e Esclarecido (TCLE) do cuidador responsável foi assinado, como também o Termo de Assentimento para os pacientes maiores de 11 anos. $O$ estudo foi aprovado pela Comissão de Ética para Análise de Projetos de Pesquisa do Instituto da Criança do Hospital das Clínicas da Faculdade de Medicina da Universidade de São Paulo em 19/09/2012, parecer CEP número 1079/34/2012. (Anexo 3)

\subsubsection{Caracterização da casuística}

Os pacientes com DM1 foram caracterizados quanto a sexo, idade e avaliados laboratorialmente quanto aos níveis de hemoglobina glicada (HbA1c). Foi utilizado o valor da $\mathrm{HbA} 1 \mathrm{c}$ à época da entrevista ou a média das duas HbA1c próximas dentro de 3 meses. O método analítico utilizado foi o HPLC 
Biorad Variante II (Bio-Rad Laboratories, Munich, Germany). Os valores foram analisados de forma quantitativa.

Para a avaliação socioeconômica foram solicitadas as seguintes informações: principal cuidador, idade e ocupação do cuidador, escolaridade materna, renda média mensal da família e renda per capita (renda média mensal dividida por número de moradores da casa).

\subsection{Tradução do DSMP}

A tradução do DSMP para pais e crianças, no Regime Convencional e no Regime Flexível para o português do Brasil foi realizada de acordo com o método de tradução-retroversão através das seguintes etapas ${ }^{29-31}$.

Etapa 1 (Tradução inicial). Tradução independente da versão original do inglês americano para o português do Brasil por dois tradutores bilíngues, seguida de discussão por uma comissão de tradução composta por uma equipe médica de endocrinologistas pediátricos junto aos tradutores bilíngues, com a intenção de combinar as duas versões traduzidas em uma única versão de consenso e adequá-la à prática clínica. Neste estágio, os pesquisadores buscaram equivalência linguística e conceitual.

Etapa 2 (Avaliação da tradução inicial). A versão traduzida para 0 português do Brasil foi então retraduzida para o inglês americano por um tradutor bilíngue, tendo como língua nativa o inglês. Subsequentemente, esta versão foi enviada aos responsáveis ${ }^{11}$ pelo instrumento para sua avaliação.

Etapa 3 (Avaliação da equivalência cultural ou pré-teste). Nesta fase, a versão traduzida foi aplicada a um grupo de pacientes atendidos em nossa clínica e aos seus cuidadores, para determinar se o mesmo era considerado aceitável, se a linguagem era simples e apropriada. Todos os pacientes deveriam ter o português como língua nativa. Cinco pacientes e cinco cuidadores de cada faixa etária foram entrevistados no segundo semestre de 2011, seguindo a metodologia de entrevista cognitiva, que consiste em realizar entrevistas diretas, dentro das quais, o entrevistador perguntou se o paciente teve alguma dificuldade no entendimento do questionário e avaliou a interpretação dada pelo paciente item a item. Ao identificar dificuldades de 
compreensão, o entrevistador propôs e também solicitou alternativas à tradução. Estas entrevistas foram gravadas.

Etapa 4 (Pós-teste). Nesta etapa itens ou instruções traduzidas que geraram mal-entendidos por parte das crianças e adolescentes ou de seus cuidadores foram modificadas. As entrevistas gravadas foram analisadas e discutidas com a equipe médica de endocrinologistas pediátricos para a produção da versão traduzida final. As modificações foram enviadas ao autor original americano ${ }^{11}$ para avaliação e a nova versão foi aplicada e rediscutida até a versão definitiva.

\subsection{Aplicação do questionário traduzido}

Nesta fase, as entrevistas foram aplicadas a um grupo de 105 pacientes, estratificados por faixa etária, e aos seus cuidadores.

O DSMP-Regime Flexível e o DSMP-Regime Flexível Para os Pais foram aplicados aos participantes, nos quais o regime prescrito incluía a contagem de carboidratos (crianças em regime de insulina basal/bolus em múltiplas aplicações de injeções de insulina ou sistema de infusão subcutânea contínua de insulina com ajustes baseados na contagem de carboidratos).

O DSMP-Regime Convencional e o DSMP-Regime Convencional Para os Pais foram aplicados a pacientes que utilizavam doses fixas de insulina de ação intermediária e insulina de ação rápida ou ultrarrápida conforme algoritmo de correção pré-estabelecido pelo grau de hiperglicemia apresentado no automonitoramento glicêmico domiciliar.

As crianças menores de 11 anos responderam a entrevista juntamente ao seu cuidador; as crianças maiores de 11 anos e seus cuidadores foram entrevistados separadamente.

Cada questionário é composto de 25 itens medindo uma das 5 subescalas do autocuidado: exercícios ( 3 itens), manejo da hipoglicemia (4 itens), dieta (5 itens), monitorização do açúcar no sangue (9 itens) e administração/ajuste de dose de insulina (4 itens). Vinte e uma questões são iguais em ambos os questionários (Regime Convencional e Regime Flexível) e 4 itens se diferenciam por mencionar o bolus de insulina no Regime Flexível. $O$ escore do DSMP já foi descrito previamente e encontra-se no Anexo 2 e 6 . 0 
tempo de aplicação foi de aproximadamente 20 minutos e foi realizada por pesquisadores treinados na aplicação do instrumento.

Todas as etapas deste estudo foram realizadas pela mestra pesquisadora, desde a tradução a aplicação.

\subsection{Validação do questionário traduzido}

A confiabilidade do questionário traduzido foi avaliada pelas seguintes análises: consistência interna, confiabilidade intra e interobservadores e validade concorrente.

A consistência interna (correlação interitens) do questionário traduzido foi avaliada pela aplicação da estatística alfa de Cronbach: um valor alfa $>0,7$ é aceitável, alfa $>0,81$ é bom e alfa $>0,91$ é excelente ${ }^{32}$. Foi avaliado também se alguma das questões individualmente poderia contribuir com a redução do alfa de Cronbach das subescalas ou do escore total.

A metodologia do teste-reteste foi utilizada para avaliação da confiabilidade intraobservador, verificando a correlação das duas avaliações realizadas, num intervalo máximo de três meses, com os mesmos indivíduos e pelo mesmo entrevistador. Para a avaliação da confiabilidade interobservadores, a primeira entrevista foi gravada e ouvida por um segundo pesquisador que pontuou os itens, sem a interferência do primeiro pesquisador. Os escores obtidos por ambos os pesquisadores foram então comparados.

A validação concorrente foi realizada através da verificação da relação entre o escore obtido no questionário traduzido com os seguintes parâmetros:

a) Nível da hemoglobina glicada (HbA1c).

b) Percepção do médico assistente sobre a qualidade do autocuidado do paciente (Anexo 4), baseado no artigo com tradução para 0 espanhol ${ }^{26}$. Este questionário foi traduzido do inglês para a língua portuguesa e utilizado pela equipe. Os escores mais altos do questionário indicam um melhor autocuidado.

c) Comparação entre os escores obtidos nos questionários respondidos pelos cuidadores e pelos adolescentes. A verificação de que não há diferença entre o escore do DSMP escore entre cuidadores e adolescentes avalia a possibilidade de estes poderem ser entrevistados separadamente. 


\subsection{Análise Estatística}

A análise estatística descritiva foi utilizada na caracterização clínica, laboral e socioeconômica dos pacientes e para a análise do escore total do questionário traduzido e das suas subescalas.

A consistência interna foi medida através da estatística alfa de Cronbach $^{33}$ tanto para a escala completa, quanto para as subescalas.

O teste de correlação de Pearson ${ }^{32}$ foi utilizado para as análises do grau de correlação existente entre o escore total e das subescalas, entre os escores obtidos nas fases de teste-reteste (intraobservador), entre os escores obtidos por dois pesquisadores diferentes (interobservadores), como também para a análise da validade concorrente pela correlação do escore total com o grau de controle metabólico (medido pela $\mathrm{HbA1c}$ ) e com o escore obtido no questionário da percepção médica sobre a qualidade do autocuidado de cada paciente.

O teste $t$ foi utilizado para a comparação do escore dos pacientes em relação a sexo, idade, tipo de regime e entre estes e seus cuidadores.

A análise dos dados foi realizada no programa estatístico SPSS V20.0 ${ }^{33}$ e valores de $\rho$ menores que 0,05 foram considerados significativos. 
7 RESULTADOS 


\subsection{Caracterização da casuística}

Foram recrutados 105 pacientes, mas 3 foram excluídos por usarem uma dose total de insulina inferior a 0,5U/kg/dia, finalizando em 102 pacientes.

Tabela 1 - Caracterização clínica da casuística

\begin{tabular}{|c|c|c|}
\hline \multirow{2}{*}{ CARACTERÍSTICA } & \multicolumn{2}{|c|}{ Participação Amostra } \\
\hline & $\mathrm{N}$ & $\%$ \\
\hline \multicolumn{3}{|l|}{ Idade } \\
\hline Menores de 11 anos & 48 & $47,1 \%$ \\
\hline Maiores de 11 anos & 54 & $52,9 \%$ \\
\hline \multicolumn{3}{|c|}{ Média de Idade $=11,3$ anos $( \pm 3,2 \mathrm{DP})$ - Mínimo 6,0/ Máximo 17,9 } \\
\hline \multicolumn{3}{|c|}{ Duração do Diabetes=6,2 anos- Mínimo 3,0/ Máximo 9,4 anos } \\
\hline \multicolumn{3}{|l|}{ Sexo } \\
\hline Homens & 46 & $45,1 \%$ \\
\hline Mulheres & 56 & $54,9 \%$ \\
\hline \multicolumn{3}{|l|}{ Tipo de Regime } \\
\hline Regime Flexível & 42 & $41,2 \%$ \\
\hline Regime Convencional & 60 & $58,8 \%$ \\
\hline TOTAL DE PACIENTES & 102 & $100 \%$ \\
\hline \multicolumn{3}{|l|}{ Hemoglobina Glicada } \\
\hline \multicolumn{3}{|c|}{ Média = 9,5\% ( \pm 1,9DP)- Mínimo 6,6\%/ Máximo 18,9\% } \\
\hline Menores de 11 anos & $8,80 \%$ & \\
\hline Maiores de 11 anos & $10,50 \%$ & \\
\hline Regime Flexível & $8,75 \%$ & \\
\hline Regime Convencional & $10,30 \%$ & \\
\hline
\end{tabular}

A maioria dos pacientes teve a mãe como cuidador principal $(84 \%, n=86$, total 102). Dentre as famílias, 74 responderam a avaliação socioeconômica, sendo que suas características encontram-se na Tabela 2. 
Tabela 2 - Caracterização socioeconômica

\begin{tabular}{|c|c|c|}
\hline Escolaridade materna & $\mathrm{n}$ & $\%$ \\
\hline Nunca estudou & 1 & $1 \%$ \\
\hline Ensino fundamental incompleto & 7 & $10 \%$ \\
\hline Ensino fundamental completo & 8 & $11 \%$ \\
\hline Ensino Médio Completo & 46 & $65 \%$ \\
\hline Ensino superior & 11 & $15 \%$ \\
\hline Pós graduação & 1 & $1 \%$ \\
\hline \multicolumn{3}{|l|}{ Idade média do cuidador } \\
\hline $21-30$ anos & 4 & $6 \%$ \\
\hline $31-40$ anos & 22 & $31 \%$ \\
\hline 41-50 anos & 32 & $46 \%$ \\
\hline $51-60$ anos & 9 & $13 \%$ \\
\hline$>60$ anos & 5 & $7 \%$ \\
\hline \multicolumn{3}{|l|}{ Ocupação do cuidador } \\
\hline Sim & 45 & $61 \%$ \\
\hline Não & 29 & $39 \%$ \\
\hline \multicolumn{3}{|l|}{ Renda familiar média mensal } \\
\hline até $2 \mathrm{SM}^{*}$ & 19 & $26 \%$ \\
\hline $2-3 \mathrm{SM}$ & 25 & $34 \%$ \\
\hline 3-5 SM & 16 & $22 \%$ \\
\hline 5-10 SM & 12 & $16 \%$ \\
\hline$>10 \mathrm{SM}$ & 2 & $3 \%$ \\
\hline \multicolumn{3}{|c|}{ Média $=2.446 \pm 1.752$ Reais } \\
\hline \multicolumn{3}{|c|}{ Renda per capita $=625 \pm 498$ Reais } \\
\hline \multicolumn{3}{|c|}{ *SM=salário mínimo jan $/ 2013=678$ reais } \\
\hline
\end{tabular}

\subsection{Tradução do DSMP}

A versão final do DSMP traduzida é apresentada no Anexo 5. O escore é apresentado no Anexo 6.

Durante o processo de tradução houve dúvidas na forma de se referir à glicemia capilar, já que há hábitos regionais em relação ao nome utilizado e optou-se por chamá-la de teste de ponta de dedo.

Durante a fase piloto, foi verificada uma grande dificuldade na compreensão temporal e matemática pela população do estudo. Nas questões 23 e 24, relativas às quantas vezes por semana o paciente aplicava mais ou menos insulina do que o prescrito, foi realizada a seguinte modificação: " 1 a 3 vezes por mês/ 4 a 6 vezes por mês/ 7 a 10 vezes por mês/mais de 10 vezes por mês" para " $1 x$ por semana/ 1-2 vezes por semana/ 2-3 vezes por semana/mais de 4 vezes por semana" nos últimos 3 meses. 
Algumas construções gramaticais foram ajustadas para evitar a necessidade de explicação de certos itens pelo entrevistador. Como por exemplo: utilizar as palavras "filho/filha" ao invés de "criança"; na pergunta sobre realizar o teste antes da refeição, trocou-se os "30 minutos" entre parênteses para a explicação "dentro de 30 minutos". Modificamos alguns pontos para uma linguagem mais coloquial como "às vezes, você pode estar envolvido com outras coisas" para "às vezes, você pode estar preocupado com outras coisas" e; "uma forma própria para cuidar do diabetes que seja mais confortável para elas" para "uma forma própria para cuidar do diabetes que seja mais fácil para elas". Assim, todas as alterações foram incorporadas na versão final do questionário pré-aplicação.

\subsection{Pontuação do questionário traduzido: escore total e subescalas}

O escore médio dos questionários respondidos pelos pais e pacientes foi de 48,99 (DP \pm 12 ), com escore máximo de 77 pontos para um total de 88 pontos. Em alimentação, insulinização e atividade física, foram alcançadas as pontuações máximas (Tabela 3). Nas escalas hipoglicemia e monitorização, o escore máximo (11 e 32 respectivamente) não foi alcançado. Nenhum paciente pontuou nas questões sobre a utilização de fitas de cetonúria ou cetonemia (questões 20 e 21) e no item sobre a utilização de braceletes e correntes de identificação do diabetes na questão 7 .

Tabela 3- Escore total e por subscalas do questionário traduzido

\begin{tabular}{|c|c|c|c|c|c|c|c|c|}
\hline \multirow[b]{2}{*}{ Escala } & \multirow[b]{2}{*}{$\mathrm{n}$} & \multirow[b]{2}{*}{ Média } & \multirow{2}{*}{$\begin{array}{l}\text { Desvio } \\
\text { Padrão }\end{array}$} & \multicolumn{3}{|c|}{ Percentil } & \\
\hline & & & & Mínimo & 25 & Mediana & 75 & Máximo \\
\hline TOTAL & 102 & 48,99 & 12 & 23 & 39 & 49,5 & 57 & 77 \\
\hline Atividade Física & 102 & 6,4 & 3,96 & 0 & 3 & 6 & 10 & 12 \\
\hline Hipoglicemia & 102 & 7,07 & 2,17 & 2 & 6 & 7 & 9 & 10 \\
\hline Alimentação & 102 & 9,46 & 3,15 & 3 & 7 & 9 & 12 & 17 \\
\hline Monitoração & 102 & 17,1 & 4,4 & 6 & 14 & 18 & 21 & 24 \\
\hline Insulina & 102 & 8,96 & 3,7 & 1 & 6 & 9 & 12 & 16 \\
\hline
\end{tabular}

Em relação às respostas das subescalas de forma individual, cabe ressaltar alguns dados: 
Atividade Física: verificou-se que $80 \%$ dos pacientes realizavam atividade física duas ou mais vezes na semana. Nossos pacientes apresentaram grande dificuldade em ajustar a dose de insulina em função da atividade física realizada, sendo que 39\% deles não faziam nenhum tipo de ajuste na insulina quando faziam mais atividade física.

Hipoglicemia: $77 \%$ dos pacientes relataram carregar sempre consigo algum tipo de carboidrato de liberação rápida para o tratamento da hipoglicemia. Quando questionados quanto à conduta tomada frente a hipoglicemia, observou-se que: 39/48 pacientes menores de 11 anos e 19/54 maiores de 11 anos, sempre testavam a glicemia antes de tratar e as correções foram adequadas apenas em $60,4 \%$ dos menores de 11 anos e em $29,6 \%$ dos maiores.

Alimentação: $50 \%$ dos pacientes não ajustavam a insulina de acordo com a alimentação; esta questão isolada teve correlação com a $\mathrm{HbA} 1 \mathrm{c}$ $(p<0,01)$, ou seja pacientes que ajustam a insulina à alimentação tiveram melhor hemoglobina glicada. Em $36 \%$ dos entrevistados há ingestão de guloseimas/alimentos com muita gordura (questão 9) em grande quantidade mais de 4 vezes na semana.

Monitorização: $85 \%$ dos pacientes realizavam quatro ou mais glicemias capilares por dia, o que está dentro do recomendado pelas diretrizes da International Society for Pediatric and Adolescent Diabetes (ISPAD).

Insulina: $48 \%$ dos pacientes atrasavam a aplicação de insulina mais de uma vez por semana e $21 \%$ deles esquecia a aplicação mais de uma vez por semana. Além disso, 21\% dos pacientes responderam aplicar doses mais altas do que as prescritas pela equipe numa frequência maior que quatro vezes por semana, enquanto $17 \%$ respondeu utilizar doses mais baixas que as prescritas neste mesmo período.

\subsection{Comparação dos Escores por Idade, Sexo e Tipo de Regime de Insulina utilizado}

$\mathrm{Na}$ comparação entre os pacientes por idade, os menores de 11 anos obtiveram um escore significativamente maior no escore total e em todas as 
subescalas, exceto na subescala alimentação (Tabela 4). Quanto ao sexo, não houve diferença entre o escore total, assim como nas subescalas. (Tabela 5).

Tabela 4- Comparação entre o escore total e subescalas entre os pacientes menores e maiores de 11 anos

\begin{tabular}{ccccc}
\hline Variável & Grupo & Média & $\begin{array}{r}\text { Desvio } \\
\text { Padrão }\end{array}$ & P-Valor \\
\hline \multirow{2}{*}{ TOTAL } & $<11$ anos & 53,98 & 9,92 & $<0.001$ \\
& $>11$ anos & 44,56 & 12,02 & \\
\hline \multirow{2}{*}{ Atividade Física } & $<11$ anos & 7,63 & 3,72 & 0,003 \\
& $>11$ anos & 5,31 & 3,88 & \\
\hline \multirow{2}{*}{ Hipoglicemia } & $<11$ anos & 8,17 & 1,65 & \\
& $>11$ anos & 6,09 & 2,11 & \\
\hline \multirow{2}{*}{ Alimentação } & $<11$ anos & 9,04 & 3,09 & 0,001 \\
& $>11$ anos & 9,83 & 3,19 & \\
\hline \multirow{2}{*}{ Monitoração } & $<11$ anos & 18,92 & 3,76 & $<0.001$ \\
& $>11$ anos & 15,48 & 4,32 & \\
\hline \multirow{2}{*}{ Insulina } & $<11$ anos & 10,23 & 3,43 & \multirow{2}{*}{0,001} \\
& $>11$ anos & 7,83 & 3,60 & \\
\hline
\end{tabular}

Teste $t$

Tabela 5- Comparação entre o escore total e subescalas entre os pacientes por sexo

\begin{tabular}{clcccc}
\hline \multirow{2}{*}{ Escala } & Sexo & N & Média & $\begin{array}{c}\text { Desvio } \\
\text { Padrão }\end{array}$ & P-Valor \\
\hline \multirow{2}{*}{ TOTAL } & Feminino & 56 & 48,3 & 11,72 & 0,526 \\
& Masculino & 46 & 49,83 & 12,4 & \\
\hline \multirow{2}{*}{ Atividade Física } & Feminino & 56 & 5,91 & 3,78 & 0,168 \\
& Masculino & 46 & 7 & 4,13 & \\
\hline \multirow{2}{*}{ Hipoglicemia } & Feminino & 56 & 7,07 & 2,12 & 0,989 \\
& Masculino & 46 & 7,07 & 2,25 & \\
\hline \multirow{2}{*}{ Alimentação } & Feminino & 56 & 9,61 & 3,07 & 0,607 \\
& Masculino & 46 & 9,28 & 3,27 & \\
\hline \multirow{2}{*}{ Monitoração } & Feminino & 56 & 16,89 & 4,35 & 0,606 \\
& Masculino & 46 & 17,35 & 4,49 & \\
\hline \multirow{2}{*}{ Insulina } & Feminino & 56 & 8,82 & 3,58 & 0,677 \\
& Masculino & 46 & 9,13 & 3,87 & \\
\hline
\end{tabular}

Teste $t$

Pacientes em regime flexível apresentaram um escore total mais elevado em comparação àqueles em regime convencional (55,0 vs 44,8 ; 
$p<0,0001)$, o que também foi observado nas subescalas de monitorização e alimentação (Tabela 6).

Tabela 6 - Comparação entre o escore total e subescalas para regime convencional e flexível

\begin{tabular}{|c|c|c|c|c|c|}
\hline Escala & Regime & $\mathbf{N}$ & Média & $\begin{array}{l}\text { Desvió } \\
\text { Padrão }\end{array}$ & p-Valor \\
\hline \multirow[t]{2}{*}{ TOTAL } & Convencional & 60 & 44,77 & 10,36 & $<0,0001$ \\
\hline & Flexível & 42 & 55,02 & 11,69 & \\
\hline \multirow{2}{*}{$\begin{array}{l}\text { Atividade } \\
\text { Física }\end{array}$} & Convencional & 60 & 5,72 & 3,78 & 0,036 \\
\hline & Flexível & 42 & 7,38 & 4,04 & \\
\hline \multirow{2}{*}{ Hipoglicemia } & Convencional & 60 & 7,02 & 2,27 & 0,774 \\
\hline & Flexível & 42 & 7,14 & 2,03 & \\
\hline \multirow[t]{2}{*}{ Alimentação } & Convencional & 60 & 7,88 & 2,26 & $<0,0001$ \\
\hline & Flexível & 42 & 11,71 & 2,87 & \\
\hline \multirow{2}{*}{ Monitoração } & Convencional & 60 & 15,7 & 4,43 & $<0,0001$ \\
\hline & Flexível & 42 & 19,1 & 3,54 & \\
\hline \multirow{2}{*}{ Insulina } & Convencional & 60 & 8,45 & 3,64 & 0,096 \\
\hline & Flexível & 42 & 9,69 & 3,71 & \\
\hline
\end{tabular}

Teste $t$

\subsection{Validação do DSMP traduzido}

\subsubsection{Consistência interna}

O questionário apresentou um valor alfa de Cronbach adequado $(0,78)$ no escore total (Tabela 7). Verificou-se uma correlação positiva e estatisticamente significativa entre as subescalas e o escore total (Tabela 8). Não foi encontrada nenhuma questão que individualmente contribuísse para a redução do alfa de Cronbach das subescalas ou do escore total.

Tabela 7 - Consistência interna obtida através do valor alfa de Cronbach total e por subescalas

\begin{tabular}{lcc}
\hline Subescala & Alfa de Cronbach & № de itens \\
\hline TOTAL & 0,788 & 25 \\
Atividade Física & 0,726 & 3 \\
Hipoglicemia & 0,366 & 4 \\
Alimentação & 0,468 & 6 \\
Monitoração & 0,667 & 8 \\
Insulina & 0,445 & 4 \\
\hline
\end{tabular}


Tabela 8- Correlação entre os valores alfa de Cronbach obtidos em cada subescala com o escore total

\begin{tabular}{ccc}
\hline Escala & $\begin{array}{c}\text { Correlação } \\
\text { (com escore total) }\end{array}$ & P-Valor \\
\hline Atividade Física & 0,66 & $<0,0001$ \\
Hipoglicemia & 0,626 & $<0,0001$ \\
Alimentação & 0,549 & $<0,0001$ \\
Monitoração & 0,824 & $<0,0001$ \\
Insulina & 0,721 & $<0,0001$ \\
\hline
\end{tabular}

Teste de correlação de Pearson

\subsubsection{Confiabilidade do DSMP traduzido}

A confiabilidade intraobservador foi verificada em 90 famílias. Considerando o escore total e as subescalas, observaram-se correlações positivas e significativas (Tabela 9).

Tabela 9 - Confiabilidade intraobservador/teste-reteste

\begin{tabular}{ccc}
\hline Escala & Correlação & P-Valor \\
\hline TOTAL & 0,428 & $<0,0001$ \\
Atividade Física & 0,400 & $<0,0001$ \\
Hipoglicemia & 0,361 & 0,0002 \\
Alimentação & 0,437 & $<0,0001$ \\
Monitoração & 0,443 & $<0,0001$ \\
Insulina & 0,324 & 0,0009 \\
\hline
\end{tabular}

Teste de correlação de Pearson

Em relação à confiabilidade interobservadores, houve uma associação positiva e estatisticamente significativa para todas as medidas $(r=0,379$, $\mathrm{p}<0,0001)$, (Tabela 10).

Tabela 10- Confiabilidade interobservadores

\begin{tabular}{ccc}
\hline Escala & Correlação & P-Valor \\
\hline TOTAL & 0,379 & 0,0001 \\
Atividade Física & 0,693 & $<0,0001$ \\
Hipoglicemia & 0,486 & $<0,0001$ \\
Alimentação & 0,286 & 0,0036 \\
Monitoração & 0,471 & $<0,0001$ \\
Insulina & 0,581 & $<0,0001$ \\
\hline
\end{tabular}

Teste de correlação de Pearson 


\subsubsection{Validação concorrente do DSMP traduzido}

a) Correlação com a Hemoglobina Glicada: Verificou-se uma associação significativa entre média mais baixa de $\mathrm{HbA1c}$ e maior pontuação tanto no escore total quanto nas subescalas (Figura 1/ Tabela 11). Em todos os casos observou-se uma correlação negativa entre as escalas e a HbA1c (Figura 2).

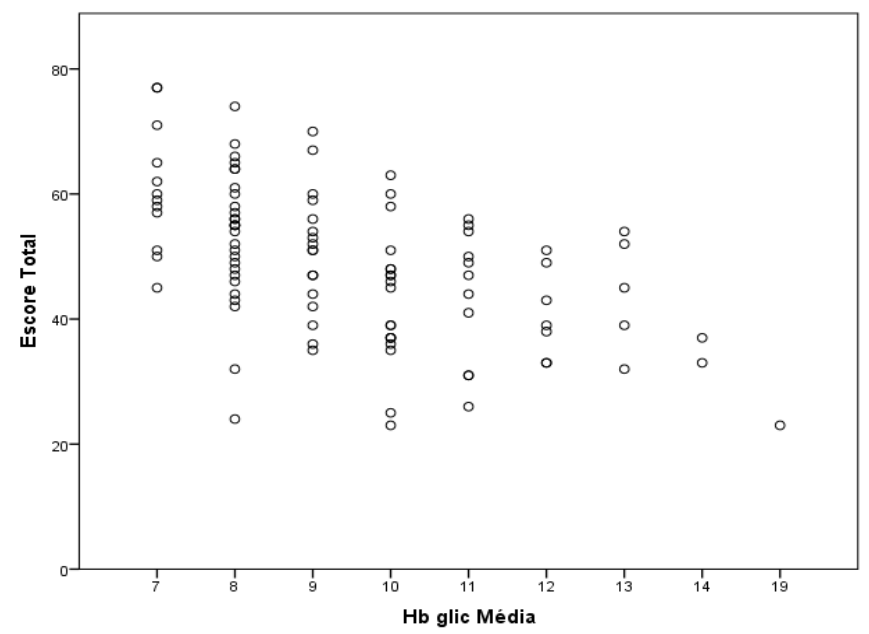

Figura 2. Correlação entre o escore total e a Hb1Ac média

Tabela 11 - Correlação entre Hb1Ac média com o escore total e subescalas

\begin{tabular}{ccc}
\hline Escala & Correlação & P-Valor \\
\hline TOTAL & $-0,532$ & $<0,0001$ \\
Atividade Física & $-0,369$ & 0,0001 \\
Hipoglicemia & $-0,26$ & 0,0083 \\
Alimentação & $-0,23$ & 0,0201 \\
Monitoração & $-0,531$ & $<0,0001$ \\
Insulina & $-0,35$ & 0,0003 \\
\hline
\end{tabular}

Teste de correlação de Pearson

b) Correlação com a percepção médica: Nota-se uma correlação positiva entre o escore total e o questionário de percepção médica, ou seja, valores altos do escore total estão associados a altos valores da percepção médica $(r=0,675 ; p<0,0001)$ (Figura 3$)$. 


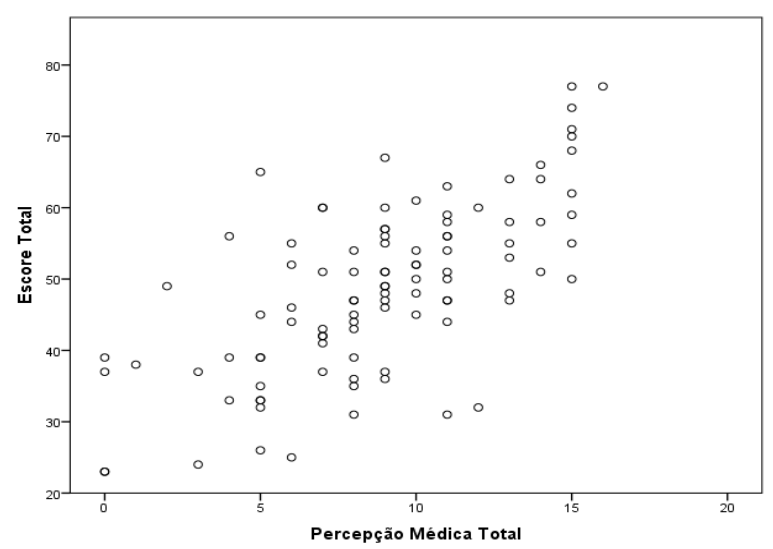

Figura 3. Correlação escore total e percepção médica

c) Comparação entre as avaliações dos pacientes (>11anos) e seus cuidadores (>11anos): com base na medida da diferença entre os escores obtidos pelos pacientes e pelo cuidador (escore filho-escore cuidador), verificou-se o comportamento das avaliações de ambos comparativamente. Observou-se uma pontuação média maior dos filhos nas escalas de atividade física, alimentação e monitorização. Por outro lado, para o escore total, hipoglicemia e insulina, os pais apresentaram uma avaliação média mais elevada que os filhos. Entretanto, não houve diferença estatística entre as avaliações dos pacientes e seus cuidadores. (Tabela 12)

Tabela 12 - Comparação entre o escore total e das subescalas dos pacientes com seus cuidadores

\begin{tabular}{cccc}
\hline Escala & Média & $\begin{array}{c}\text { Desvio } \\
\text { Padrão }\end{array}$ & P-Valor \\
\hline Total & $-0,222$ & 9,199 & 0,8598 \\
Atividade Física & 0,352 & 3,577 & 0,473 \\
Hipoglicemia & $-0,593$ & 2,211 & 0,0541 \\
Alimentação & 0,333 & 2,835 & 0,3915 \\
Monitoração & 0,278 & 2,91 & 0,4861 \\
Insulina & $-0,593$ & 4,021 & 0,2838 \\
\hline
\end{tabular}


8 DISCUSSÃO 
Dificuldades na compreensão do tratamento do diabetes são descritas em populações de países em desenvolvimento como o Brasil, muitas vezes relacionadas a questões familiares, culturais e socioeconômicas, o que interfere na qualidade do seu controle metabólico ${ }^{34}$.

A população do nosso estudo caracterizou-se por um inadequado controle glicêmico avaliado pela concentração da hemoglobina glicada, apresentando níveis superiores em relação às populações anteriormente analisadas em estudos de validação do $\operatorname{DSMP}\left(9,5 \% \times 8,1 \%{ }^{11} \times 7,9 \%{ }^{25}\right)$. No entanto, nossa população apresentava tempo de duração do diabetes superior àquele das populações desses estudos prévios (6,2 versus $4,9^{11}$ versus 2,9 $a_{n o s^{25}}$ ). É bem descrito na literatura que o maior tempo de diabetes está associado a um pior controle metabólico ${ }^{35}$. O estudo do DSMP validado em população brasileira adulta encontrou nível de HbA1c semelhante ao nosso $(9,2 \%)$.

Foi encontrado um baixo nível socioeconômico nesta população, caracterizado pela baixa escolaridade (apenas 16\% das mães apresenta curso superior) e baixa renda familiar média ( $59 \%$ da população com renda familiar inferior a três salários mínimos). A renda familiar per capita mensal média em nosso estudo foi de $625 \pm 418$ reais/per capita, sendo bem inferior àquela encontrada no estado de São Paulo no ano de 2014 (1.432 reais/per capita) ${ }^{36}$. Apesar da maioria das mães declararem apresentar ensino médio completo, houve importante dificuldade de assimilação dos conteúdos e de compreensão matemática.

Comparando com a população americana avaliada ${ }^{26}$, a renda média familiar anual no estudo de 2012 foi de $77.160 \pm 80.800$ dólares (mediana de 60.000) no grupo de língua inglesa e 40.040 \pm 47.650 dólares (mediana 25.000) no grupo hispânico. Na normatização de $2010^{25}$, a mediana foi de 36.000 dólares (a mediana americana de renda familiar na época era de 37.300 dólares). A nossa população teve como renda média familiar anual 0 equivalente a 15.682 11 1.221dólares (cambio médio jan/2013: 1 dólar=2,03 
reais ${ }^{37}$ ), valor bem inferior à média americana, o que também denota a diferença entre as populações.

Quando o estudo é comparado à população adulta brasileira que respondeu o questionário, há grande semelhança em relação ao nível socioeconômico (classe B2-D) e no tempo médio de estudo $\left(10,7 \pm 4\right.$ anos) ${ }^{28}$.

Em nossa população $84 \%$ dos cuidadores eram mães, assim como 0 encontrado nos estudos anteriores $(78 \%)^{26}$. Outro fato encontrado foi que $61 \%$ dos cuidadores exerciam alguma atividade remunerada, o que foi semelhante à população geral (dentre as mulheres, em 2013, 61\% trabalham fora de casa) ${ }^{38}$.

A metodologia de tradução-retroversão mostrou-se adequada para a preparação da versão final do questionário para o português do Brasil; entretanto, foi a realização do teste piloto que revelou dificuldades na compreensão de certos itens que exigiram maiores explicações por parte do entrevistador, além das dificuldades de raciocínio abstrato dessa população, que exigiram que alguns itens fossem ajustados novamente.

O questionário final mostrou adequada consistência interna, quando avaliado pelo alfa de Cronbach $(0,79)$. Os escores das subescalas tiveram significante correlação com o escore total.

A validação foi possível devido à aplicação do teste-reteste e da avaliação do segundo observador que mostraram adequada confiabilidade, porém com uma correlação regular (0,3-0,6). Esta correlação regular pode ser decorrente da maior interferência do avaliador em perguntas abertas e da diferença de interpretação entre o primeiro e segundo avaliador em questões de resposta duvidosa pelo paciente. Por exemplo, na pergunta: "Nos últimos 3 meses, quantas vezes você praticou esta atividade física por pelo menos 20 minutos? Menos de 1 vez por mês/ 1 vez ao mês/ 2-3 vezes por semana/ Mais de 3 vezes por semana", muitos pacientes realizavam atividade na escola uma vez por semana apenas, mas como no questionário não havia esta opção, o dado foi superestimado, pois era necessário optar por uma alternativa e muitos pais optavam por 2-3 vezes por semana. Também o fato do tempo de referência ser 20 minutos auxiliou a indução desta resposta, já que crianças pequenas brincam bastante e este tempo foi contabilizado. Ao ouvir a resposta, esta questão gerou dúvida na avaliação dos pesquisadores, sendo este um 
ponto fraco do questionário a ser melhorado. Este fato não foi notado durante o piloto do estudo.

A validação concorrente mostrou uma correlação negativa moderada com a hemoglobina glicada, o que fortalece a utilidade clínica desse instrumento, sendo compatível com as validações anteriores ${ }^{11,25,26,28}$.

O questionário correlacionou-se positivamente com a percepção médica realizada pela equipe. Assim, podemos inferir que ele é concordante à percepção da equipe de saúde em relação ao autocuidado do paciente ${ }^{26}$.

Corrobora com a validação concorrente, o fato de não haver diferença entre os escores dos questionários respondidos por adolescentes e cuidadores, o que sugere que entrevista-los separadamente não altera os escores do DSMP. Nas validações anteriores ${ }^{11,26}$ também foi encontrada uma correlação positiva entre a resposta dos adolescentes e cuidadores.

Como observado na literatura os pacientes mais jovens (menores de 11 anos), apresentaram melhor hemoglobina glicada, assim como escores total e das subescalas mais elevados. Este dado também é relatado nos estudos de validação prévios ${ }^{11,26}$. Na adolescência, a existência de importante resistência à insulina gerada pelos hormônios puberais, aliada sobretudo as questões psicossociais, são responsáveis pela piora do controle glicêmico e do autocuidado ${ }^{39}$.

Os pacientes sob regime flexível também apresentaram melhor controle glicêmico e escore mais elevado. Isto é esperado, já que na prática clínica, pacientes com melhor compreensão do autocuidado, monitorização glicêmica frequente e poucas falhas na aplicação de insulina são orientados a uma insulinoterapia mais individualizada em função de seus estilos de vida. Estudos internacionais têm mostrado que quanto mais intensivo o regime de insulinoterapia, com maior flexibilidade e adequação à vida do paciente, melhor é o controle metabólico atingido ${ }^{40}$.

Não houve diferença no autocuidado em relação ao sexo dos pacientes. $\mathrm{Na}$ literatura geralmente meninas adolescentes têm pior controle glicêmico, devido a questões psicossociais e a manipulação da dieta e da dose da insulina visando a perda de peso ${ }^{39}$. Esta diferença pode não ter sido 
evidenciada neste trabalho, talvez em decorrência da análise de uma população com pior controle glicêmico.

Quanto à análise individualizada das subescalas, podemos observar que em relação ao domínio monitorização verificou-se a ausência da utilização de fitas de cetonúria ou cetonemia pelos pacientes, o que está em desacordo às diretrizes do tratamento do DM1 preconizadas pelas várias sociedades internacionais de diabetes ${ }^{38}$. Duas hipóteses são aventadas frente a esta constatação: a ausência de distribuição das fitas pelo sistema público de saúde em nosso país, associada à dificuldade de encontra-las na rede privada e a falta de orientação da necessidade da monitorização da cetonúria pela equipe de saúde.

Um destaque observado na subescala hipoglicemia foi o reduzido número de pacientes que usava algum acessório para identifica-los como portadores de diabetes. A identificação é recomendada pela ISPAD fazendo parte do nível primário de educação em diabetes ${ }^{40}$. Nos Estados Unidos, o uso de colares, pingentes, pulseiras com a informação sobre a doença do paciente é habitual entre portadores de doenças crônicas, sendo esse um comportamento fortemente estimulado pelos profissionais de saúde. Existem diversos websites sobre o assunto, incluindo aqueles das universidades médicas de referencia ${ }^{42}$.Nenhum paciente do estudo utilizava qualquer desses itens, somente relatavam uso do cartão de identificação do DM1 na bolsa ou na carteira. Culturalmente, em nosso país, a exposição de uma doença não é frequente entre pacientes e suas famílias, talvez por acreditarem que existe risco de serem estigmatizados e excluídos de seu meio social. Ao responder a esta questão, a maioria dos pacientes relatou ter vergonha da doença e restringir tal conhecimento às poucas pessoas a sua volta, implicando em comportamentos como omissão da administração de insulina em público e também no ambiente de trabalho. Isso reflete uma falta de aceitação do diabetes que dificulta o autocuidado ${ }^{40}$.

Seguindo na subescala de hipoglicemia, observou-se importante erro na correção da hipoglicemia principalmente entre os adolescentes. Apenas 35\% (19/54) dos pacientes maiores de 11 anos, sempre testavam a glicemia antes de tratar e as correções foram adequadas apenas em 29,6\%. Muitos referiam 
ingerir alimentos sem qualquer monitoramento $(51,8 \%)$. Este pode ser mais um fator associado à deterioração glicêmica nesta fase, já que percepção e correção inadequadas da hipoglicemia levam à hiperglicemia.

$\mathrm{Na}$ subescala de atividade física, muitos relataram atividade duas ou mais vezes na semana, incluindo a atividade física na escola. Contudo, em nosso país, as escolas promovem atividade esportiva duas vezes por semana, porém com pouca supervisão e revezamento frequente dos alunos nos jogos, resultando em pouco tempo útil em atividade. Assim, esta frequência de atividade física vista em nosso estudo, pode ter sido superestimada, já que outros trabalhos apontam uma população infantil mais sedentária em nosso país, com aproximadamente $60 \%$ de inatividade física ${ }^{43-44}$. Neste mesmo item, ressaltamos a baixa frequência com que os pacientes modificavam as doses de insulina em função do grau de atividade física realizada.

Nas entrevistas evidenciou-se a insegurança dos pacientes em executar ajustes de doses de insulina. Eles relatavam como bom o fato de nunca alterarem as doses prescritas pelo médico, o que reflete dificuldade na compreensão da necessidade de um ajuste continuo e dinâmico da insulinoterapia.

$\mathrm{Na}$ subescala alimentação, além dos pacientes não modificarem as doses de insulina em função da dieta consumida, observou-se uma ingestão frequente de alimentos gordurosos (questão 9), já que $36 \%$ ingere guloseimas mais de quatro vezes na semana em maior quantidade do que o recomendado.

A aplicação das entrevistas evidenciou, sobretudo, que nossa população realiza monitorização numa frequência adequada, mas não é capaz de transformar a informação obtida em conduta terapêutica, ou seja, em modificações da insulinoterapia nas diferentes situações do dia a dia. Isto pode ser percebido pelo alto escore em monitorização e baixo em administração de insulina. Corrobora com esta análise, o fato de que as perguntas sob o ajuste da insulina de acordo com a alimentação (questões 11 e 13) tiveram individualmente correlação negativa com a hemoglobina glicada $(p<0.001)$. Assim, tornam-se evidentes muitas falhas no autocuidado da nossa população e a necessidade de um processo de educação em diabetes capaz de 
"empoderar" os pacientes e suas famílias para assumirem o controle da doença.

Esta abordagem de capacitação deve habilitar os pacientes e suas famílias a usarem o conhecimento para resolverem problemas e estarem aptos para a definição de metas no seu tratamento. Em essência, os pacientes precisam experimentar que eles têm influência sobre suas próprias vidas tomando decisões informadas sobre o sua doença. Regimes terapêuticos modernos complexos com múltiplas injeções diárias, uso de diferentes insulinas e análogos de insulina subcutânea, sistema de infusão continua de insulina (CSII), bem como dispositivos de monitoramento continuo de glicose exigem uma educação apropriada, de preferência multidisciplinar.

As limitações deste estudo incluem: a falta de um instrumento ideal de avaliação do autocuidado em DM1 na língua portuguesa do Brasil, específico para a faixa etária pediátrica, que pudesse ser comparado com o do estudo; diferenças técnicas que podem ter interferido na consistência interna da subescalas de monitorização e hipoglicemia (fazia parte da avaliação do autocuidado o uso de fitas de cetonemia e acessórios de identificação da doença os quais não eram utilizados pela nossa população à época do estudo) e questões relativas à população de estudo (baixo nível socioeconômico e cultural, baixa escolaridade, baixa capacidade de abstração matemática, inadequado controle metabólico, nenhum paciente em uso de sistema de infusão continua).

Como força principal deste estudo destacam-se os seguintes fatos: este ser um instrumento validado em nossa língua para avaliação do autocuidado passível de uso para crianças e adolescentes; estes dados terem sido os primeiros sobre o autocuidado em uma população pediátrica brasileira; baixo custo para implementação; possibilidade de extensão universitária e avaliação do paciente, presença de boa correlação com a hemoglobina glicada e percepção médica. 
9 CONCLUSÕES 
- O instrumento DMSP foi traduzido e validado para a língua portuguesa do Brasil em pacientes entre 6 e 18 anos portadores de DM1, mostrando propriedades psicométricas e consistência interna adequadas para a avaliação do autocuidado na população pediátrica brasileira.

- A consistência interna foi adequada na versão traduzida e a confiabilidade intra e interobservadores foram consideradas regulares.

- O escore total médio obtido na versão do DSMP traduzida para o português foi de 48,99 ( \pm 12$)$ e a pontuação máxima não foi obtida por nenhum paciente nas subescalas hipoglicemia e monitorização.

- Houve uma correlação negativa entre os níveis da HbA1c e o escore da versão traduzida e positiva com a percepção médica do autocuidado do paciente $(p<0,0001)$.

- O escore total obtido foi maior no subgrupo dos pacientes menores de 11 anos e naqueles sob regime flexível, não havendo diferença entre os sexos e nas avaliações dos pacientes e seus cuidadores 
10 ANEXOS 


\section{Anexo 1}

\section{1 - Versão Original do DSMP}

\section{DSMP Conventional Regimen}

Taking care of diabetes means doing a lot of different things like taking insulin, doing blood sugar tests, following a meal plan, getting exercise and dealing with low and high blood sugars. It's not easy doing all of these things exactly the way doctors and nurses might want. Very few kids with diabetes do everything exactly according to plan. Sometimes there are other things that grab your child's attention or [he/she] might just forget to take care of [his/her] diabetes, even though they may have wanted to. Most kids with diabetes, and their families, develop their own habits for taking care of their diabetes that are comfortable for them. What we're trying to learn in this interview is what you and your family usually do to take care of your child's diabetes. I will ask you questions and write down your answers. You may stop me at any time, or go back to earlier questions to change your answers. Only the FMOD team will see or hear your answers. Your participation is completely voluntary. You do not have to answer any question that you do not want to answer. You will not be penalized in any way if you decide to skip a question. Your answers won't be shared with anyone else, so you can feel comfortable telling me exactly what you and your family do, not just what you think you're supposed to do or what you think I want you to say. So, try to be completely honest with me about what you and your family have usually done in taking care of your child's diabetes in the past 3 months.

\section{EXERCISE}

One part of taking care of diabetes is getting regular exercise, like running, bike riding and swimming. Some kids manage to do this very regularly, while others have a hard time finding the time to get enough exercise. In this part of the interview, l'll be asking about your child's exercise habits. This could be something like taking part in sports, PE at school or walking or riding [his/her] bike to school. Try to be as honest and accurate as you can about your child's exercise habits in the past 3 months.

1. What kind of exercise does your child get?

In the past 3 months, how often has your child gotten one of those kinds of exercise for at least 20 minutes?

More than three times per week

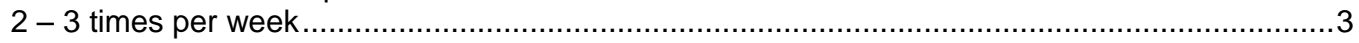

Once a month

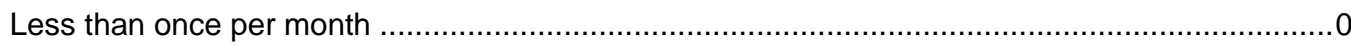

2. If your child gets more exercise than usual, or if [he/she] plans to get more exercise, does [he/she] make changes in [his/her] diet or insulin? [If respondent replies no, circle 0 and skip to question 3]

What does [he/she] do?

In the past 3 months, can you remember how many times [he/she] made this change?

Exercises so consistently that adjustments are unnecessary ............................................... 4

Always eats more or gives less insulin............................................................................

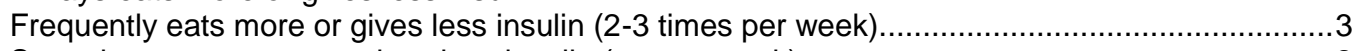

Sometimes eats more or gives less insulin (once a week) ....................................................

Occasionally eats more or gives less insulin (few times a month) ................................................

Eats less than usual or gives more insulin or does not adjust eating or insulin............................ 0 
3. If your child gets less exercise than usual, or if [he/she] plans to get less exercise, does [he/she] make changes in [his/her] meal plan or insulin? [If respondent replies no, circle 0 and skip to question 4]

\section{What does [he/she] do?}

In the past 3 months, can you remember how many times [he/she] made this change?

Exercises so consistently that adjustments are unnecessary ................................................4

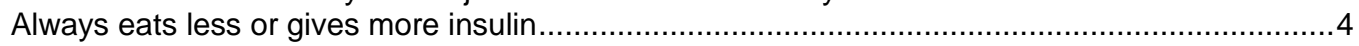

Frequently eats less or gives more insulin (2-3 times per week) ........................................ 3

Sometimes eats less or gives more insulin (once a week) .................................................

Occasionally eats less or gives more insulin (few times a month) ...........................................

Eats more than usual or gives less insulin or does not adjust eating or insulin............................

\section{HYPOGLYCEMIA}

Everyone with diabetes has low blood sugar reactions now and then that can cause them to feel dizzy, sweaty, shaky, confused, weak, hungry or irritable. Your child's doctor and nurses have probably taught [him/her] some things to do to keep low blood sugars from happening and to take care of [himself / herself] when they do happen. This part of the interview is about what your child usually does about low blood sugar reactions. Try to be as honest and accurate as you can about what your child did about low blood sugar in the past 3 months.

4. Does your child keep something handy in case [he/she] has an insulin reaction or [his/her] sugar gets too low? For example, when [he/she] is at school or at a ball game, or in the car and [his/her] sugar gets too low, does [he/she] have something handy to eat?

Yes

No

5. If your child thinks [he/she] has a low blood sugar, how often does [he/she] test before treating?

Always test before treating a low blood sugar or

(insist that they have never had a low blood sugar)

Usually test before treating a low blood sugar

( $75 \%$ of the time) or (more than half the time)

Sometimes test before treating a low blood sugar

(50\% of the time) or (half the time)

Infrequently test before treating a low blood sugar

( $25 \%$ of the time) or (less than half the time).....

Never test before treating a low blood sugar 
6. People manage low blood sugars in many different ways. What does your child usually do to treat [his/her] low blood sugar reactions? [If respondent replies [he/she] eats something, probe "How many grams of carbs is that?'] Then [If child takes a specified amount of carbs not equal to15gm, probe "Is that the amount your child's doctor told [him/her] to take?"] Then [If child takes a prescribed amount of carbs, but does not mention testing, probe "does [he/she] test after eating?']

Careful to quickly take the prescribed amount of carbohydrates

(15gm if applicable) and test blood if possible after 10 minutes or

(insist that they have never had a low blood sugar)

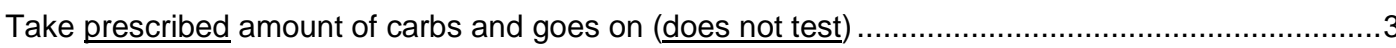

Take carbs (not the prescribed amount) without considering how much .....................................

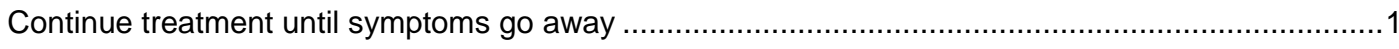

Ignore symptoms until he/she gets a chance to do something

(waiting until it is convenient to treat symptoms)

7. Does your child wear or carry anything that identifies [him/her] as having diabetes, like a card or bracelet?

Wears necklace, bracelet or charm

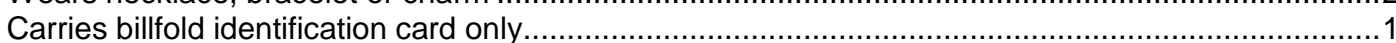

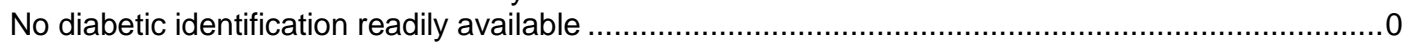

\section{EATING}

Doctors, nurses and dieticians ask kids with diabetes to follow a meal plan that allows them to maintain a healthy weight and good blood sugar control. Lots of things can get in the way of doing this and, even when they try their best, many kids still struggle with eating exactly according to the plan. In this part of the interview, l'll be asking about your child's eating habits. Try to be as honest and accurate as you can about your child's eating habits in the past 3 months.

8. Does your child measure [his/her] food, count carbs (or use exchanges) to figure out how much [he/she] should eat, or does [he/she] generally eat the same amounts of food without counting carbs? [If respondent replies [[He/She] count carbs" ask "Tell me how [he/she] would count carbs for a food [he/she] has never eaten before?"]

Uses carb counting (or exchange list) as a guide and measures food or reads labels.....

Uses carb counting (or exchange list) as a guide, but knows meal plan well enough so that he/she can eat the right amounts without measuring or reading labels................2

Eats about the same amounts of food each meal, but doesn't measure or use carb counting (or exchange list)

Eats the amount he/she is hungry for and doesn't follow any set patterns of types or amounts of foods...... 
9. There are foods that we all should avoid such as sweets and fatty foods like cookies, cakes, ice cream, chips, pizza, french fries, hot dogs, or others. Eating some of these foods is not necessarily bad for your child; however, eating large amounts of sweets and/or fatty foods is not good for [him/her]. In the past 3 months, how often has your child eaten more of these foods than is healthy?

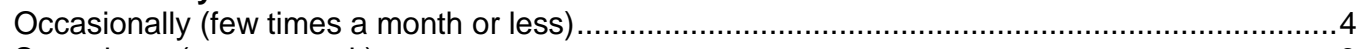

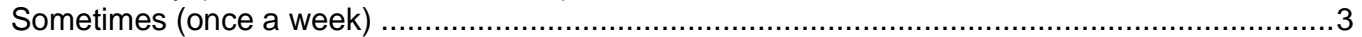

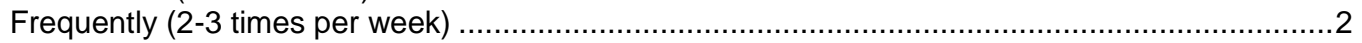

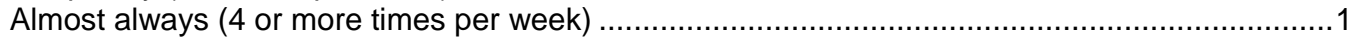

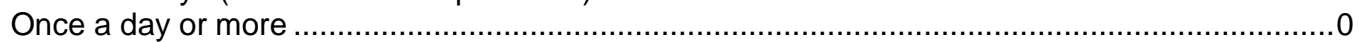

10. Sometimes people eat "MORE" food than what's on their meal plan. This does not include times when your child should eat more when [he/she] gets more exercise or when [his/her] sugar gets low. This might be when [he/she] eats because [he/she] is extra hungry or [he/she] might snack some before dinner.

In the past 3 months, how often has your child eaten MORE than what is recommended for [his/her] meal plan?

Never or hardly ever (1-2 times in the last 3 months) .................................................... 4

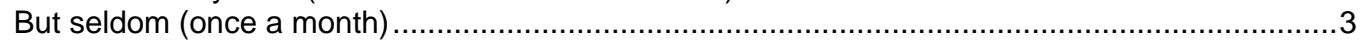

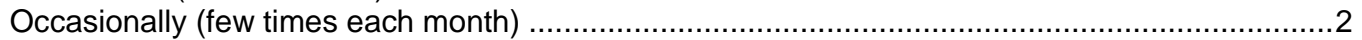

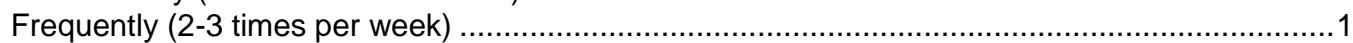

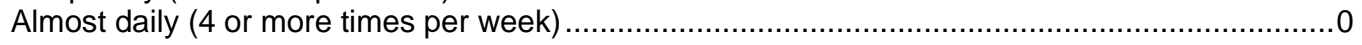

11. Before your child eats MORE than [he/she] normally would, does [he/she] make any changes in [his/her] insulin? What does [he/she] do?

Gives MORE insulin when eats more

Gives LESS insulin when eats more ......................... 0

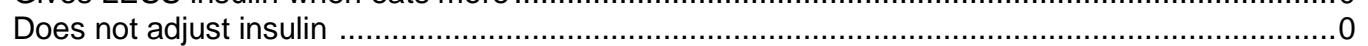

12. Sometimes people eat "LESS" food than what's on their diet plan. This does not include when your child's exercise changes, when [he/she] is sick or when [his/her] sugar is too high. This might be times when [he/she] just doesn't feel like eating everything on [his/her] plate.

In the past 3 months, how often has your child eaten LESS than what is recommended for [his/her] meal plan?

Never or hardly ever $(1-2$ times in the last 3 months) ..................................................... 4

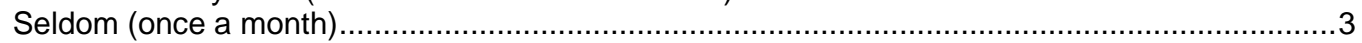

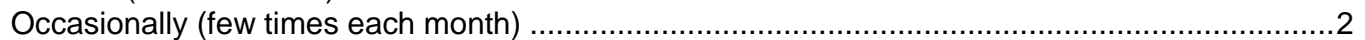

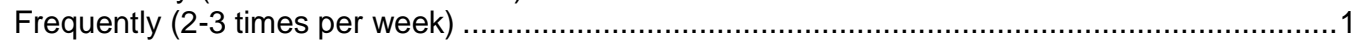

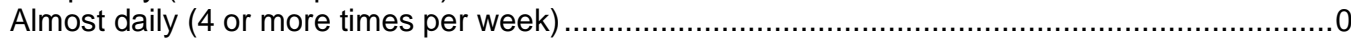

13. Before your child eats LESS than [he/she] normally would, does [he/she] make any changes in [his/her] insulin? What does [he/she] do?

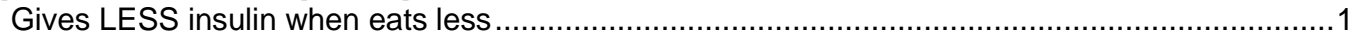

Gives MORE insulin when eats less

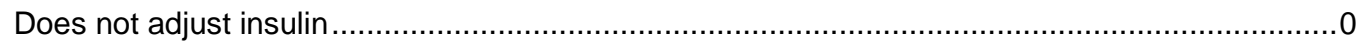

\section{BLOOD GLUCOSE TESTING}

Some kids do all of their blood sugar tests, but lots of other kids have trouble doing all of the tests their doctors and nurses want them to do. Next, l'll be asking about your child's habits when it comes to testing [his/her] blood sugar. Try to be as honest and accurate as you can about [his/her] testing habits in the past 3 months.

\section{In the past 3 months, how often has your child tested [his/her] blood?}

Tests blood sugar 6 or more times daily .................................................................... 4

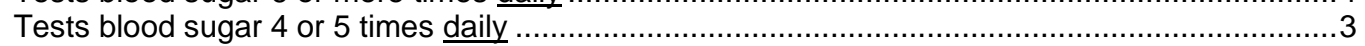

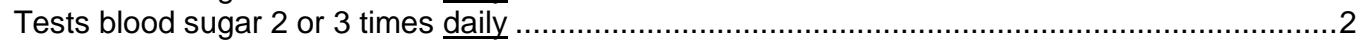

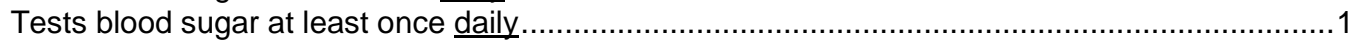

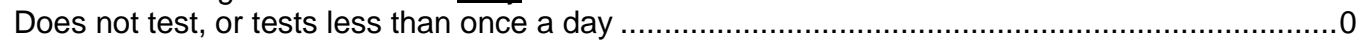

15. How often has the doctor suggested that your child test?

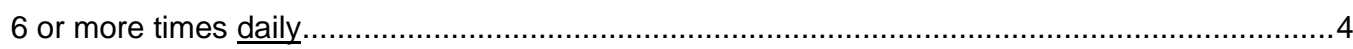

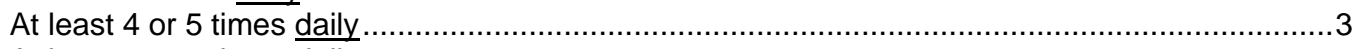

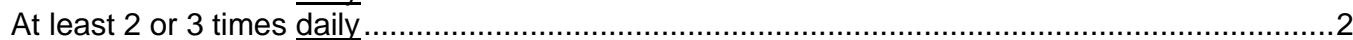


At least once daily 1

Does not know

16. How often does your child test [his/her] blood sugar within 30 minutes before a meal?

Always tests within 30 minutes before every meal .......................................................... 4

Usually tests within 30 minutes before meals

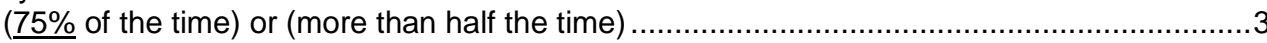

Sometimes tests within 30 minutes before meals

( $50 \%$ of the time) or (half the time)

Infrequently tests within 30 minutes before meals

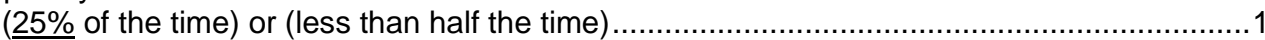

Never tests within 30 minutes before meals ............................................................... 0

17. How often does your child test [his/her] blood sugar within 2-3 hours after a meal?

Tests within 2-3 hours after a meal 4 or more times per week .................................................

Tests within $2-3$ hours after a meal 3 times per week ........................................................

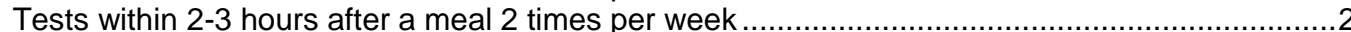

Tests within $2-3$ hours after a meal once a week ...............................................................

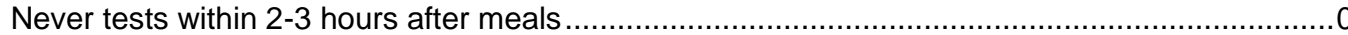

18. How often does your child test [his/her] blood sugar within 2-3 hours after heavy or intense exercise?

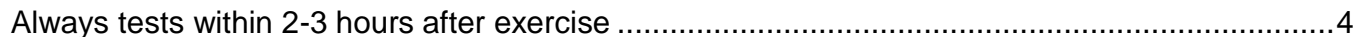

Usually tests within $2-3$ hours after exercise ( $75 \%$ of the time) or (more than half the time) .......... 3

Sometimes tests within 2-3 hours after exercise

$(50 \%$ of the time) or (half the time)

Infrequently tests within 2-3 hours after exercise

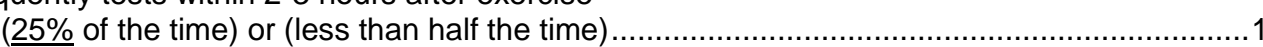

Never tests within 2-3 hours after exercise 1

19. In the past three months, how often has your child adjusted [his/her] insulin dose, [his/her] diet or [his/her] exercise when [his/her] blood sugar test results were running high?

Made an adjustment every time it was needed

Usually made an adjustment when needed

$(>75 \%)$ or (more than half the time)

Sometimes made an adjustment when needed

$(>50 \%)$ or (half the time)

Infrequently made an adjustment when needed

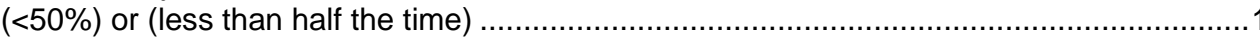

Never made an adjustment 
20. Does your child ever test for ketones?

Yes

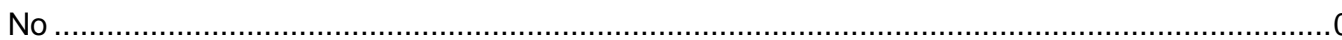

If your child had two blood sugar results above 240 in a row, how often does [he/she] do a ketone test?

Can't remember child having two blood sugars in a row above 240

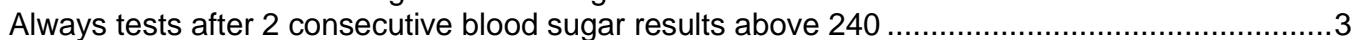

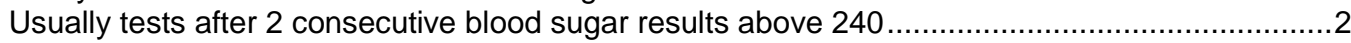

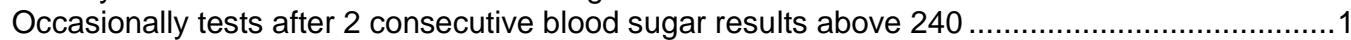

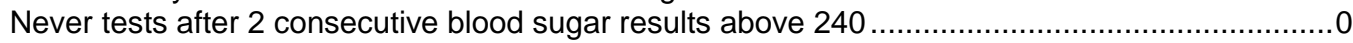

21. When your child is sick, how often does [he/she] do a ketone test?

[If respondent replies "always", probe for number of times/day]

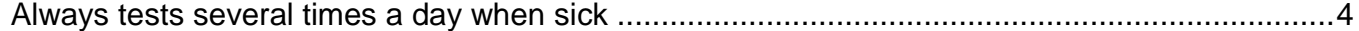

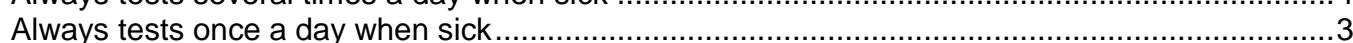

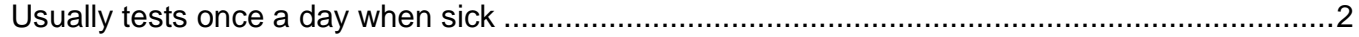

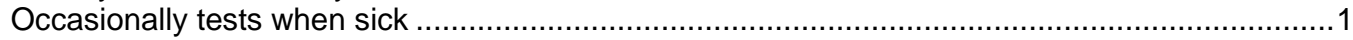

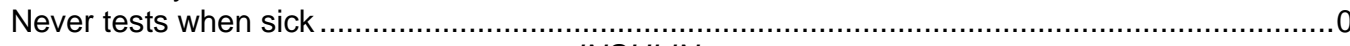

\section{INSULIN}

Taking insulin shots includes measuring the doses carefully, taking the shots on time, and maybe changing the dose depending on your child's blood sugar test results. This is all very complicated and takes time that many kids would prefer to spend doing other things. This part of the interview is about what your child usually does about [his/her] insulin shots. Try to be totally honest when you answer my questions.

22. In the last three months, how often has your child delayed taking [his/her] insulin?

Never, always take insulin on time

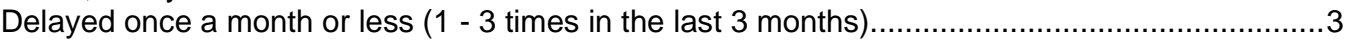

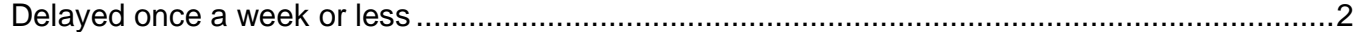

Delayed more than once a week .............................................................................

23. In the past 3 months, how often has your child taken MORE than the prescribed amount of insulin, even more than [his/her] sliding scale allows for?

Always took prescribed amount

Took more than prescribed amount $(1-3$ times in the last 3 months) ...................................... 3

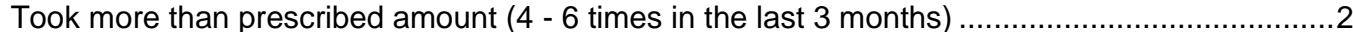

Took more than prescribed amount $(7-10$ times in the last 3 months) ................................... 1

Took more than prescribed amount (more than 10 times in the last 3 months) .......................... 0

24. In the past 3 months, how often has your child taken LESS than the prescribed amount of insulin, even less than [his/her] sliding scale allows for?

Always took the prescribed amount . .4

Took less than prescribed amount $(1-3$ times in the last 3 months) ....................................... 3

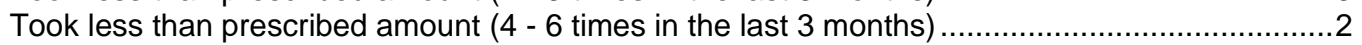

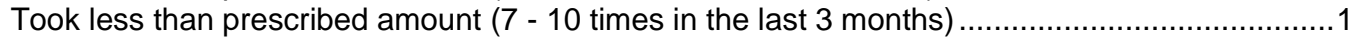

Took less than prescribed amount (more than 10 times in the last 3 months) ..........................

25. In the last three months, how often has your child missed giving an insulin shot because [he/she] forgot or was too busy?

Never forgot, always take insulin

Forgot once a month or less $(1-3$ times in the last 3 months) .......................................... 3

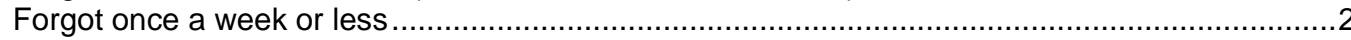

Forgot more than once a week

Thank you. 


\section{Anexo 2}

Escore versão inglesa do DSMP

Participant: Wother Father. Child

Regimen: Coaventional Fexible

Chidd's Age:

\section{DLABETES SELF-MANAGEMENT PROFILE}

SCORE SHEET

EXERCISE

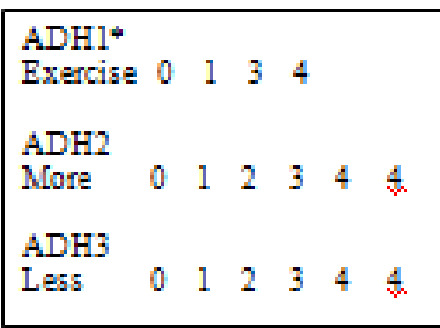

HYPOGLYCEMIIA

$\begin{array}{lllllll}\text { ADH4 } & & & & & \\ \text { Experg } & 0 & 1 & & & \\ \text { ADH5 } & & & & & \\ \text { Low } & 0 & 1 & 2 & 3 & 4 \\ \text { ADH6 } & & & & & \\ \text { Treat } & 0 & 1 & 2 & 3 & 4 \\ \text { ADH7 } & & & & & \\ \text { ID } & 0 & 1 & 2 & & \end{array}$

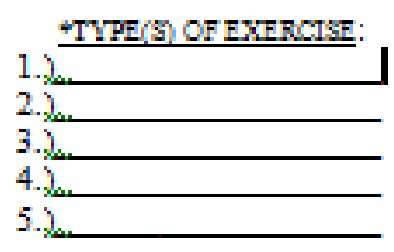

EATING

\begin{tabular}{lllllll|}
\hline $\begin{array}{l}\text { ADH8 } \\
\text { Measure }\end{array}$ & 0 & 1 & 2 & 3 & \\
ADH9 & & & & & \\
Foods & 0 & 1 & 2 & 3 & 4 \\
ADH10 & & & & & \\
More & 0 & 1 & 2 & 3 & 4 \\
$\begin{array}{l}\text { ADH11 } \\
\text { Adjust }\end{array}$ & 0 & Q & 1 & & \\
ADH12 & & & & & \\
Less & 0 & 1 & 2 & 3 & 4 \\
ADH13 & & & & & \\
Adjust & 0 & Q & 1 & & \\
\hline
\end{tabular}

\begin{tabular}{|l} 
INSULIN \\
\begin{tabular}{|llllll|}
\hline ADH22 & & & & & \\
Delay & 0 & 2 & 3 & 4 & \\
ADH23 & & & & & \\
More & 0 & 1 & 2 & 3 & 4 \\
ADH24 & & & & & \\
Les5 & 0 & 1 & 2 & 3 & 4 \\
ADH25 & & & & & \\
Skip & 0 & 2 & 3 & 4 & \\
\hline
\end{tabular}
\end{tabular}

GL UCOSE TESTING

\begin{tabular}{|c|c|c|c|c|c|}
\hline $\mathrm{ADHl} 4$ & & & & & \\
\hline Freq & 0 & 1 & 2 & 3 & 4 \\
\hline $\mathrm{ADH} 15$ & & & & & \\
\hline Differ & 0 & 1 & 2 & 3 & 4 \\
\hline ADH 16 & & & & & \\
\hline Before & 0 & 1 & 2 & 3 & 4 \\
\hline $\mathrm{ADH} 1 ?$ & & & & & \\
\hline After & 0 & 1 & 2 & 3 & 4 \\
\hline ADH18 & & & & & \\
\hline Exercise & 0 & 1 & 2 & 3 & 4 \\
\hline ADH19 & & & & & \\
\hline Adjust & 0 & 1 & 2 & 3 & 4 \\
\hline $\mathrm{ADH} 20$ & & & & & \\
\hline High & 0 & 1 & 2 & 3 & 4 \\
\hline ADH21 & & & & & \\
\hline Sick & 0 & 1 & 2 & 3 & 4 \\
\hline DBT & 0 & 1 & 2 & 3 & 4 \\
\hline
\end{tabular}




\section{Anexo 3}

Termos de consentimento, assentimento e Aprovação da Comissão de Ética para Analise de Projeto de Pesquisa CAPPesq do Hospital das Clínicas da FMUSP.

HOSPITAL DAS CLÍNICAS DA FACULDADE DE MEDICINA DA UNIVERSIDADE DE SÄO PAULO-HCFMUSP

TERMO DE CONSENTIMENTO LIVRE E ESCLARECIDO

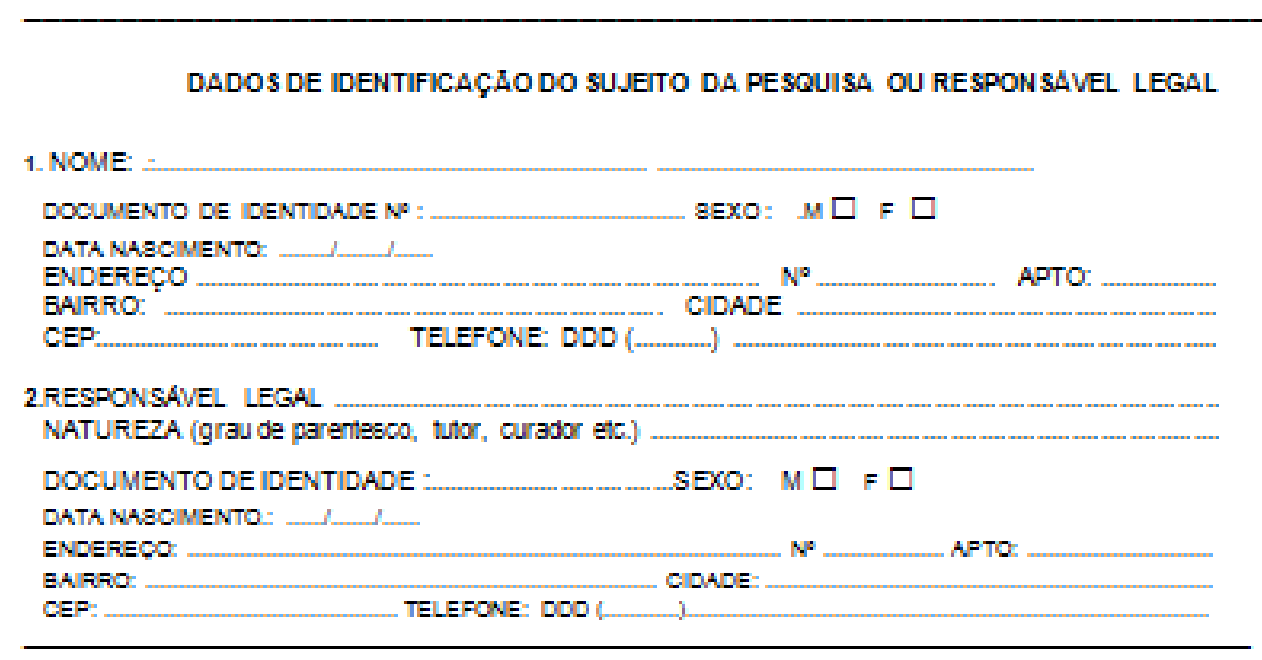

DADOS SOBRE A PESQUISA

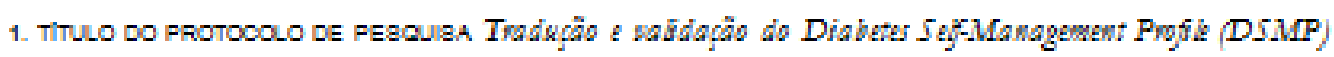
para a Lingua Portuguesa do Brasit um instmumento pana avas̄ar o autocuidado no diabetes tipo 1 numa populacâo brasibira

PEgCulaADCR : Theis Della Manne

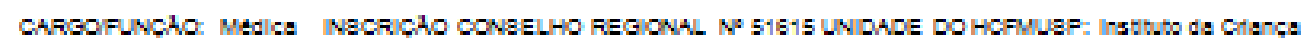
3. AVALIACAO DO RIBCO DA FEBCUIBA:

$\begin{array}{ll}\text { RIaCO MININO } X & \text { RIaCO MEOIO } \square \\ \text { RIaCO BAXO } \square & \text { RIaCO MAIOR } \square\end{array}$

4. DURACAO DA FEBCUIBA : 2 anos 


\section{HOSPITAL DAS CLÍNICAS DA FACULDADE DE MEDICINA DA UNIVERSIDADE DE SÃo PAULO-HCFMUSP}

O(A) $\operatorname{Sr}(a)$. e seu tino (a) estăo sendo comidados a particlpar de um estudo que tem por objetwo traduzir e validar o instrumento de autoculdado em diabetes mellis tpo 1- Dlabetes Self Management Profle (DSMP). O autoculdado e como woce e sua famllia culdam do dabetes da sua crlança. Esse estudo conslste en uma entrevista, que avalla 0 autoculdado en dabeles do paclente e de seus

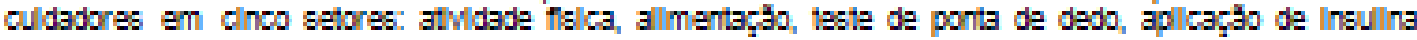
e hipogllcemla. Para lsto sera ut zado um questionarlo para os culdadores e um para o paclente, ambos com 25 perguntas, junto com a equjpe de pesqulsa. Os menores de 11 anos responderăo apenas um questionario junto aos responsanels.

Su35 respostas, 3ssim como a dos outros particlpantes da pesqulsa serăo anallsadas em conjunto, sem a identficaçăo de nenhum paclente ou culdador. Essa etapa da pesqulsa tera duraçăo madima de 2 anos. Seus dados serăo tratados de forma anonima e contidenclal sendo que as unlcas informaçbes que serăo ut zadas no estudo sấ 35 fornecldas no questionarilo, os resultados dos exames laboratorials que săo normalmente reallzados para a consulta de rotina e a avallaçăb da sltuaç̧̧ socioeconomica. Voce sera mantido atualizado sobre os resultados parclals das pesqulsas, ou de resultados que sejam do connecimento dos pesqulsadores.

A particlpaçăo e voluntaria e năo implica en qualquer vantagem. Da mesma forma, sua recusa

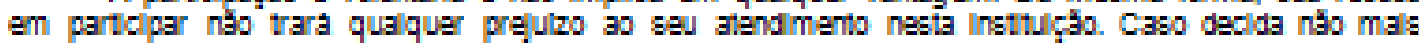
particlpar da pesqulsa sera garantida sua liberdade de retirada deste Termo de Consentmento a qualquer momento, sem que lis6o traga qualquer prefulzo a continuldade do seu tratamento. Durante qualquer etapa do estudo, woce lerä acesso aos profisslonals responsatvels pela pesqulsa para esclaredimentos de eventuals dóldas sobre ela. A médica executora do estudo é a Dra Carolne de Gouvela Butf Passone que pode ser encontrada na Av. Dr Eneas de Carvalho Agular, 647, Säo Paulo, SP. Departamento de Diabeiologla e Endocrinologla; fone (11) 8145-7909; e-mal carol.passoneggmall.com Se woce tver alguma conslderaç3o ou dólida sobre a etica da pesqulsa, entre en contato com o Comile de Etica en Pesqulsa (CEP) - Rua Ovido Pires de Campos, $225-5^{\circ}$ andar - 1a: $3069-6442$ ramals 16, 17, 18 ou 20 - e-mall: cappesq Qhcnet.usp.br.

Năo ha despesas pessoals para o particlpante en qualquer fase do estudo, incluindo exames e consultas. Tambem năo ha compensaçăo financelra relaclonada a sua particlpaçăo. Se edstir qualquer despesa adiclonal, ela sera absorvida pelo orçamento da pesqulsa. 


\section{HOSPITAL DAS CLINICAS DA FACULDADE DE MEDICINA DA UNIVERSIDADE DE SAO PAULO-HCFMUSP}

Acredito ter sido suffclentemente linformado a respeito des informaçes que II ou que foram llides para

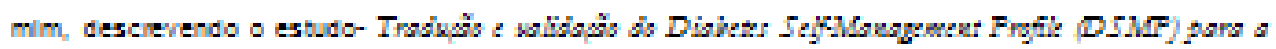

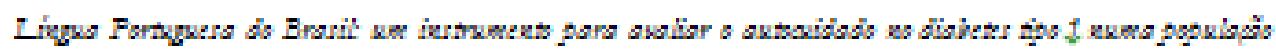
irerileirs

Eu discut com a Dia Carollne de Gourela Buat Bassoca sobre a minha decis do em perticlpar nesse estudo. Ficaram claros para mim quals sdo os propdsiltos do estudo, os procedimentos a seiem reallzados, seus desconfortos e itscos, es garantias de confidenclalldade e de esclarecimentos

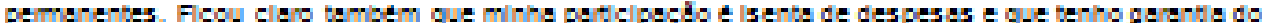
acesso a tratamento hospltalar quando necessuito. Concordo voluntartamente em paticlpar deste estudo e poderel retirar o meu consentimento a qualouer momento, antes ou durante o mesmo, sem penallades ou prejula ou peids de qualour beneflelo que eu possa ter adoulifio, eu ne mou atendimente neate Seripe.

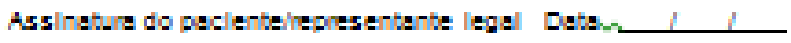

Assinatura da testemung

Deta

pora cescs de peclentes menores de 18 anos, andtabebos, seml-analabebos ou portadores de deficlencla euditiva ou visual.

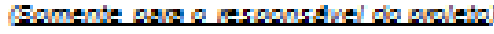

Declaro que obove de forme apopitade e voluntarta o Consentimento Uvire e Esclarecido deste peclente ou representante legal para a particloacto neste estudo.

Assinatura do responstrel pelo estudo

Data 
TERMO DE ASSENTIMENTO

\section{DADOS DE IDENTIFICAÇAO DO SUJEITO DA PESQUISA OU RESPON SAVEL LEGAL}

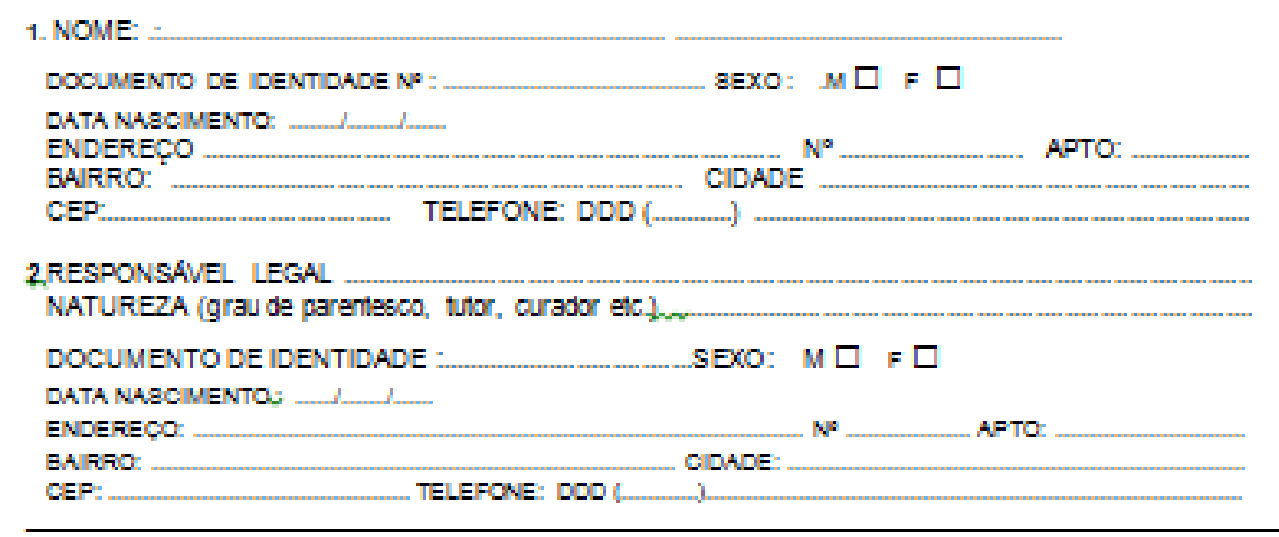

\section{DADOS SOBRE A PESQUISA}

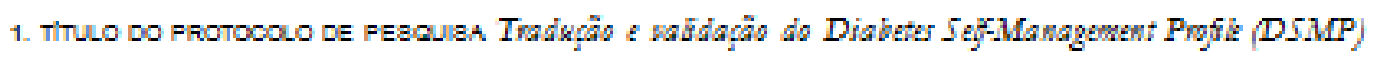
para a Lingua Portuguesa do Brasiz um instrumento para avas̃ar o autockidado no diabeter tipo 1 numa populaçâo brasibina

Bgaculasoori. The's Dells Mans

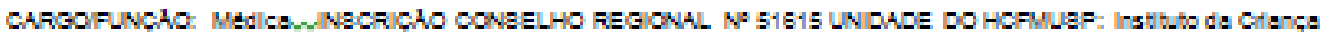
3. AVALIACAO DO RIBCO DA FEBCUIBA:

$\begin{array}{ll}\text { fiaco MiNmo } X & \text { fiaco mEDIO } \square \\ \text { Riaco BAXO } \square & \text { fiaco MAIOR } \square\end{array}$

4.DURACAO DA FEBQUIBA : 2 anos 
Vocé está sendo convidados a participar de um estudo que tem por objetivo traduzir e validar o instrumento de autocuidado em diabetes mellitus tipo 1- Diabetes Self- Management Profile (DSMP). 0 autocuidado é como vocé e sua familia cuidam do diabetes. Esse estudo consiste em uma entrevista, que avalia 0 autocuidado em diabetes do paciente e de seus cuidadores em cinco setores: atividade fisica, alimentaçáo, teste de ponta de dedo, aplicaçáo de insulina e hipoglicemia. Para isto será utilizado um questionário para os cuidadores e um para o paciente, ambos com 25 perguntas, junto com a equipe de pesquisa. Os menores de 11 anos responderăo apenas um questionário junto aos responsáveis.

Suas respostas, assim como a dos outros participantes da pesquisa serảo analisadas em conjunto, sem a identificaçäo de nenhum paciente ou cuidador. Essa etapa da pesquisa terá duraçäo maxima de 2 anos. Seus dados seräo tatados de forma anónima e confidencial sendo que as únicas informaçóes que serăo utilizadas no estudo săo as fornecidas no questionário, os resultados dos exames laboratoriais que sáo normalmente realizados para a consulta de rotina e a avaliaçảo da situaçäo socioeconömica. Vocé serả mantido atualizado sobre os resulados parciais das pesquisas, ou de resultados que sejam do conhecimento dos pesquisadores.

A participaçăo é voluntária e năo implica em qualquer vantagem. Da mesma forma, sua recusa em participar nảo trará qualquer prejuizo ao seu atendimento nesta instituiçáo. Caso decida nảo mais participar da pesquisa será garantida sua liberdade de retirada deste Termo de Consentimento a qualquer momento, sem que isso traga qualquer prejuizo a continuidade do seu tratamento. Durante qualquer etapa do estudo, vocé terá acesso aos profissionais responsáveis pela pesquisa para esclarecimentos de eventuais dúvidas sobre ela. A médica executora do estudo é a Dra Caroline de Gouveia Buff Passone que pode ser encontrada na Av. Dr Eneas de Carvalho Aguiar, 647, Sáo Paulo, SP. Departamento de Diabetologia e Endocrinologia; fone (11) 8146-7909; e-mail carol.passone@gmail.com Se vocé tiver alguma consideraçáo ou düvida sobre a ética da pesquisa, entre em contato com o Comité de Etica em Pesquisa (CEP) - Rua Ovidio Pires de Campos, 225 - $5^{\circ}$ andar - tel: 3069-6442 ramais 16, 17, 18 ou 20 - e-mail: cappesqQhcnet.usp.br.

Nào hà despesas pessoais para o participante em qualquer fase do estudo, incluindo exames e consultas. Tambèm nảo há compensaçáo financeira relacionada à sua participaçào. Se existir qualquer despesa adicional, ela será absorvida pelo orçamento da pesquisa. 
HOSPITAL DAS CLÍNICAS DA FACULDADE DE MEDICINA DA UNIVERSIDADE DE SÃO PAULO-HCFMUSP

Projeto de Pesquisa: Tradução e validação do Diabetes Self-Management Profile (DSMP) para a Língua Portuguesa do Brasil: um instrumento para avaliar o autocuidado no diabetes tipo 1 numa população brasileira

Eu entendi que este projeto de pesquisa é uma entrevista sobre o meu autocuidado em diabetes. Entendi que responderei as perguntas feitas pelo pesquisador na.entrevistas e irei colher os eyames de rotina do acompanhamento do dia betes. A minha participação é voluntária, e não preciso responder algo se eu não quiser. Entendi que não irei perder ou ganhar nada se não quiser participar e todas as minhas informações serão mantidas em segredo pelo pesquisador.

Você aceita participar do projeto de pesquisa?

Aceito: (U)

Não aceito:

Assinatura do paciente

Data

Assinatura da testemunha

Data $1 / 1$

Bara casos de pacientes menores de 18 anos, analfabetos, semi-analfabetos ou portadores de deficiencia auditiva ou visual.

(Somente para o responsàvel do projeto)

Declaro que obtive de forma apropriada e voluntária o Assentimento deste paciente ou representante legal para a participaçäo neste estudo.

Data 


\section{Hospital das Clínicas da FMUSP}

Comissão de Ética para Análise de Projetos de Pesquisa - CAPPesq

\section{PROJETO DE PESQUISA}

Título: TRADUÇÃO E VALIDAÇÃO DO DIABETES SELF-MANAGEMENT PROFILE (DSMP) PARA A LÍNGUA PORTUGUESA DO BRASIL: UM INSTRUMENTO PARA AVALIAR O AUTOCUIDADO NO DIABETES TIPO 1 NUMA POPULAÇÃO BRASILEIRA Pesquisador Responsável: Thais Della Manna Pesquisador Executante: Caroline de Gouveia Buff Passone CAAE: 10768112.7.0000.0068 Co-autores: Lygia Spassapan Oliveira

Finalidade Acadêmica Mestrado Instituição: HCFMUSP

Departamento: PEDIATRIA

\section{PARECER CONSUBSTANCIADO DO CEP}

Registro on-line: 9812

Número do Parecer: 236.810

Data da Relatoria: 03/04/2013

Apresentação do Projeto: Clara, concisa, pertinente e cientificamente bem estruturada Objetivo da Pesquisa: Tradução e validação de questionário de autocuidados para DM tipo 1.

Avaliação dos Riscos e Benefícios: Risco mínimo: aplicação de questionária. benefícios: melharia do tratamento do DM tipo 1 e aprimoramento do serviço assistencial da DM da pediatria

Comentários e Considerações sobre a Pesquisa: Projeto relevante cientificamente embasado. O grupo dispõe de recursos humanos, técnicos e econômicos para sua execução, finalização e publicação além de aplicabilidade institucional assistencial

Considerações sobre os Termos de apresentação obrigatória: Todos as termos obrigatórios foram adequadamente apresentados

Recomendações: Não hả

Conclusões ou Pendências e Lista de Inadequações: Todas as questões levantadas pelo revisor foram adequadamente esclarecidas e o trabalho está dentro dos padrões da bioética.

Situação do Parecer: Aprovado

Necessita Apreciação da CONEP: Não

Considerações Finais a critério do CEP: Em conformidade com a item IX.2 da Resolução CNS no 196/96 - cabe ao pesquisador: a) desenvolver o projeto conforme delineado; b)

Rua Dr. Ovídio Pires de Campos, 225 - Prédio da Administração - 5 andar CEP 05403-010 - São Paulo - SP.

5511 2661-7585 - 5511 2661-6442 ramais: 16, 17, 18 | marcia.carvalho@hc.fm.usp.br 


\section{Hospital das Clínicas da FMUSP}

\section{Comissão de Ética para Análise de Projetos de Pesquisa - CAPPesq}

elaborar e apresentar relatórios parciais e final; clapresentar dados solicitados pelo CEP, a qualquer momento; d) manter em arquivo sob sua guarda, por 5 anos da pesquisa, contendo fichas individuais e todos os demais documentos recomendados pelo CEP; e) encaminhar os resultados para publicação, com os devidos créditos aos pesquisadores associados e ao pessoal técnico participante do projeto; f) justificar perante ao CEP interrupção do projeto ou a não publicação dos resultados.

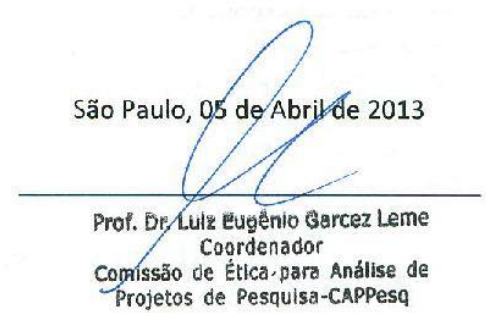

Rua Dr. Ovidio Pires de Campos, 225 - Prédio da Administração - 50 andar CEP 05403-010 - São Paulo - SP.

5511 2661-7585 - 5511 2661-6442 ramais: 16, 17, 18 | marcia.carvalho@hc.fm.usp.br 


\section{Anexo 4}

\section{Questionário de Percepcão do médico}

1) Frequência de administração de insulina/bolus:

bom média ruim

2) Frequência de monitorizaçào glicêmica

bom média ruim

3) Ajuste da insulina

bom média ruim

4) Adesảo à dieta

bom média ruim

5) Manejo da hipoglicemia

bom média ruim

6) Participação na consulta

bom média ruim

7) Aderência global:

a) "De uma maneira geral esta criança adere ao regime prescrito?"

totalmente de acordo com o prescrito

média

totalmente em desacordo com o prescrito

b) "De uma maneira geral esta criança é capaz de aderir ao regime prescrito?"

totalmente de acordo com o prescrito

média

totalmente em desacordo com o prescrito 


\title{
Anexo 5
}

\section{Versão traduzida do DSMP}

\author{
Tradução DSMP Criança \\ Regime Convencional
}

Cuidar do diabetes significa fazer muitas coisas diferentes como tomar insulina, fazer testes para avaliar o açúcar no sangue, seguir um plano alimentar, fazer exercícios físicos e lidar com o açúcar alto e baixo no sangue. Não é fácil fazer todas estas coisas exatamente como os médicos e as enfermeiras pedem. Muito poucas crianças com diabetes fazem tudo exatamente de acordo com o planejado. Às vezes, você pode estar preocupado com outras coisas ou você pode simplesmente esquecer-se de cuidar do diabetes, apesar de querer fazê-lo. A maioria das crianças e suas famílias desenvolvem uma forma própria para cuidar do diabetes que seja mais fácil para elas.

O que nós estamos tentando aprender nesta entrevista é como você e sua família cuidam do seu diabetes. Eu vou te fazer perguntas e escrever suas respostas. Você pode parar a qualquer momento, ou voltar atrás para as primeiras questões para mudar suas respostas. Somente a nossa equipe irá saber as suas respostas. Sua participação é completamente voluntária. Você não precisa responder qualquer pergunta se não quiser. Você não terá qualquer problema se você quiser pular uma questão. Suas respostas não serão compartilhadas com ninguém, assim você pode ficar tranquilo para me dizer exatamente o que você faz, não somente o que você pensa que deveria fazer ou o que eu gostaria que você dissesse.

Assim, tente ser completamente honesto (a) comigo sobre o que você e sua família têm normalmente feito para cuidar do diabetes nos últimos 3 meses.

\section{Atividade Física}

Uma parte do cuidado com o diabetes é praticar exercícios regularmente, como correr, andar de bicicleta e nadar. Algumas crianças tentam fazer isto regularmente, enquanto outras têm dificuldade de encontrar tempo suficiente para fazer exercício. Nesta parte da entrevista, eu irei perguntar a você sobre a sua prática de atividade física, que pode ser praticar algum esporte, participar das aulas de educação física na escola, caminhar ou andar de bicicleta até a escola.

Tente ser o mais honesto (a) e preciso possível sobre a prática de atividade física nos últimos 3 meses.

\section{1- Qual tipo de atividade física você pratica?}

Nos últimos $\mathbf{3}$ meses, quantas vezes você praticou esta atividade física por pelo menos $\mathbf{2 0}$ minutos ?

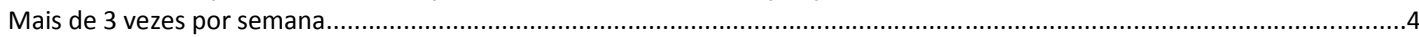

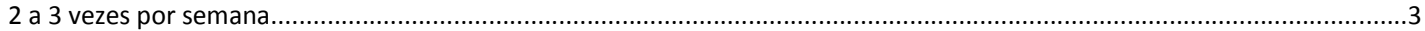

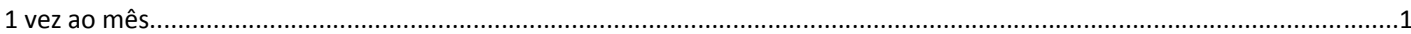

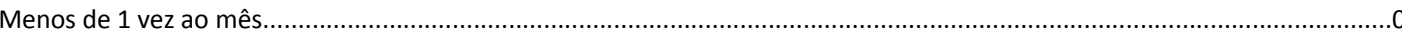

2- Se você faz mais exercícios do que o habitual, ou se você planeja fazer mais exercício, você muda alguma coisa na alimentação ou na insulina? (se o entrevistado responder não, circule 0 , e siga para a questão 3 )

O que você faz?

Nos últimos 3 meses, você consegue se lembrar de quantas vezes você fez esta mudança?

Faz exercícios de forma tão regular que ajustes são desnecessários...................................................................................

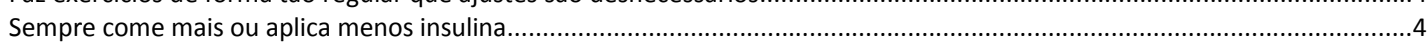

Com frequência come mais ou aplica menos insulina ( 2 a 3 vezes por semana) ……...........................................................

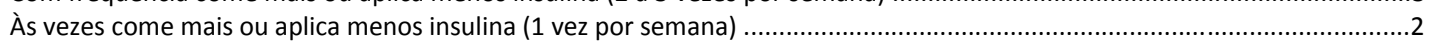

Ocasionalmente come mais ou aplica menos insulina (poucas vezes no mês) ....................................................................1

Come menos do que o normal e aplica mais insulina ou não ajusta a comida ou a insulina ......................................................

3- Se você faz menos exercícios do que o normal, ou se você planeja fazer menos exercício, você muda alguma coisa na alimentação ou na insulina? (se o entrevistado responder não, circule 0 , e siga para a questão 4)

O que você faz?

Nos últimos 3 meses, você consegue se lembrar quantas vezes você fez esta mudança?

Faz exercícios de forma tão regular que ajustes são desnecessários........................................................................................

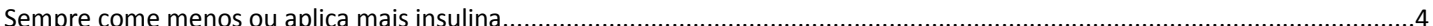

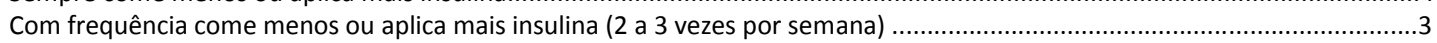

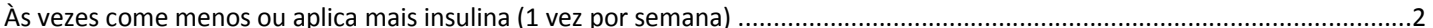

Ocasionalmente come menos ou aplica mais insulina (poucas vezes no mês) ........................................................................1

Come mais e aplica menos insulina ou não ajusta a comida ou a insulina...............................................................................

\section{Hipoglicemia}

Todas as pessoas com diabetes, às vezes, têm reações pelo baixo açúcar no sangue que podem causar a sensação de tontura, tremedeira, confusão, sudorese, náuseas, fraqueza, fome e irritabilidade. 0 médico e as enfermeiras provavelmente já te ensinaram algumas coisas para evitar que ocorra a queda do açúcar no sangue e como se cuidar quando isto acontece. Esta parte da entrevista é sobre o que você geralmente faz quando tem estas reações. Tente ser o mais honesto (a) e preciso (a) possível sobre como você lidou com as quedas de açúcar no sangue nos últimos 3 meses.

4- Você leva alguma coisa com você em caso de ter uma reação por causa da queda de açúcar no sangue? Por exemplo, quando você está na escola ou jogando bola, ou num carro e o seu açúcar está muito baixo, você tem algo em mãos para comer?

Sim . 
5- Se você pensa que o açúcar está baixo, quantas vezes você faz o teste de ponta de dedo antes de se tratar? Sempre faz teste de ponta de dedo antes de tratar o açúcar baixo (insiste em dizer que nunca teve açúcar baixo no sangue). 4 Geralmente faz teste de ponta de dedo antes de tratar o açúcar baixo ( $75 \%$ das vezes ou mais da metade) ..........................3 Algumas vezes faz teste de ponta de dedo antes de tratar o açúcar baixo ( $50 \%$ das vezes ou a metade) ................................ Raramente faz teste de ponta de dedo antes e trato o açúcar baixo ( $25 \%$ das vezes ou menos da metade) .............................1 Nunca faz o teste de ponta de dedo antes de tratar o açúcar baixo no sangue ..................................................................

6- As pessoas lidam com uma queda de açúcar no sangue de formas diferentes. $\mathbf{O}$ que você normalmente faz para tratar as reações de uma queda de açúcar no sangue?( se o entrevistado responder que come alguma coisa, pergunte "Quantas gramas de carboidrato tem isso?". Se o entrevistado responder algo diferente de 15g pergunte "É essa a quantidade que 0 seu médico falou para você ingerir?". Então se o entrevistado responder que ingere a quantidade prescrita, mas não menciona o teste, pergunte: "você faz o teste após comer?")

Toma cuidado para rapidamente ingerir a quantidade de carboidratos prescrita ( $15 \mathrm{~g}$ se aplicável) e faz o teste de ponta de dedo após 10 minutos ou insiste que nunca teve açúcar baixo no sangue.....

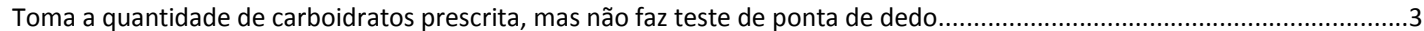
Ingere carboidratos (não a quantidade prescrita) sem levar em conta quanto. ......................................................................

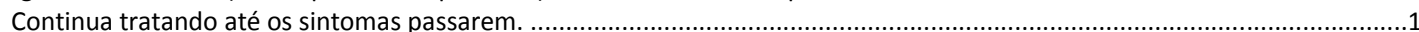
Ignora os sintomas até ter a chance de fazer alguma coisa (espera até o momento em que é conveniente tratar)...................0

7- Você usa ou leva com você algo que identifica que você tem diabetes, como um cartão ou bracelete? Você pode me mostrar?

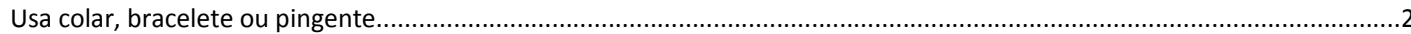

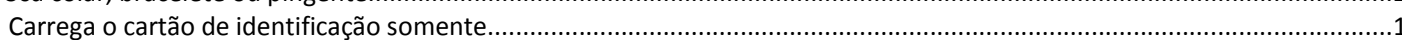

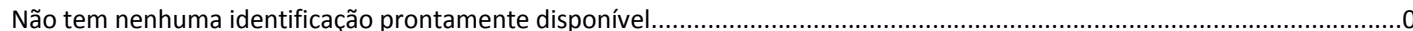

\section{Alimentação}

Médicos, enfermeiras e nutricionistas pedem às crianças com diabetes que sigam um plano alimentar que os ajude a ter um peso saudável e um bom controle do açúcar no sangue. Várias coisas podem atrapalhar o seguimento desse plano, e mesmo quando se esforçam ao máximo, algumas crianças acham difícil se alimentar exatamente de acordo com o plano. Nessa parte da entrevista eu vou fazer algumas perguntas sobre seus hábitos alimentares. Tente ser o mais honesto (a) e preciso (a) possível sobre os seus hábitos alimentares nos últimos 3 meses.

8- Você quantifica o que come, conta carboidratos (ou faz trocas) para saber o quanto você deve comer, ou você geralmente come sempre a mesma quantidade de comida sem contar carboidratos? (se o entrevistado responder "Eu conto carboidratos", pergunte "Diga-me como você faz para contar carboidratos de uma comida que você nunca comeu antes?") Usa a contagem de carboidratos ou lista de trocas como um guia e quantifica a comida e lê os rótulos ..................................3 Usa a contagem de carboidratos (ou lista de trocas) como um guia, mas conhece bem o plano alimentar para que possa

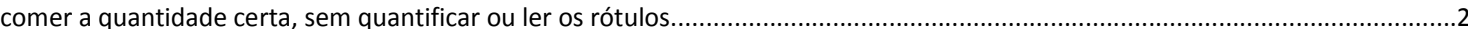
Come aproximadamente a mesma quantia de comida por refeição, mas não quantifica ou usa a contagem de carboidratos (ou lista de trocas)

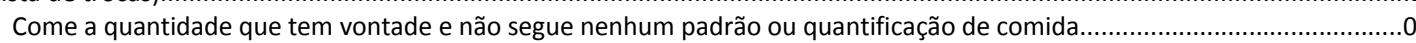

9- Existem alguns tipos de comida que todos deveríamos evitar como doces e comidas com muita gordura como bolachas, salgadinhos, bolos, sorvete, pizza, batata frita, cachorro quente, entre outros. Comer algumas dessas comidas não é necessariamente ruim para você, no entanto, comer grandes quantidades de doce ou comidas com muita gordura não é bom para ninguém. Nos últimos 3 meses, com qual frequência você comeu mais desse tipo de comida do que a quantidade saudável?

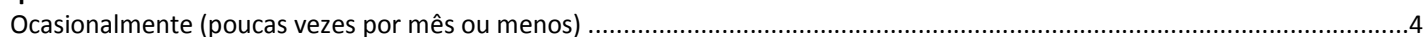

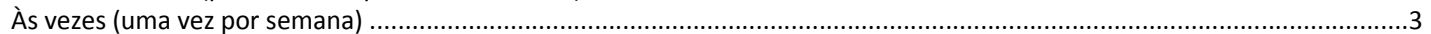

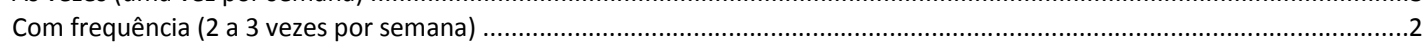

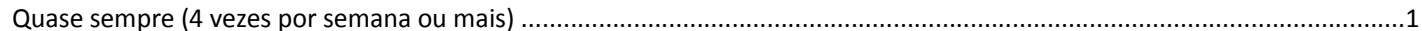

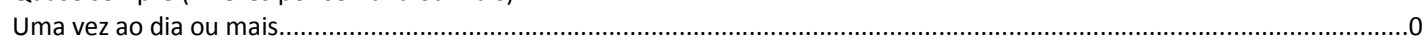

10- Algumas vezes as pessoas comem "MAIS" do que a quantidade prevista no seu plano alimentar. Isso não inclui as vezes em que você precisa comer mais porque está se exercitando mais ou quando tem uma queda de açúcar no sangue. Isso pode acontecer quando você está com muita fome ou quando tem vontade de fazer um lanche antes do jantar.

Nos últimos 3 meses, quantas vezes você comeu mais do que o recomendado no seu plano alimentar?

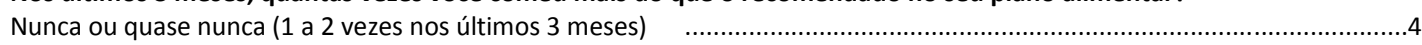

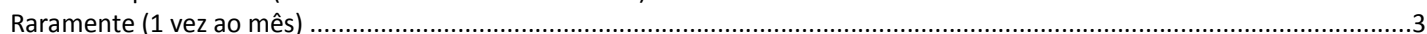

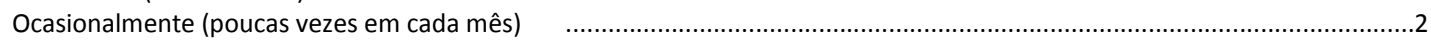

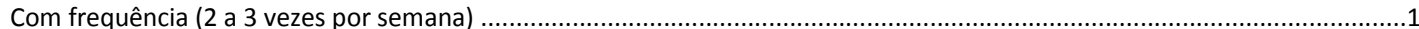

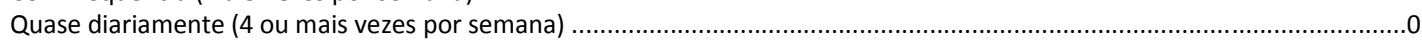

11- Antes de você comer "MAIS" do que você normalmente come, você faz alguma mudança na insulina? O que você faz?

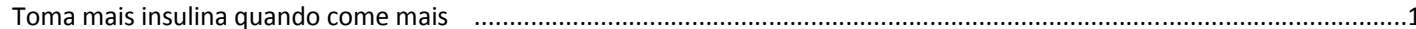

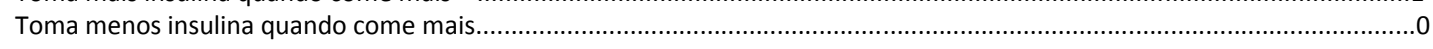

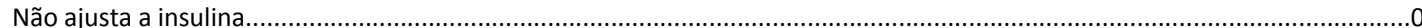


12- Algumas vezes as pessoas comem "MENOS" do que a quantidade prevista no seu plano alimentar. Isso não inclui as vezes em que você faz modificações na atividade física, quando fica doente ou quando sua taxa de açúcar no sangue está muito alta. Isso pode acontecer quando você simplesmente não tem vontade de comer tudo o que está no seu prato.

Nos últimos 3 meses, quantas vezes você comeu menos do que o recomendado no seu plano alimentar?

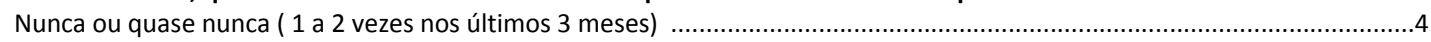

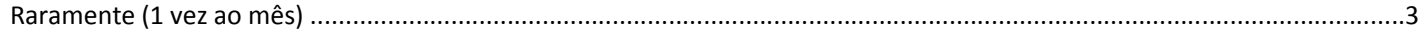

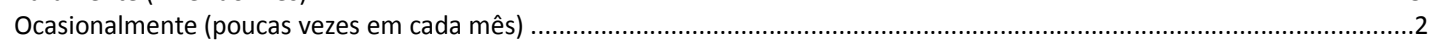

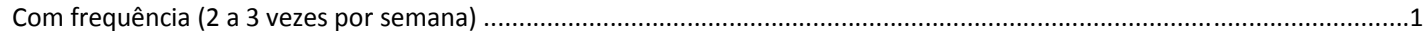

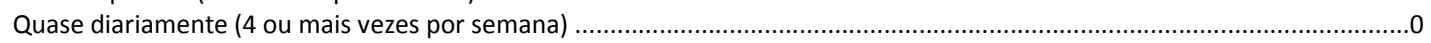

13- Antes de você comer "MENOS" do que você normalmente come, você faz alguma mudança na insulina? O que você faz?

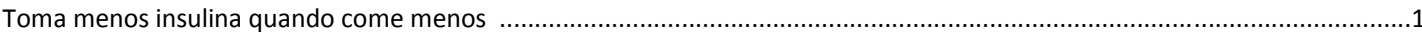

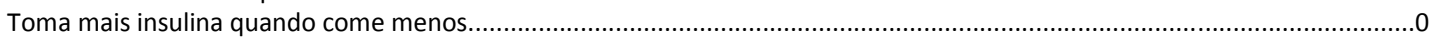

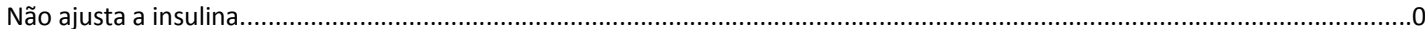

Monitorização do açúcar no sangue- teste de ponta de dedo

Algumas crianças fazem todos os seus testes de ponta de dedo, mas muitas crianças acham difícil em fazer todos os testes que os médicos e enfermeiros pedem. A seguir, eu vou lhe perguntar sobre os seus hábitos em relação a fazer teste de ponta de dedo. Tente ser o mais honesto (a) e preciso (a) possível sobre seus hábitos em relação a fazer os teste de ponta de dedo nos últimos 3 meses.

14- Nos últimos 3 meses, quantas vezes você fez o teste de ponta de dedo por dia?

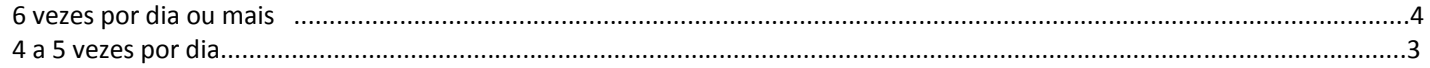

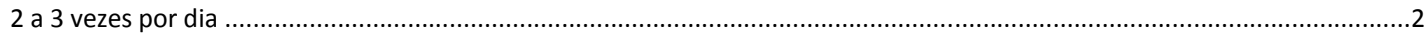

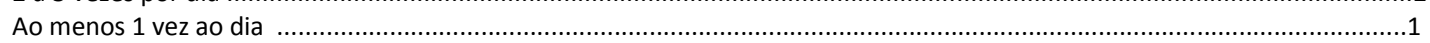

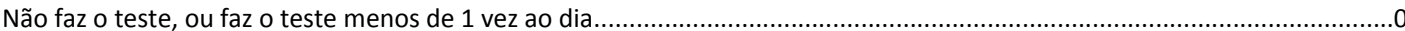

15- Com qual frequência seu médico sugeriu que você fizesse o seu teste de ponta de dedo?

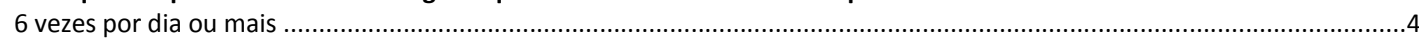

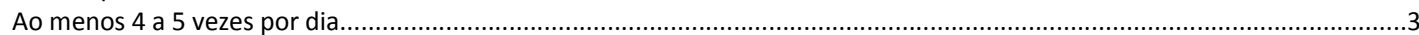

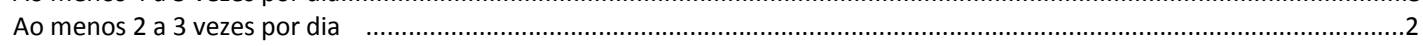

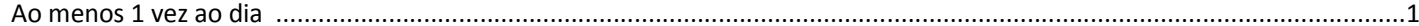

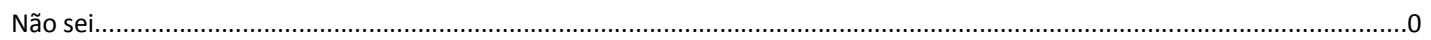

16- Quantas vezes você faz o teste de ponta de dedo (dentro de $\mathbf{3 0}$ minutos) antes da refeição?

Sempre faz o teste de ponta de dedo (30 minutos) antes de cada refeição...........................................................................

Com frequência ( $75 \%$ das vezes u mais de metade das vezes) faz o teste de ponta de dedo (30 minutos) antes das refeições.

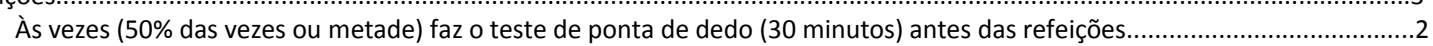

Raramente ( $25 \%$ das vezes ou menos de metade das vezes) faz o teste de ponta de dedo (30 minutos) antes das refeições....1

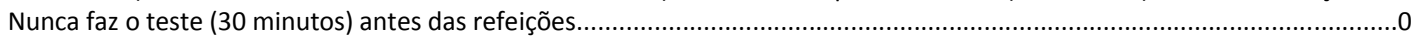

17- Quantas vezes você faz o teste de ponta de dedo 2 a 3 horas após a refeição?

Faz o teste 2 a 3horas após a refeição 4 vezes ou mais vezes por semana................................................................................

Faz o teste 2 a 3horas após a refeição 3 vezes por semana...................................................................................................

Faz o teste 2 a 3horas após a refeição 2 vezes por semana......................................................................................................

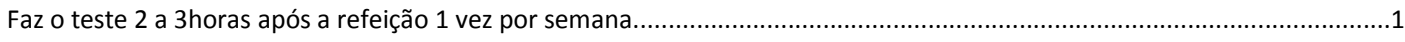

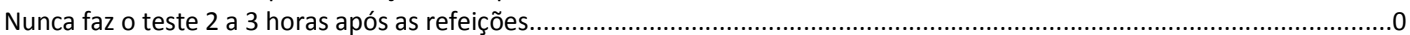

18- Quantas vezes você faz o teste de ponta de dedo 2 a 3 horas após atividade física intensa?

Sempre faz o teste de ponta de dedo 2 a 3 horas após o exercício....................................................................................

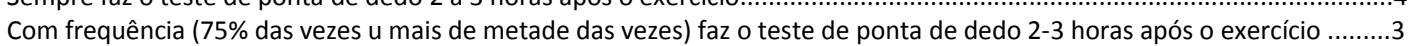

Às vezes (50\% das vezes ou metade) faz o teste de ponta de dedo 30 minutos 2-3 horas após o exercício .............................2

Raramente ( $25 \%$ das vezes ou menos de metade das vezes) faz o teste de ponta de dedo $2-3$ horas após o exercício................

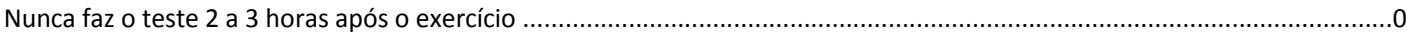

19- Nos últimos 3 meses, quantas vezes você ajustou a sua dose de insulina, sua alimentação, ou atividade física quando os seus testes de ponta de dedo estavam ficando altos?

Fez um ajuste toda vez que foi preciso.

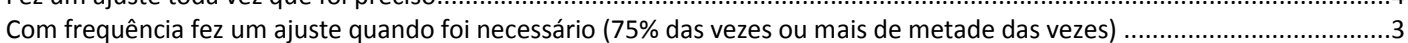

Às vezes fez um ajuste quando foi necessário ( $50 \%$ das vezes ou metade das vezes) .............................................................

Raramente fez um ajuste quando foi necessário ( $25 \%$ das vezes ou menos de metade das vezes) .......................................

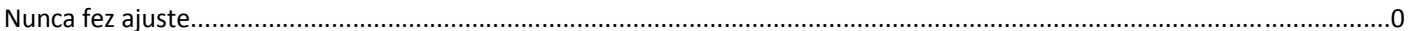

20- Você costuma fazer o teste para cetonas? Sim $\square \quad$ Não $\square$

Se você tem 2 resultados de ponta de dedo acima de 240 em sequência, quantas vezes você faz o teste de cetona na urina?

Não se lembra de ter tido 2 testes acima de 240 em sequência.............................................................................................4

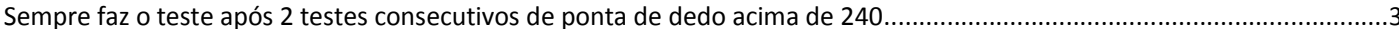


Com frequência faz o teste após 2 testes consecutivos de ponta de dedo acima de 240......................................................2

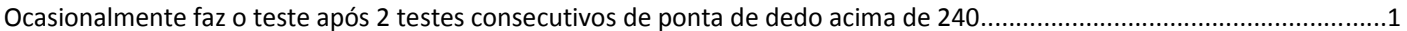

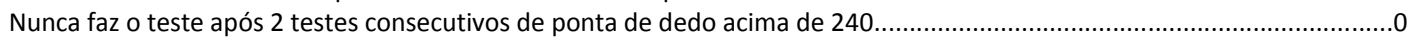

21- Quando você está doente, quantas vezes você faz um teste de cetona na urina? ( Se responder "sempre", pergunte quantas vezes por dia?)

Sempre faz o teste várias vezes ao dia quando está doente $\quad$.........................................................................................

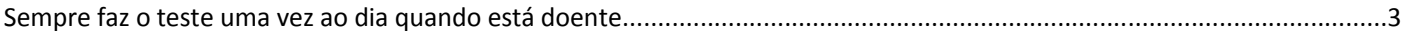

Com frequência faz o teste uma vez ao dia quando está doente......................................................................................

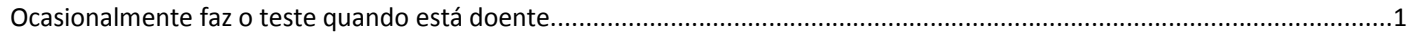

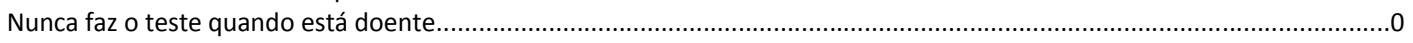

Insulina

Tomar injeções de insulina inclui medir as doses cuidadosamente, tomar as injeções na hora certa e talvez mudar a dose dependendo do resultado do seu teste de ponta de dedo. Tudo isso não é simples e requer um certo tempo que muitas crianças prefeririam gastar fazendo outras coisas Esta parte da entrevista é sobre seus hábitos em relação as aplicações de insulina. Tente ser totalmente honesto (a) quando você responder as perguntas.

22- Nos últimos 3 meses, quantas vezes você atrasou para tomar insulina?

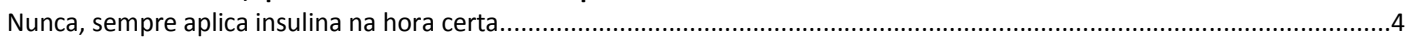

Atrasou 1 vez por mês, ou menos ( 1 a 3 vezes nos últimos 3 meses) ............................................................................

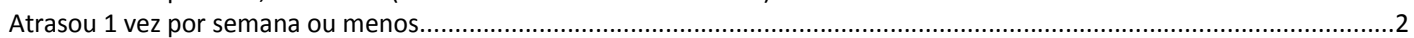

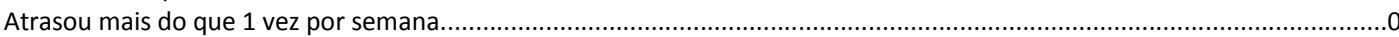

23- Nos últimos 3 meses, quantas vezes você aplicou MAIS insulina do que foi prescrito, até mesmo mais do que seu esquema de correção te permitia?

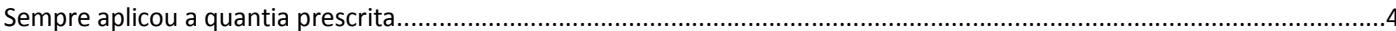

Aplicou mais do que a quantia prescrita (até 1 vez por mês nos últimos 3 meses)............................................................

Aplicou mais do que a quantia prescrita ( 1 a 2 vezes por mês nos últimos 3 meses) ............................................................

Aplicou mais do que a quantia prescrita ( 3 a 4 vezes por mês nos últimos 3 meses) …….................................................... 1

Aplicou mais do que a quantia prescrita (mais de 4 vezes por mês nos últimos 3 meses) …………………………………....

24- Nos últimos 3 meses, quantas vezes você tomou MENOS insulina do que foi prescrito, até mesmo menos do que o seu esquema de correção te permitia?

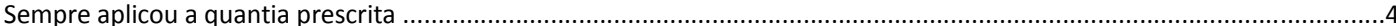

Aplicou menos do que a quantia prescrita (até 1 vez por mês nos últimos 3 meses) ............................................................

Aplicou menos do que a quantia prescrita ( 1 a 2 vezes por mês nos últimos 3 meses) ..........................................................

Aplicou menos do que a quantia prescrita ( 3 a 4 vezes por mês nos últimos 3 meses) .........................................................

Aplicou menos do que a quantia prescrita (mais de 4 vezes por mês nos últimos 3 meses) ...................................................

25- Nos últimos 3 meses, quantas vezes você deixou de aplicar insulina porque você esqueceu ou estava muito ocupado?

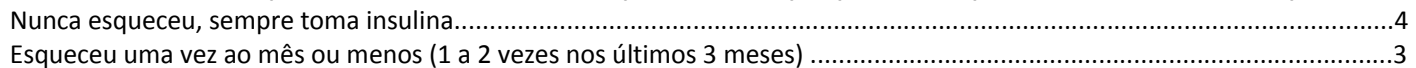

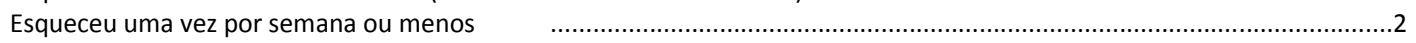

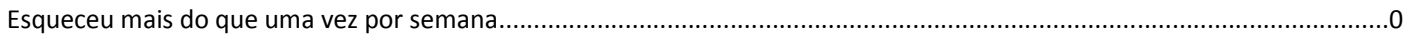




\title{
Tradução DSMP para Crianças
}

\author{
Regime Flexível
}

Cuidar do diabetes significa fazer muitas coisas diferentes como tomar insulina, fazer testes para avaliar o açúcar no sangue, seguir um plano alimentar, fazer exercícios físicos e lidar com o açúcar alto e baixo no sangue. Não é fácil fazer todas estas coisas exatamente como os médicos e as enfermeiras pedem. Muito poucas crianças com diabetes fazem tudo exatamente de acordo com o planejado. Às vezes, você pode estar preocupado com outras coisas ou você pode simplesmente esquecer-se de cuidar do diabetes, apesar de querer cuidar. A maioria das crianças e suas famílias desenvolvem uma forma própria para cuidar do diabetes que seja mais fácil para elas.

O que nós estamos tentando aprender nesta entrevista é como você e sua família cuidam do seu diabetes. Eu vou te fazer perguntas e escrever suas respostas. Você pode parar a qualquer momento, ou voltar atrás para as primeiras questões para mudar suas respostas. Somente a nossa equipe irá saber as suas respostas. Sua participação é completamente voluntária. Você não precisa responder qualquer pergunta se não quiser. Você não terá qualquer problema se você quiser pular uma questão. Suas respostas não serão divididas com ninguém, assim você pode ficar tranqüilo para me dizer exatamente o que você faz, não somente o que você pensa que deveria fazer ou o que eu gostaria que você dissesse.

Assim, tente ser completamente honesto (a) comigo sobre o que você e sua família têm normalmente feito para cuidar do diabetes nos últimos 3 meses.

\section{Atividade Física}

Uma parte do cuidado com o diabetes é praticar exercícios regularmente, como correr, andar de bicicleta e nadar. Algumas crianças tentam fazer isto regularmente, enquanto outras têm dificuldade de encontrar tempo suficiente para fazer exercício. Nesta parte da entrevista, eu irei perguntar a você sobre a sua prática de atividade física, que pode ser praticar algum esporte, participar das aulas de educação física na escola, caminhar ou andar de bicicleta até a escola.

Tente ser o mais honesto (a) e preciso possível sobre a prática de atividade física nos últimos 3 meses.1- Qual tipo de atividade física você pratica?

1- Nos últimos 3 meses, quantas vezes você praticou esta atividade física por pelo menos 20 minutos ?

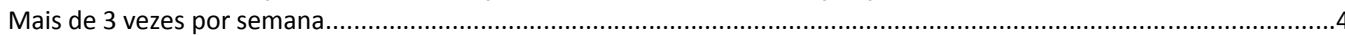

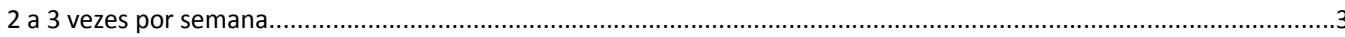

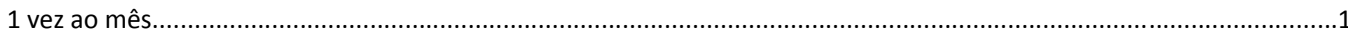

Menos de 1 vez ao mês..................................................................................................................................

2- Se você faz mais exercícios do que o habitual, ou se você planeja fazer mais exercício, você muda alguma coisa na alimentação ou na insulina? (se o entrevistado responder não, circule 0 , e siga para a questão 3 )

O que você faz?

Nos últimos 3 meses, você consegue se lembrar de quantas vezes você fez esta mudança?

Faz exercícios de forma tão regular que ajustes são desnecessários..............................................................................

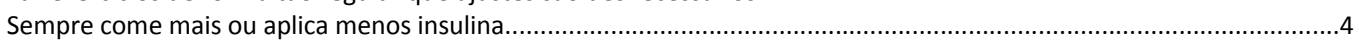

Com frequência come mais ou aplica menos insulina ( 2 a 3 vezes por semana) ..............................................................

Às vezes come mais ou aplica menos insulina (1 vez por semana) .............................................................................

Ocasionalmente come mais ou aplica menos insulina (poucas vezes no mês)....................................................................1

Come menos do que o normal e aplica mais insulina ou não ajusta a comida ou a insulina ..............................................

3- Se você faz menos exercícios do que o normal, ou se você planeja fazer menos exercício, você muda alguma coisa na alimentação ou na insulina? (se o entrevistado responder não, circule 0 , e siga para a questão 4)

O que você faz?

Nos últimos 3 meses, você consegue se lembrar quantas vezes você fez esta mudança?

Faz exercícios de forma tão regular que ajustes são desnecessários..........................................................................4

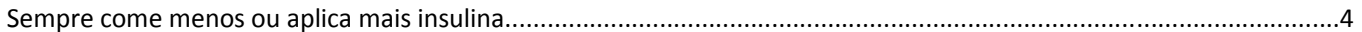

Com frequência come menos ou aplica mais insulina ( 2 a 3 vezes por semana) ............................................................

Às vezes come menos ou aplica mais insulina (1 vez por semana)...............................................................................

Ocasionalmente come menos ou aplica mais insulina (poucas vezes no mês) .................................................................1

Come mais e aplica menos insulina ou não ajusta a comida ou a insulina........................................................................

\section{Hipoglicemia}

Todas as pessoas com diabetes, às vezes, têm reações pelo baixo açúcar no sangue que podem causar a sensação de tontura, tremedeira, confusão, sudorese, náuseas, fraqueza, fome e irritabilidade. 0 médico e as enfermeiras provavelmente já te ensinaram algumas coisas para evitar que ocorra a queda do açúcar no sangue e como se cuidar quando isto acontece. Esta parte da entrevista é sobre o que você geralmente faz quando tem estas reações. Tente ser o mais honesto (a) e preciso (a) possível sobre como você lidou com as quedas de açúcar no sangue nos últimos 3 meses.

4- Você leva alguma coisa com você em caso de ter uma reação por causa da queda de açúcar no sangue? Por exemplo, quando você está na escola ou jogando bola, ou num carro e o seu açúcar está muito baixo, você tem algo em mãos para comer? 
5- Se você pensa que o açúcar está baixo, quantas vezes você faz o teste de ponta de dedo antes de se tratar? Sempre faz teste de ponta de dedo antes de tratar o açúcar baixo (insiste em dizer que nunca teve açúcar baixo no

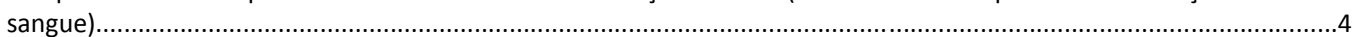
Geralmente faz teste de ponta de dedo antes de tratar o açúcar baixo ( $75 \%$ das vezes ou mais da metade).................... Algumas vezes faz teste de ponta de dedo antes de tratar o açúcar baixo ( $50 \%$ das vezes ou a metade)........................2 Raramente faz teste de ponta de dedo antes e trato o açúcar baixo ( $25 \%$ das vezes ou menos da metade).....................1 Nunca faz o teste de ponta de dedo antes de tratar o açúcar baixo no sangue..............................................................

6- As pessoas lidam com uma queda de açúcar no sangue de formas diferentes. O que você normalmente faz para tratar as reações de uma queda de açúcar no sangue?(se o entrevistado responder que come alguma coisa, pergunte "Quantas gramas de carboidrato tem isso?". Se o entrevistado responder algo diferente de 15g pergunte "É essa a quantidade que o seu médico falou para você ingerir?". Então, se o entrevistado responder que ingere a quantidade prescrita, mas não menciona o teste, pergunte: "você faz o teste após comer?")

Toma cuidado para rapidamente ingerir a quantidade de carboidratos prescrita ( $15 \mathrm{~g}$ se aplicável) e faz o teste de ponta de dedo após 10 minutos ou insiste que nunca teve açúcar baixo no sangue................................................................. Toma a quantidade de carboidratos prescrita, mas não faz teste de ponta de dedo.......................................................... Ingere carboidratos (não a quantidade prescrita) sem levar em conta quanto...............................................................2 Continua tratando até os sintomas passarem...................................................................................................... Ignora os sintomas até ter a chance de fazer alguma coisa (espera até o momento em que é conveniente tratar)0

7- Você usa ou leva com você algo que identifica que você tem diabetes, como um cartão ou bracelete? Você pode me mostrar?

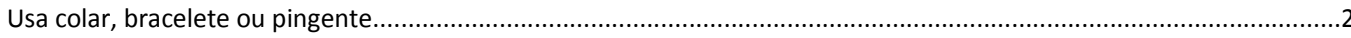

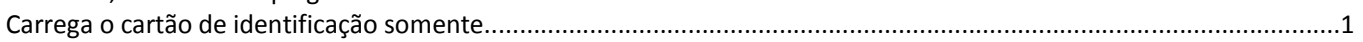

Não tem nenhuma identificação prontamente disponível.........................................................................................

\section{Alimentação}

Médicos, enfermeiras e nutricionistas pedem às crianças com diabetes que sigam um plano alimentar que os ajude a ter um peso saudável e um bom controle do açúcar no sangue. Várias coisas podem atrapalhar o seguimento desse plano, e mesmo quando se esforçam ao máximo, algumas crianças acham difícil se alimentar exatamente de acordo com o plano. Nessa parte da entrevista eu vou fazer algumas perguntas sobre seus hábitos alimentares. Tente ser o mais honesto (a) e preciso possível sobre os seus hábitos alimentares nos últimos 3 meses.

8- Você quantifica o que come, conta carboidratos (ou faz trocas) para saber o quanto você deve comer, ou você geralmente come sempre a mesma quantidade de comida sem contar carboidratos? (se o entrevistado responder "Eu conto carboidratos", pergunte "Diga-me como você faz para contar carboidratos de uma comida que você nunca comeu antes?")

Usa a contagem de carboidratos ou lista de trocas como um guia e quantifica a comida e lê os rótulos............................ Usa a contagem de carboidratos (ou lista de trocas) como um guia, mas conhece bem o plano alimentar para que possa comer a quantidade certa, sem quantificar ou ler os rótulos.

Come aproximadamente a mesma quantia de comida por refeição, mas não quantifica ou usa a contagem

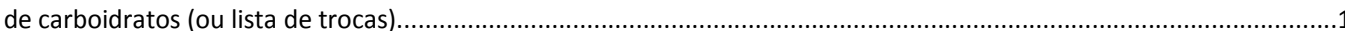
Come a quantidade que tem vontade e não segue nenhum padrão ou quantificação de comida. .....................................

9- Existem alguns tipos de comida que todos deveríamos evitar como doces e comidas com muita gordura como bolachas, salgadinhos, bolos, sorvete, pizza, batata frita, cachorro quente, entre outros. Comer algumas dessas comidas não é necessariamente ruim para você, no entanto, comer grandes quantidades de doce ou comidas com muita gordura não é bom para ninguém. Nos últimos 3 meses, com qual freqüência você comeu mais desse tipo de comida do que a quantidade saudável?

Ocasionalmente (poucas vezes por mês ou menos).

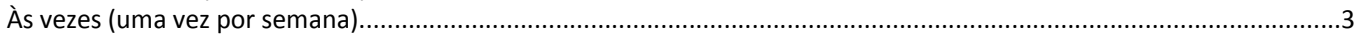

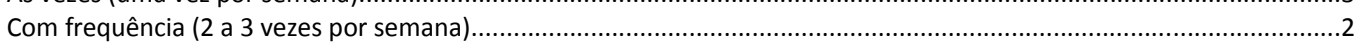

Quase sempre (4 vezes por semana ou mais) ........................................................................................................

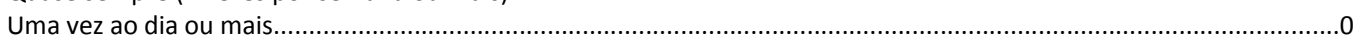

10- Algumas vezes as pessoas comem "MAIS" em relação à insulina previamente calculada e ingerida (bolus). Isso não inclui as vezes em que você precisa comer mais porque está fazendo mais atividade física ou porque teve uma queda de açúcar no sangue. Isso pode acontecer quando você está com muita fome ou quando tem vontade de fazer um lanche antes do jantar. Nos últimos 3 meses, quantas vezes você comeu mais do que o havia feito de bolus de insulina? (se o paciente responder "Eu não faço bolus até depois de comer" circule 0 e pergunte você faz o bolus após comer porque o seu médico te recomendou? Se responder sim, risque o quadrado.)

Nunca ou quase nunca ( $1-2$ vezes nos últimos 3 meses).....................................................................................

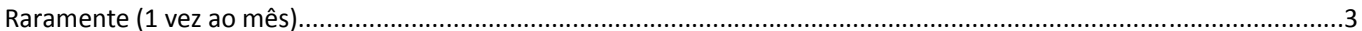

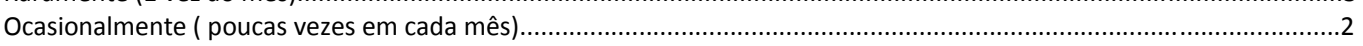

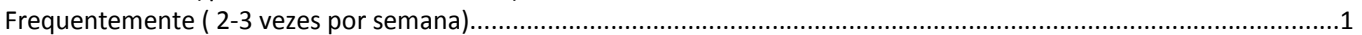

Quase diariamente ( 4 ou mais vezes por semana) ou não faz o bolus até depois de comer ..............................................

Bolus após comer baseado na recomendação médica $\square$ 
11- Se você espera comer MAIS do que está no seu plano alimentar, você muda a dose do bolus de insulina? Se sim, como?

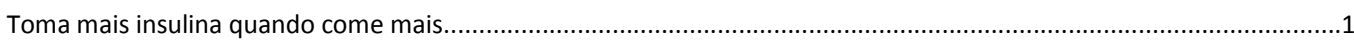

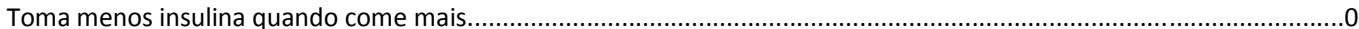

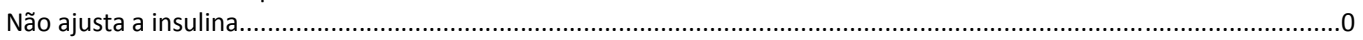

12- Algumas vezes as pessoas comem "MENOS" do que fizeram de bolus de insulina. Isto não inclui quando você faz modificações na atividade física, ou quando você está doente ou quando o açúcar no sangue está muito alto. Isto inclui as vezes que não quer comer tudo o que está no seu prato.

Nos últimos 3 meses, quantas vezes você comeu menos do que havia feito de bolus? (se o paciente responder "Eu não faço bolus até depois de comer" circule 0 e pergunte você faz o bolus após comer porque o seu médico te recomendou? Se responder sim, risque o quadrado.

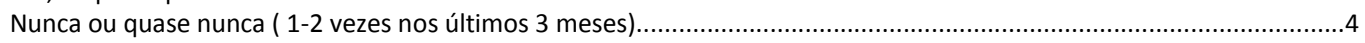

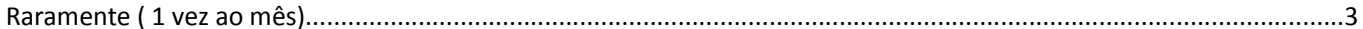

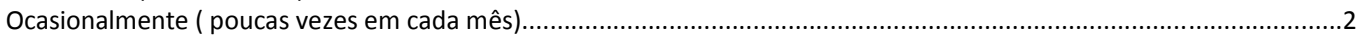

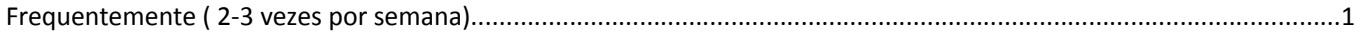

Quase diariamente ( 4 ou mais vezes por semana) ou não faz o bolus até depois de comer ...........................................

Bolus após comer baseado na recomendação médica

13- Se você espera comer MENOS do que está no seu plano alimentar, você muda a dose do bolus de insulina? Se sim, como?

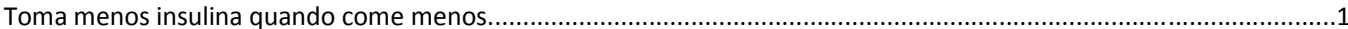

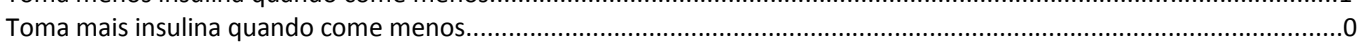

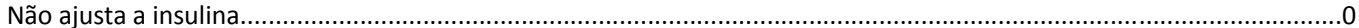

Monitorização do açúcar no sangue- teste de ponta de dedo

Algumas crianças fazem todos os seus testes de ponta de dedo, mas muitas crianças têm problemas em fazer os testes que seus médicos e enfermeiros querem que eles façam. A seguir, eu vou lhe perguntar sobre os seus hábito, em relação a monitorizar o açúcar no sangue/ fazer teste de ponta de dedo. Tente se honesto e preciso o quanto puder sobre seus hábitos em relação a fazer os teste de ponta de dedo nos últimos 3 meses.

14- Nos últimos 3 meses, quantas vezes você fez o teste de ponta de dedo por dia?

4 a 5 vezes por

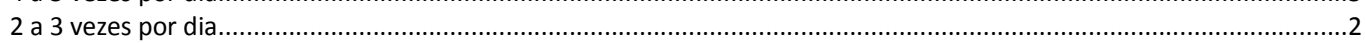

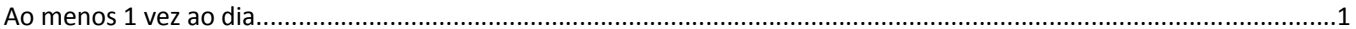

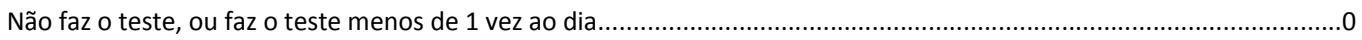

15- Com qual frequência seu médico sugeriu que você fizesse o seu teste de ponta de dedo?

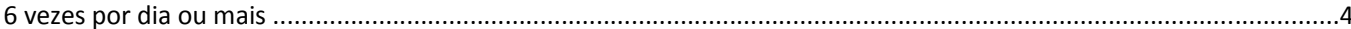

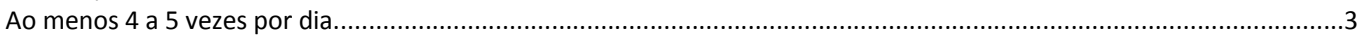

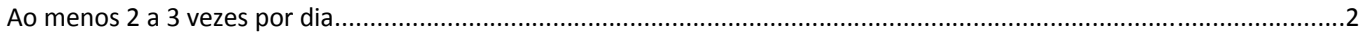

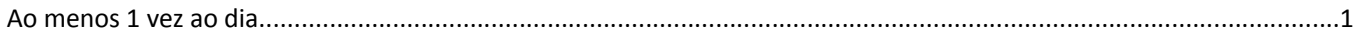

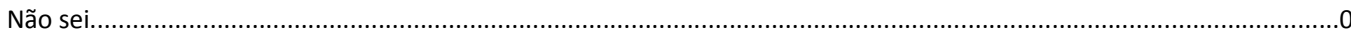

16- Quantas vezes você faz o teste de ponta de dedo (dentro de 30 minutos) antes da refeição?

Sempre faz o teste de ponta de dedo (30 minutos) antes de cada refeição..................................................................

Com frequência ( $75 \%$ das vezes u mais de metade das vezes) faz o teste de ponta de dedo (30 minutos) antes das refeições........

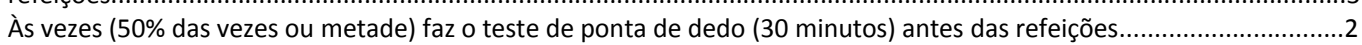
Raramente ( $25 \%$ das vezes ou menos de metade das vezes) faz o teste de ponta de dedo (30 minutos) antes das

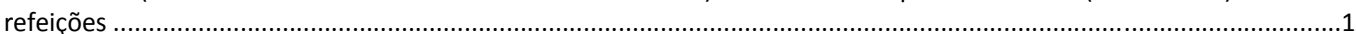

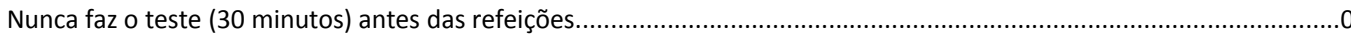

17- Quantas vezes você faz o teste de ponta de dedo $\mathbf{2}$ a $\mathbf{3}$ horas após a refeição?

Faz o teste 2 a 3horas após a refeição 4 vezes ou mais vezes por semana..................................................................... 4

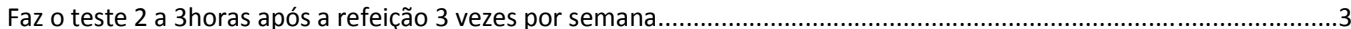

Faz o teste 2 a 3horas após a refeição 2 vezes por semana......................................................................................

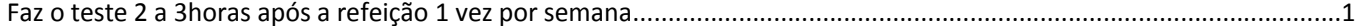

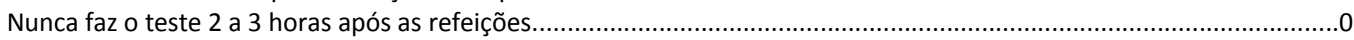

18- Quantas vezes você faz o teste de ponta de dedo $\mathbf{2}$ a $\mathbf{3}$ horas após atividade física intensa?

Sempre faz o teste de ponta de dedo 2 a 3 horas após o exercício

Com frequência (75\% das vezes u mais de metade das vezes) faz o teste de ponta de dedo 2-3 horas após o exercício...3

Às vezes ( $50 \%$ das vezes ou metade) faz o teste de ponta de dedo 30 minutos $2-3$ horas após o exercício........................

Raramente ( $25 \%$ das vezes ou menos de metade das vezes) faz o teste de ponta de dedo $2-3$ horas após o exercício.....1

Nunca faz o teste 2 a 3 horas após o exercício. 
19- Nos últimos 3 meses, quantas vezes você ajustou a sua dose de insulina, sua alimentação, ou atividade física quando os seus testes de ponta de dedo estavam ficando altos?

Fez um ajuste toda vez que foi preciso...................................................................................................................

Com frequência fez um ajuste quando foi necessário ( $75 \%$ das vezes ou mais de metade das vezes)...............................

Às vezes fez um ajuste quando foi necessário ( $50 \%$ das vezes ou metade das vezes)......................................................

Raramente fez um ajuste quando foi necessário (25\% das vezes ou menos de metade das vezes)..................................1

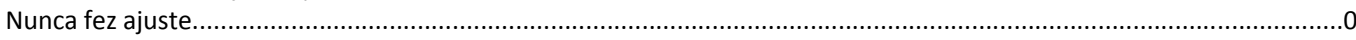

20- Você costuma fazer o teste para cetonas? Sim $\square \quad$ Não $\square$

Se você tem 2 resultados de ponta de dedo acima de 240 em sequência, quantas vezes você faz o teste de cetona na urina?

Não se lembra de ter tido 2 testes acima de 240 em sequência.................................................................................

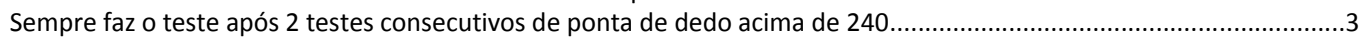

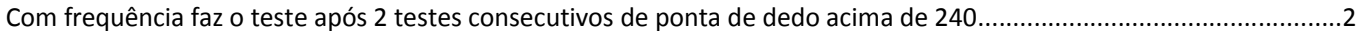

Ocasionalmente faz o teste após 2 testes consecutivos de ponta de dedo acima de 240................................................

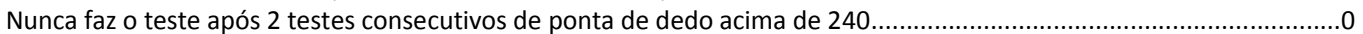

21- Quando você está doente, quantas vezes você faz um teste de cetona na urina? (Se responder "sempre", pergunte quantas vezes por dia?)

Sempre faz o teste várias vezes ao dia quando está doente.........................................................................................

Sempre faz o teste uma vez ao dia quando está doente..........................................................................................

Com frequência faz o teste uma vez ao dia quando está doente.............................................................................

Ocasionalmente faz o teste quando está doente......................................................................................................

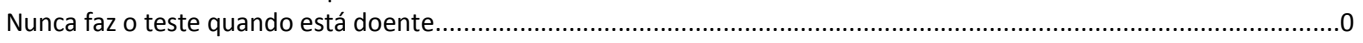

Insulina

Tomar injeções de insulina incluiu medir as doses cuidadosamente, fazer bolus ou tomar as injeções na hora certa e talvez mudar a dose dependendo do resultado do seu teste de ponta de dedo.Tudo é muito complicado e há vezes que muitas crianças preferem gastar o tempo fazendo outras coisas. Esta parte da entrevista é sobre o que você geralmente faz sobre as suas aplicações de insulina. Tente ser totalmente honesto quando você responde as perguntas.

22- Nos últimos 3 meses, quantas vezes você atrasou um bolus ou aplicação de insulina que você não deveria ter atrasado?

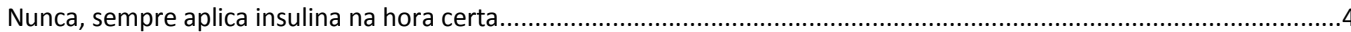

Atrasou 1 vez por mês, ou menos ( 1 a 3 vezes nos últimos 3 meses) ........................................................................

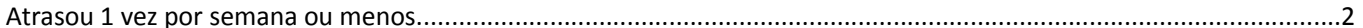

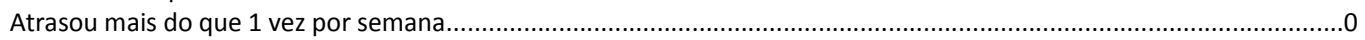

23- Nos últimos 3 meses, quantas vezes você aplicou MAIS insulina ou fez mais bolus do que deveria ter feito, ou, você alguma vez aplicou muita insulina?

Sempre aplicou a quantia prescrita......................................................................................................................

Aplicou mais do que a quantia prescrita (até 1 vez por mês nos últimos 3 meses) ...........................................................

Aplicou mais do que a quantia prescrita ( 1 a 2 vezes por mês nos últimos 3 meses) ....................................................

Aplicou mais do que a quantia prescrita ( 3 a 4 vezes por mês nos últimos 3 meses) ....................................................

Aplicou mais do que a quantia prescrita (mais de 4 vezes por mês nos últimos 3 meses) .................................................

24- Nos últimos 3 meses, quantas vezes você aplicou MENOS insulina ou fez MENOS bolus do que deveria ter feito, ou, você alguma vez aplicou pouca insulina?

Sempre aplicou a quantia prescrita.......................................................................................................................

Aplicou menos do que a quantia prescrita (até 1 vez por mês nos últimos 3 meses) …...................................................3

Aplicou menos do que a quantia prescrita ( 1 a 2 vezes por mês nos últimos 3 meses) …...............................................2

Aplicou menos do que a quantia prescrita ( 3 a 4 vezes por mês nos últimos 3 meses) ….............................................

Aplicou menos do que a quantia prescrita (mais de 4 vezes por mês nos últimos 3 meses).............................................

25- Nos últimos 3 meses, quantas vezes você perdeu o bolus ou a aplicação de insulina porque você esqueceu ou estava muito ocupado, ou, falhou na administração da insulina basal porque a sua bomba não estava funcionando ou não estava inserida?

Nunca esqueceu, sempre toma insulina.............................................................................................................

Esqueceu uma vez ao mês ou menos ( 1 a 2 vezes nos últimos 3 meses) ....................................................................

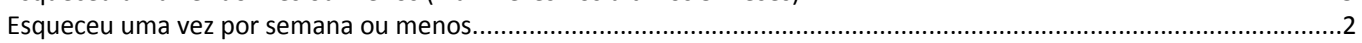

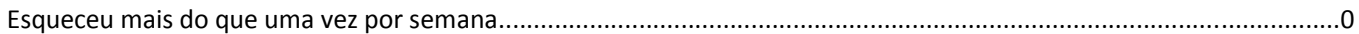




\section{Tradução DSMP- para Pais}

\section{Regime Convencional}

Cuidar do diabetes significa fazer muitas coisas diferentes como tomar insulina, fazer testes para avaliar o açúcar no sangue, seguir um plano alimentar, fazer exercícios físicos e lidar com o açúcar alto e baixo no sangue. Não é fácil fazer todas estas coisas exatamente como os médicos e as enfermeiras pedem. Muito poucas crianças com diabetes fazem tudo exatamente de acordo com o planejado. Às vezes, o (a) seu (sua) filho/filha pode estar preocupado com outras coisas ou ele/ela pode simplesmente esquecer-se de cuidar do diabetes, apesar de querer cuidar. A maioria das crianças e suas famílias desenvolvem uma forma própria para cuidar do diabetes que seja mais fácil para elas.

O que nós estamos tentando aprender nesta entrevista é como você e sua família cuidam do diabetes da sua criança. Eu vou te fazer perguntas e escrever suas respostas. Você pode parar a qualquer momento, ou voltar atrás para as primeiras questões para mudar suas respostas. Somente a nossa equipe irá saber as suas respostas. Sua participação é completamente voluntária. Você não precisa responder qualquer pergunta se não quiser. Você não terá qualquer problema se você quiser pular uma questão. Suas respostas não serão compartilhadas com ninguém, assim você pode ficar tranquilo para me dizer exatamente o que você faz, não somente o que você pensa que deveria fazer ou o que eu gostaria que você dissesse.

Assim, tente ser completamente honesto (a) comigo sobre o que você e sua família têm normalmente feito para cuidar do diabetes do(a) seu(sua) filho/filha nos últimos 3 meses.

\section{Exercício}

Uma parte do cuidado com o diabetes é praticar exercícios regularmente, como correr, andar de bicicleta e nadar. Algumas crianças tentam fazer isto regularmente, enquanto outras têm dificuldade de encontrar tempo suficiente para fazer exercício. Nesta parte da entrevista, eu irei perguntar a você sobre a prática de atividade física do (a) seu(sua) filho/filha, que pode ser praticar algum esporte, participar das aulas de educação física na escola, caminhar ou andar de bicicleta até a escola.

Tente ser o mais honesto (a) e preciso (a) possível sobre a prática de atividade física da sua criança nos últimos 3 meses.

1- Qual tipo de atividade física o (a)seu (sua) filho/filha pratica?

Nos últimos $\mathbf{3}$ meses, quantas vezes ele/ela praticou esta atividade física por pelo menos $\mathbf{2 0}$ minutos ?

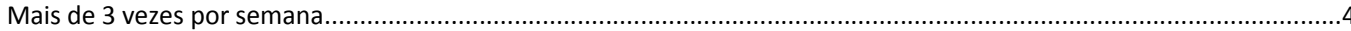

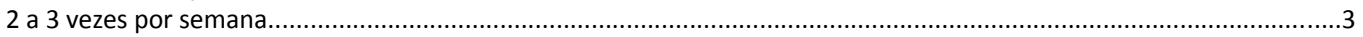

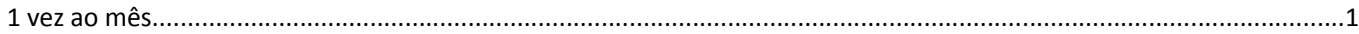

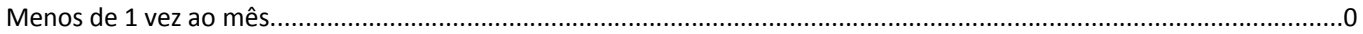

2- Se o (a)seu (sua) filho/filha faz mais exercícios do que o habitual, ou se ele/ela planeja fazer mais exercício, ele/ela muda alguma coisa na alimentação ou na insulina? (se o entrevistado responder não, circule 0 , e siga para a questão 3) O que ele/ela faz?

Nos últimos 3 meses, você consegue se lembrar de quantas vezes ele/ela fez esta mudança?

Faz exercícios de forma tão regular que ajustes são desnecessários............................................................................

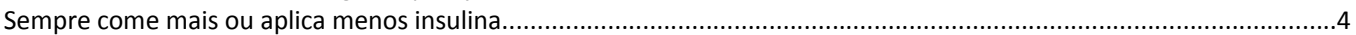

Com frequência come mais ou aplica menos insulina (2 a 3 vezes por semana) ...............................................................

Às vezes come mais ou aplica menos insulina (1 vez por semana)...............................................................................

Ocasionalmente come mais ou aplica menos insulina (poucas vezes no mês)...................................................................

Come menos do que o normal ou aplica mais insulina ou não ajusta a comida ou a insulina ............................................

3- Se o (a)seu (sua) filho/filha faz menos exercícios do que o normal, ou se ele/ela planeja fazer menos exercício, ele/ela muda alguma coisa na alimentação ou na insulina? (se o entrevistado responder não, circule 0 , e siga para a questão 4)

O que ele/ela faz?

Nos últimos 3 meses, você consegue se lembrar quantas vezes ele/ela fez esta mudança?

Faz exercícios de forma tão regular que ajustes são desnecessários............................................................................

Sempre come menos ou aplica mais insulina........................................................................................................

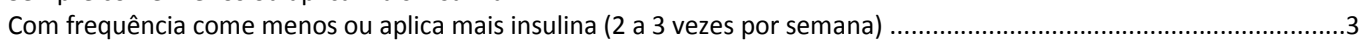

Às vezes come menos ou aplica mais insulina (1 vez por semana) ........................................................................

Ocasionalmente come menos ou aplica mais insulina (poucas vezes no mês) .................................................................

Come mais e aplica menos insulina ou não ajusta a comida ou a insulina.......................................................................

\section{Hipoglicemia}

Todas as pessoas com diabetes, às vezes, têm reações pelo baixo açúcar no sangue que podem causar a sensação de tontura, tremedeira, confusão, sudorese, náuseas, fraqueza, fome e irritabilidade. 0 médico e as enfermeiras provavelmente já te ensinaram algumas coisas para evitar que ocorra a queda do açúcar no sangue e como cuidar quando isto acontece. Esta parte da entrevista é sobre o que o (a)seu (sua) filho/filha geralmente faz quando tem estas reações. Tente ser o mais honesto (a) e preciso (a) possível sobre como o (a)seu (sua) filho/filha lidou com as quedas de açúcar no sangue nos últimos 3 meses. 
4- $\quad$ (a)seu (sua) filho/filha leva alguma coisa com ela em caso de ter uma reação por causa da queda de açúcar no sangue? Por exemplo, quando ele/ela está na escola ou jogando bola, ou num carro e o açúcar está muito baixo, ele/ela tem algo em mãos para comer?

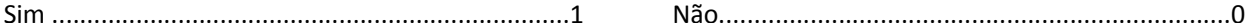

5- Se o (a)seu (sua) filho/filha pensa que o açúcar está baixo, quantas vezes ele/ela faz o teste de ponta de dedo antes de se tratar?

Sempre faz teste de ponta de dedo antes de tratar o açúcar baixo (insiste em dizer que nunca teve açúcar baixo no

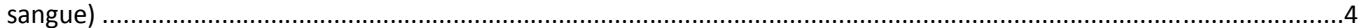
Geralmente faz teste de ponta de dedo antes de tratar o açúcar baixo ( $75 \%$ das vezes ou mais da metade)..................... Algumas vezes faz teste de ponta de dedo antes de tratar o açúcar baixo ( $50 \%$ das vezes ou a metade)..........................2 Raramente faz teste de ponta de dedo antes e trato o açúcar baixo ( $25 \%$ das vezes ou menos da metade)......................1 Nunca faz o teste de ponta de dedo antes de tratar o açúcar baixo no sangue.................................................................

6- As pessoas lidam com uma queda de açúcar no sangue de formas diferentes. $O$ que o (a)seu (sua) filho/filha normalmente faz para tratar as reações de uma queda de açúcar no sangue?( se o entrevistado responder que ele/ela come alguma coisa, pergunte "Quantas gramas de carboidrato tem isso?". Se o entrevistado responder algo diferente de 15g pergunte "É essa a quantidade que o médico falou para ele/ela ingerir?". Então se o entrevistado responder que ele/ela ingere a quantidade prescrita, mas não menciona o teste, pergunte:" ele/ela faz o teste após comer?")

Toma cuidado para rapidamente ingerir a quantidade de carboidratos prescrita ( $15 \mathrm{~g}$ se aplicável) e faz o teste de ponta de dedo após 10 minutos ou insiste que ele/ela nunca teve açúcar baixo no sangue....................................................... Toma a quantidade de carboidratos prescrita, mas não faz teste de ponta de dedo......................................................... Ingere carboidratos (não a quantidade prescrita) sem levar em conta quanto..............................................................

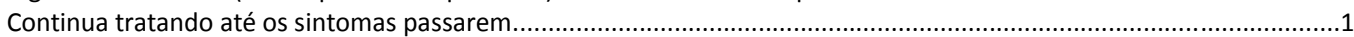
Ignora os sintomas até ter a chance de fazer alguma coisa (espera até o momento em que é conveniente tratar)...........0

7- O (a)seu (sua) filho/filha usa ou carrega consigo algo que a identifica como tendo diabetes, como um cartão ou bracelete?

Usa colar, bracelete ou pingente.

. .2

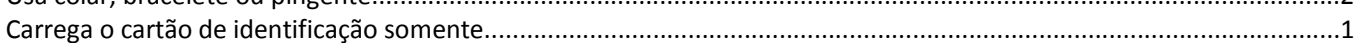

Não tem nenhuma identificação prontamente disponível ..........................................................................................

\section{Alimentação}

Médicos, enfermeiras e nutricionistas pedem às crianças com diabetes que sigam um plano alimentar que os ajude a ter um peso saudável e um bom controle do açúcar no sangue. Várias coisas podem atrapalhar o seguimento desse plano, e mesmo quando se esforçam ao máximo, algumas crianças acham difícil se alimentar exatamente de acordo com o plano. Nessa parte da entrevista eu vou fazer algumas perguntas sobre os hábitos alimentares do (a)seu (sua) filho/filha. Tente ser o mais honesto (a) e preciso (a) possível sobre os hábitos alimentares do (a)seu (sua) filho/filha nos últimos 3 meses.

8- $\mathrm{O}$ (a)seu (sua) filho/filha quantifica o que come, conta carboidratos (ou faz trocas) para saber o quanto ele/ela deve comer, ou ele/ela geralmente come sempre a mesma quantidade de comida sem contar carboidratos? (se o entrevistado responder "Ele/Ela conta carboidratos", pergunte "Diga-me como ele/ela faz para contar carboidratos de uma comida que ele/ela nunca comeu antes?")

Usa a contagem de carboidratos ou lista de trocas como um guia e quantifica a comida e lê os rótulos .......................... Usa a contagem de carboidratos (ou lista de trocas) como um guia, mas conhece bem o plano alimentar para que possa comer a quantidade certa, sem quantificar ou ler os rótulos....................................................................................2 Come aproximadamente a mesma quantia de comida por refeição, mas não quantifica ou usa a contagem de carboidratos (ou lista de trocas).

Come a quantidade que tem vontade e não segue nenhum padrão ou quantificação de comida ......................................

9- Existem alguns tipos de comida que todos deveríamos evitar como doces e comidas com muita gordura como bolachas, salgadinhos, bolos, sorvete, pizza, batata frita, cachorro quente, entre outros. Comer algumas dessas comidas não é necessariamente ruim para o (a)seu (sua) filho/filha, no entanto, comer grandes quantidades de doce ou comidas com muita gordura não é bom para ninguém.

Nos últimos 3 meses, com qual freqüência o (a)seu (sua) filho/filha comeu mais desse tipo de comida do que a quantidade saudável?

Ocasionalmente (poucas vezes por mês ou menos).

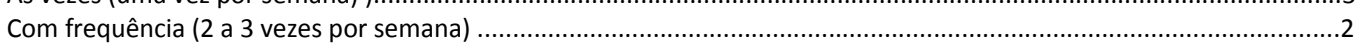

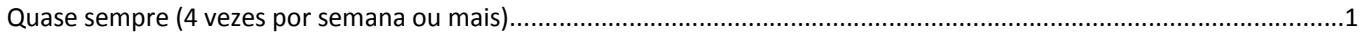

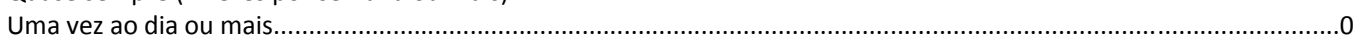

10- Algumas vezes as pessoas comem "MAIS" do que a quantidade prevista no seu plano alimentar. Isso não inclui as vezes em que o (a)seu (sua) filho/filha precisa comer mais porque está se exercitando mais ou quando tem uma queda de açúcar no sangue. Isso pode acontecer quando ele/ela está com muita fome ou quando ele/ela tem vontade de fazer um lanche antes do jantar.

Nos últimos 3 meses, quantas vezes ele/ela comeu mais do que o recomendado no plano alimentar?

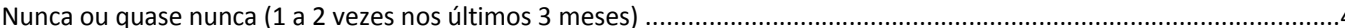

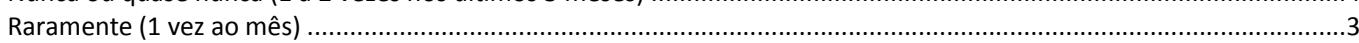

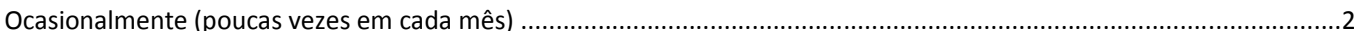




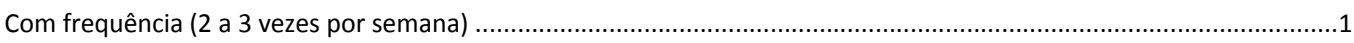

Quase diariamente (4 ou mais vezes por semana) ...............................................................................................

11- Antes de sua criança comer "MAIS" do que ele/ela normalmente come, ele/ela faz alguma mudança na insulina? 0 que ele/ela faz?

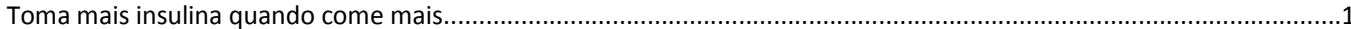

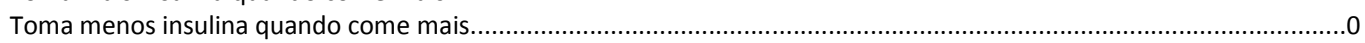

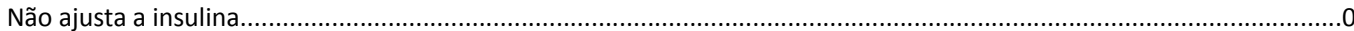

12- Algumas vezes as pessoas comem "MENOS" do que a quantidade prevista no seu plano alimentar. Isso não inclui as vezes em que o (a)seu (sua) filho/filha faz modificações na atividade física, quando ele/ela fica doente ou quando a taxa de açúcar no sangue dele/dela está muito alta. Isso pode acontecer quando ele/ela simplesmente não tem vontade de comer tudo o que está no prato.

Nos últimos 3 meses, quantas vezes o (a)seu (sua) filho/filha comeu menos do que o recomendado no plano alimentar?

Nunca ou quase nunca ( 1 a 2 vezes nos últimos 3 meses) .................................................................................

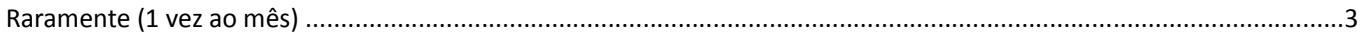

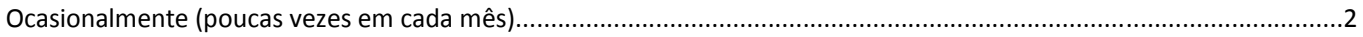

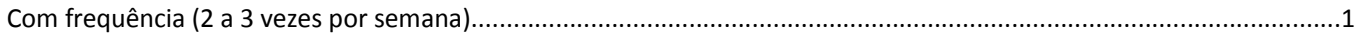

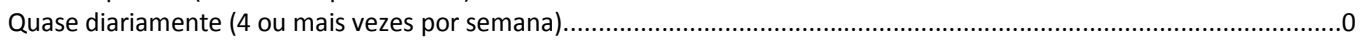

13- Antes de sua criança comer "MENOS" do que ele/ela normalmente come, ele/ela faz alguma mudança na insulina? 0 que ele/ela faz?

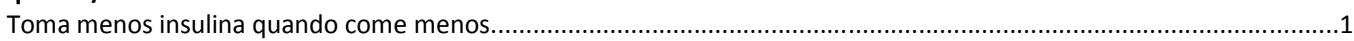

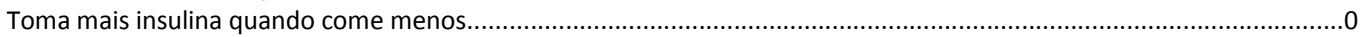

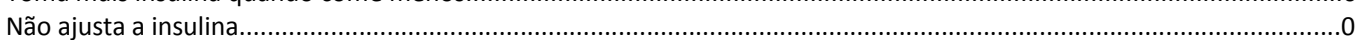

Monitorização do açúcar no sangue- teste de ponta de dedo

Algumas crianças fazem todos os seus testes de ponta de dedo, mas muitas crianças acham difícil em fazer todos os testes que os médicos e enfermeiros pedem. A seguir, eu vou lhe perguntar sobre os hábitos do (a)seu (sua) filho/filha em relação a fazer teste de ponta de dedo. Tente ser o mais honesto (a) e preciso (a) possível sobre os hábitos do (a)seu (sua) filho/filha em relação a fazer os teste de ponta de dedo nos últimos 3 meses.

14- Nos últimos 3 meses, quantas vezes ele/ela fez teste de ponta de dedo por dia?

6 vezes por dia

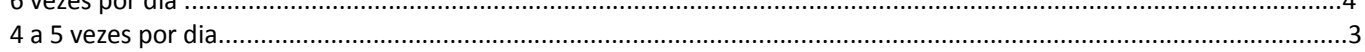

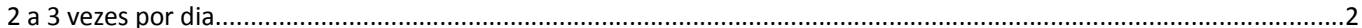

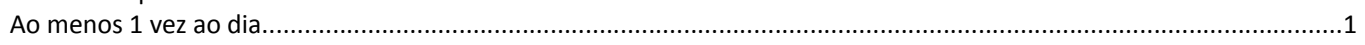

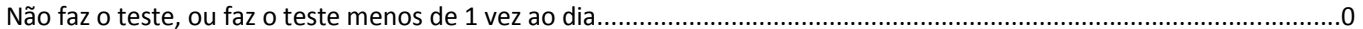

15- Com qual frequência o médico sugeriu que a ele/ela fizesse o teste de ponta de dedo?

6 vezes por dia ou mais.

Ao menos 4 a 5 vezes por dia

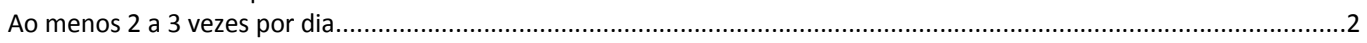

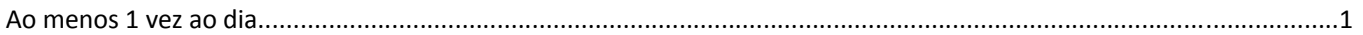

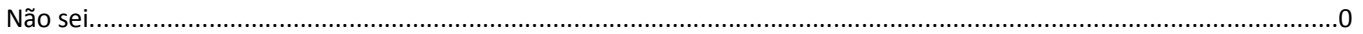

16- Quantas vezes ele/ela faz o teste de ponta de dedo (dentro de $\mathbf{3 0}$ minutos) antes da refeição?

Sempre faz o teste de ponta de dedo (30 minutos) antes de cada refeição.....................................................................4

Com frequência ( $75 \%$ das vezes u mais de metade das vezes) faz o teste de ponta de dedo (30 minutos) antes das refeições.

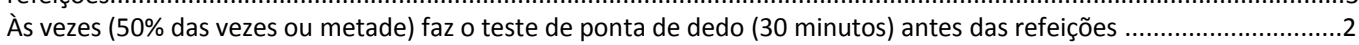
Raramente ( $25 \%$ das vezes ou menos de metade das vezes) faz o teste de ponta de dedo (30 minutos) antes das refeições .......

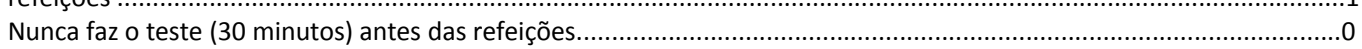

17- Quantas vezes ele/ela faz o teste de ponta de dedo 2 a 3 horas após a refeição?

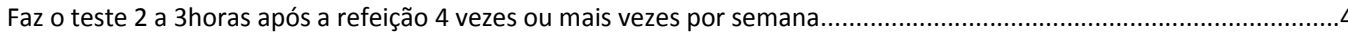

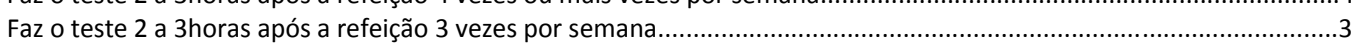

Faz o teste 2 a 3horas após a refeição 2 vezes por semana........................................................................................

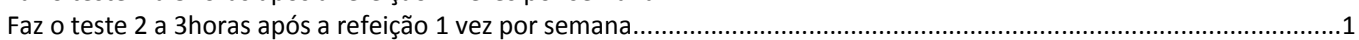

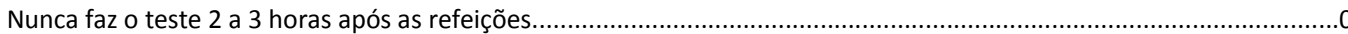

18- Quantas vezes ele/ela faz o teste de ponta de dedo $\mathbf{2}$ a $\mathbf{3}$ horas após atividade física intensa?

Sempre faz o teste de ponta de dedo 2 a 3 horas após o exercício...........................................................................

Com frequência (75\% das vezes u mais de metade das vezes) faz o teste de ponta de dedo 2-3 horas após o exercício...3 Às vezes (50\% das vezes ou metade) faz o teste de ponta de dedo 30 minutos 2-3 horas após o exercício .....................2 Raramente ( $25 \%$ das vezes ou menos de metade das vezes) faz o teste de ponta de dedo 2-3 horas após o exercício.....1

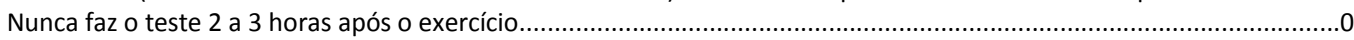


19- Nos últimos 3 meses, quantas vezes ele/ela ajustou a sua dose de insulina, a alimentação, ou a atividade física quando os testes de ponta de dedo dele/dela estavam ficando altos?

Com frequência fez um ajuste quando foi necessário ( $75 \%$ das vezes ou mais de metade das vezes)

Às vezes fez um ajuste quando foi necessário ( $50 \%$ das vezes ou metade das vezes) ..........................................................2

Raramente fez um ajuste quando foi necessário ( $25 \%$ das vezes ou menos de metade das vezes) ...................................1

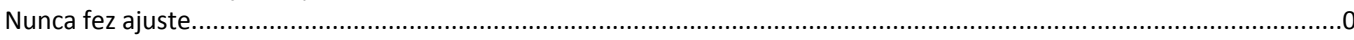

20- $O$ (a)seu (sua) filho/filha costuma fazer o teste para cetonas? Sim $\square \quad$ Não $\square$

Se ele/ela tem 2 resultados de ponta de dedo acima de 240 em sequência, quantas vezes ele/ela faz o teste de cetona na urina?

Não se lembra de ele/ela ter tido 2 testes acima de 240 em sequência.............................................................................

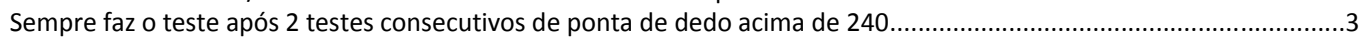

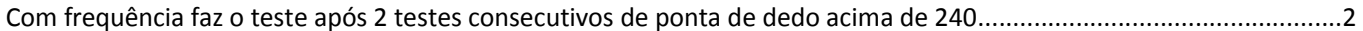

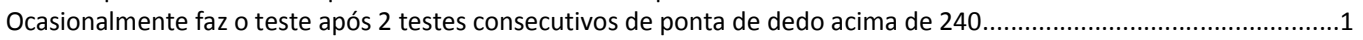

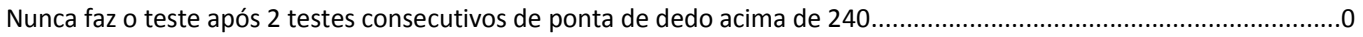

21- Quando o (a)seu (sua) filho/filha está doente, quantas vezes ele/ela faz um teste de cetona na urina? (Se responder "sempre", pergunte quantas vezes por dia?)

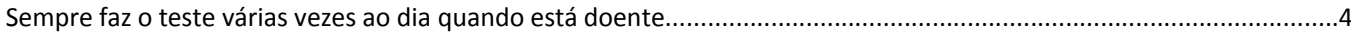

Sempre faz o teste uma vez ao dia quando está doente.........................................................................................

Com frequência faz o teste uma vez ao dia quando está doente................................................................................

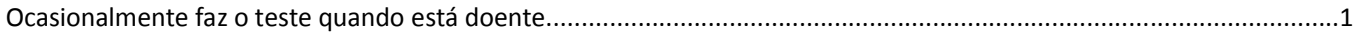

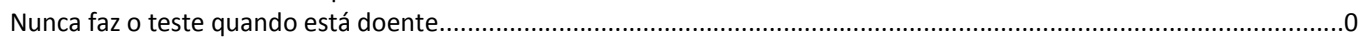

Insulina

Tomar injeções de insulina inclui medir as doses cuidadosamente, tomar as injeções na hora certa e talvez mudar a dose dependendo do resultado do teste de ponta de dedo. Tudo isso não é simples e requer um certo tempo que muitas crianças prefeririam gastar fazendo outras coisas Esta parte da entrevista é sobre os hábitos em relação as aplicações de insulina do (a)seu (sua) filho/filha. Tente ser totalmente honesto (a) quando você responder as perguntas.

22- Nos últimos 3 meses, quantas vezes o (a)seu (sua) filho/filha atrasou para tomar insulina?

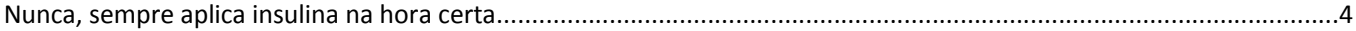

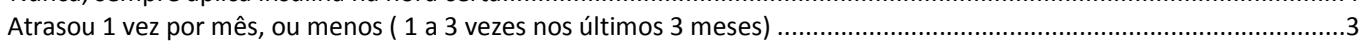

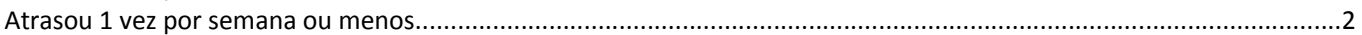

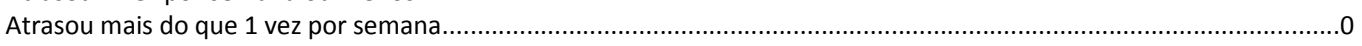

23- Nos últimos 3 meses, quantas vezes o (a)seu (sua) filho/filha aplicou MAIS insulina do que foi prescrito, até mesmo mais do que o esquema de correção permitia?

Sempre aplicou a quantia prescrita.......

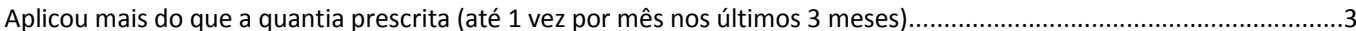

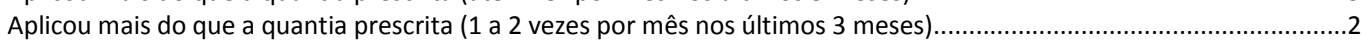

Aplicou mais do que a quantia prescrita ( 3 a 4 vezes por mês nos últimos 3 meses) ........................................................

Aplicou mais do que a quantia prescrita (mais de 4 vezes por mês nos últimos 3 meses)............................................

24- Nos últimos 3 meses, quantas vezes o (a)seu (sua) filho/filha tomou MENOS insulina do que foi prescrito, até mesmo menos do que o esquema de correção permitia?

Sempre aplicou a quantia prescrita.

Aplicou menos do que a quantia prescrita (até 1 vez por mês nos últimos 3 meses)

Aplicou menos do que a quantia prescrita ( 1 a 2 vezes por mês nos últimos 3 meses) ..................................................

Aplicou menos do que a quantia prescrita ( 3 a 4 vezes por mês nos últimos 3 meses)...................................................

Aplicou menos do que a quantia prescrita (mais de 4 vezes por mês nos últimos 3 meses) .............................................

25- Nos últimos 3 meses, quantas vezes o (a)seu (sua) filho/filha deixou de aplicar insulina porque ele/ela esqueceu ou estava muito ocupado?

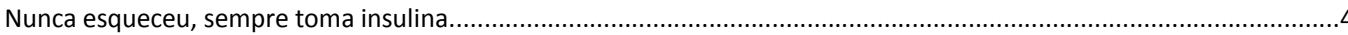

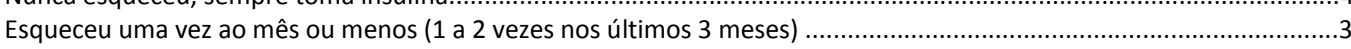

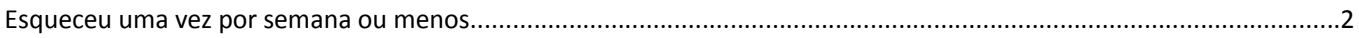

Esqueceu mais do que uma vez por semana 
Tradução DSMP para Pais

Regime Flexível

Cuidar do diabetes significa fazer muitas coisas diferentes como tomar insulina, fazer testes para avaliar o açúcar no sangue, seguir um plano alimentar, fazer exercícios físicos e lidar com o açúcar alto e baixo no sangue. Não é fácil fazer todas estas coisas exatamente como os médicos e as enfermeiras pedem. Muito poucas crianças com diabetes fazem tudo exatamente de acordo com o planejado. Às vezes, o (a) seu (sua) filho/filha pode estar preocupado com outras coisas ou ele/ela pode simplesmente esquecer-se de cuidar do diabetes, apesar de querer cuidar. A maioria das crianças e suas famílias desenvolvem uma forma própria para cuidar do diabetes que seja mais fácil para elas.

O que nós estamos tentando aprender nesta entrevista é como você e sua família cuidam do diabetes do (a)seu (sua) filho/filha. Eu vou te fazer perguntas e escrever suas respostas. Você pode parar a qualquer momento, ou voltar atrás para as primeiras questões para mudar suas respostas. Somente a nossa equipe irá saber as suas respostas. Sua participação é completamente voluntária. Você não precisa responder qualquer pergunta se não quiser. Você não terá qualquer problema se você quiser pular uma questão. Suas respostas não serão divididas com ninguém, assim você pode ficar tranqüilo para me dizer exatamente o que você faz, não somente o que você pensa que deveria fazer ou o que eu gostaria que você dissesse.

Assim, tente ser completamente honesto (a) comigo sobre o que você e sua família têm normalmente feito para cuidar do diabetes do (a)seu (sua) filho/filha nos últimos 3 meses.

\section{Exercício}

Uma parte do cuidado com o diabetes é praticar exercícios regularmente, como correr, andar de bicicleta e nadar. Algumas crianças tentam fazer isto regularmente, enquanto outras têm dificuldade de encontrar tempo suficiente para fazer exercício. Nesta parte da entrevista, eu irei perguntar a você sobre a prática de atividade física do (a) seu(sua) filho/filha, que pode ser praticar algum esporte, participar das aulas de educação física na escola, caminhar ou andar de bicicleta até a escola.

Tente ser o mais honesto (a) e preciso (a) possível sobre a prática de atividade física do (a)seu (sua) filho/filha nos últimos 3 meses.

1- Qual tipo de atividade física o (a)seu (sua) filho/filha pratica?

Nos últimos $\mathbf{3}$ meses, quantas vezes ele/ela praticou esta atividade física por pelo menos 20 minutos ?

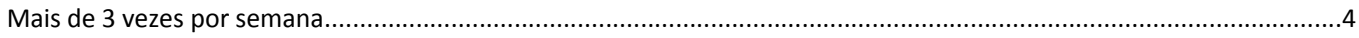

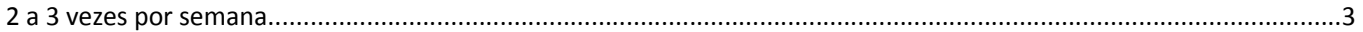

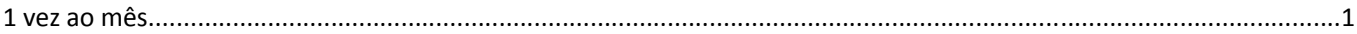

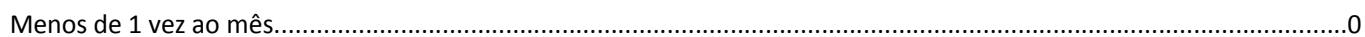

2- Se o (a)seu (sua) filho/filha faz mais exercícios do que o habitual, ou se ele/ela planeja fazer mais exercício, ele/ela muda alguma coisa na alimentação ou na insulina? (se o entrevistado responder não, circule 0 , e siga para a questão 3)

O que ele/ela faz?

Nos últimos 3 meses, você consegue se lembrar de quantas vezes ele/ela fez esta mudança?

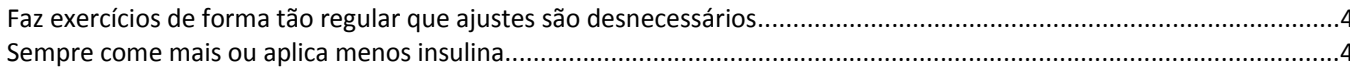

Com frequência come mais ou aplica menos insulina ( 2 a 3 vezes por semana) .............................................................

Às vezes come mais ou aplica menos insulina (1 vez por semana).............................................................................

Ocasionalmente come mais ou aplica menos insulina (poucas vezes no mês)..................................................................

Come menos do que o normal ou aplica mais insulina ou não ajusta a comida ou a insulina ...........................................

3- Se o (a)seu (sua) filho/filha faz menos exercícios do que o normal, ou se ele/ela planeja fazer menos exercício, ele/ela muda alguma coisa na alimentação ou na insulina? (se o entrevistado responder não, circule 0 , e siga para a questão 4)

O que ele/ela faz?

Nos últimos 3 meses, você consegue se lembrar quantas vezes ele/ela fez esta mudança?

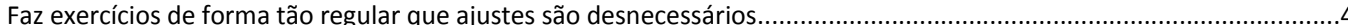

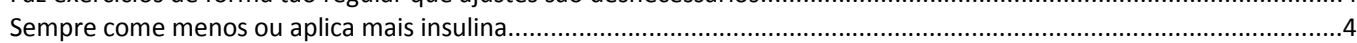

Com frequência come menos ou aplica mais insulina (2 a 3 vezes por semana) .............................................................

Às vezes come menos ou aplica mais insulina (1 vez por semana) ............................................................................

Ocasionalmente come menos ou aplica mais insulina (poucas vezes no mês).................................................................1

Come mais e aplica menos insulina ou não ajusta a comida ou a insulina.......................................................................

\section{Hipoglicemia}

Todas as pessoas com diabetes, às vezes, têm reações pelo baixo açúcar no sangue que podem causar a sensação de tontura, tremedeira, confusão, sudorese, náuseas, fraqueza, fome e irritabilidade. O médico e as enfermeiras provavelmente já te ensinaram algumas coisas para evitar que ocorra a queda do açúcar no sangue e como cuidar quando isto acontece. Esta parte da entrevista é sobre o que o (a)seu (sua) filho/filha geralmente faz quando tem estas reações. Tente ser o mais honesto (a) e preciso (a) possível sobre como o (a)seu (sua) filho/filha lidou com as quedas de açúcar no sangue nos últimos 3 meses. 
4- $\quad O$ (a)seu (sua) filho/filha leva alguma coisa com ela em caso de ter uma reação por causa da queda de açúcar no sangue? Por exemplo, quando ele/ela está na escola ou jogando bola, ou num carro e o açúcar está muito baixo, ele/ela tem algo em mãos para comer?

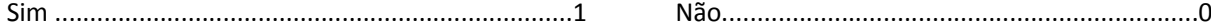

5- Se o (a)seu (sua) filho/filha pensa que o açúcar está baixo, quantas vezes ele/ela faz o teste de ponta de dedo antes de se tratar?

Sempre faz teste de ponta de dedo antes de tratar o açúcar baixo (insiste em dizer que nunca teve açúcar baixo no sangue).

Geralmente faz teste de ponta de dedo antes de tratar o açúcar baixo ( $75 \%$ das vezes ou mais da metade).....................

Algumas vezes faz teste de ponta de dedo antes de tratar o açúcar baixo ( $50 \%$ das vezes ou a metade).........................2 Raramente faz teste de ponta de dedo antes e trato o açúcar baixo ( $25 \%$ das vezes ou menos da metade)....................... Nunca faz o teste de ponta de dedo antes de tratar o açúcar baixo no sangue..............................................................

6- As pessoas lidam com uma queda de açúcar no sangue de formas diferentes. $O$ que o (a)seu (sua) filho/filha normalmente faz para tratar as reações de uma queda de açúcar no sangue?( se o entrevistado responder que ele/ela come alguma coisa, pergunte "Quantas gramas de carboidrato tem isso?". Se o entrevistado responder algo diferente de 15g pergunte "É essa a quantidade que o médico falou para ele/ela ingerir?". Então se o entrevistado responder que ele/ela ingere a quantidade prescrita, mas não menciona o teste, pergunte:" ele/ela faz o teste após comer?")

Toma cuidado para rapidamente ingerir a quantidade de carboidratos prescrita (15g se aplicável) e faz o teste de ponta de dedo após 10 minutos ou insiste que ele/ela nunca teve açúcar baixo no sangue........................................................ Toma a quantidade de carboidratos prescrita, mas não faz teste de ponta de dedo.......................................................... Ingere carboidratos (não a quantidade prescrita) sem levar em conta quanto...............................................................2

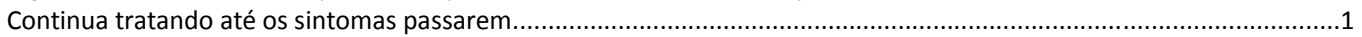
Ignora os sintomas até ter a chance de fazer alguma coisa (espera até o momento em que é conveniente tratar)............

7- $O$ (a)seu (sua) filho/filha usa ou carrega consigo algo que a identifica como tendo diabetes, como um cartão ou bracelete?

Usa colar, bracelete ou pingente.............................................................................................................................

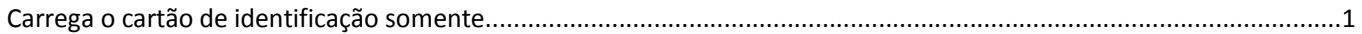

Não tem nenhuma identificação prontamente disponível .................................................................................................

Alimentação

Médicos, enfermeiras e nutricionistas pedem às crianças com diabetes que sigam um plano alimentar que os ajude a ter um peso saudável e um bom controle do açúcar no sangue. Várias coisas podem atrapalhar o seguimento desse plano, e mesmo quando se esforçam ao máximo, algumas crianças acham difícil se alimentar exatamente de acordo com o plano. Nessa parte da entrevista eu vou fazer algumas perguntas sobre os hábitos alimentares do (a)seu (sua) filho/filha. Tente ser o mais honesto (a) e preciso (a) possível sobre os hábitos alimentares do (a)seu (sua) filho/filha nos últimos 3 meses.

8- $\quad O$ (a)seu (sua) filho/filha quantifica o que come, conta carboidratos (ou faz trocas) para saber o quanto ele/ela deve comer, ou ele/ela geralmente come sempre a mesma quantidade de comida sem contar carboidratos? (se o entrevistado responder "Ele/Ela conta carboidratos", pergunte "Diga-me como ele/ela faz para contar carboidratos de uma comida que ele/ela nunca comeu antes?")

Usa a contagem de carboidratos ou lista de trocas como um guia e quantifica a comida e lê os rótulos ............................3 Usa a contagem de carboidratos (ou lista de trocas) como um guia, mas conhece bem o plano alimentar para que possa comer a quantidade certa, sem quantificar ou ler os rótulos.........................................................................................2 Come aproximadamente a mesma quantia de comida por refeição, mas não quantifica ou usa a contagem de carboidratos (ou lista de trocas) .......................................................................................................... Come a quantidade que tem vontade e não segue nenhum padrão ou quantificação de comida.......................................

9- Existem alguns tipos de comida que todos deveríamos evitar como doces e comidas com muita gordura como bolachas, salgadinhos, bolos, sorvete, pizza, batata frita, cachorro quente, entre outros. Comer algumas dessas comidas não é necessariamente ruim para o (a)seu (sua) filho/filha, no entanto, comer grandes quantidades de doce ou comidas com muita gordura não é bom para ninguém.

Nos últimos 3 meses, com qual frequência o (a)seu (sua) filho/filha comeu mais desse tipo de comida do que a quantidade saudável?

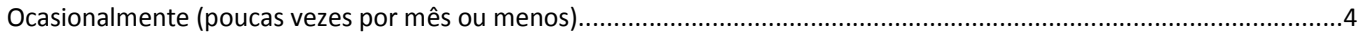

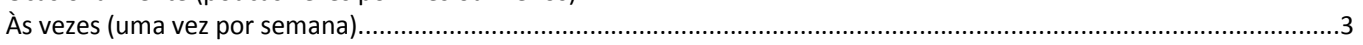

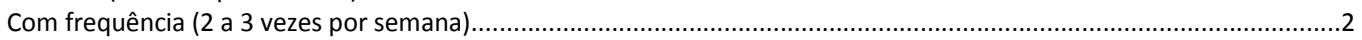

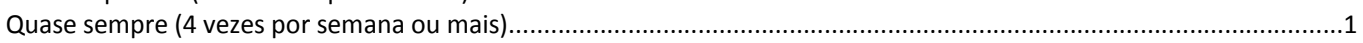

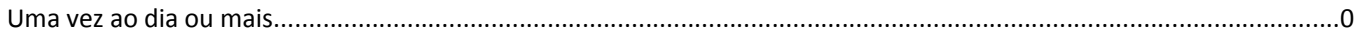

10- Algumas vezes as pessoas comem "MAIS" em relação à insulina previamente calculada e ingerida (bolus). Isso não inclui as vezes em que o (a)seu (sua) filho/filha precisa comer mais porque está fazendo mais atividade física ou porque teve uma queda de açúcar no sangue. Isso pode acontecer quando ele/ela está com muita fome ou quando tem vontade de fazer um lanche antes do jantar.

Nos últimos 3 meses, quantas vezes ele/ela comeu mais do que o havia feito de bolus de insulina?

(se o paciente responder "Ele/ela não faz bolus até depois de comer" circule 0 e pergunte o (a)seu (sua) filho/filha faz o bolus após comer porque o médico recomendou? Se responder sim, risque o quadrado.) 
Nunca ou quase nunca ( $1-2$ vezes nos últimos 3 meses) ........................................................................................

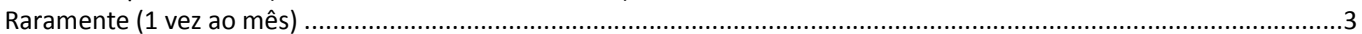

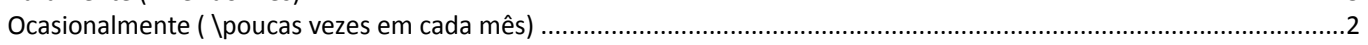

Frequentemente ( 2-3 vezes por semana) ………………....................................................................................

Quase diariamente ( 4 ou mais vezes por semana) ou não faz o bolus até depois de comer ................................................

Bolus após comer baseado na recomendação médica___

11- Se o (a)seu (sua) filho/filha espera comer MAIS do que está no seu plano alimentar, ele/ela muda a dose do bolus de insulina? Se sim, como?

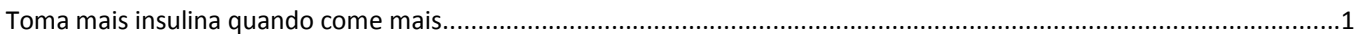

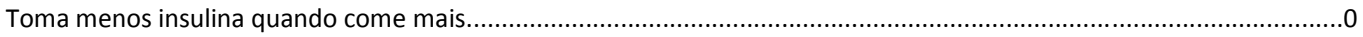

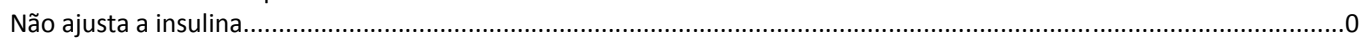

12- Algumas vezes as pessoas comem "MENOS" do que fizeram de bolus de insulina. Isto não inclui quando o (a)seu (sua) filho/filha faz modificações na atividade física, ou quando ele/ela está doente ou quando o açúcar no sangue está muito alto. Isto inclui as vezes que ele/ela não quer comer tudo o que está no seu prato.

Nos últimos 3 meses, quantas vezes o (a)seu (sua) filho/filha comeu menos do que havia feito de bolus? (se o paciente responder "Ele/ela não faz bolus até depois de comer" circule 0 e pergunte o (a)seu (sua) filho/filha faz o bolus após comer porque o médico recomendou? Se responder sim, risque o quadrado.

Nunca ou quase nunca ( $1-2$ vezes nos últimos 3 meses) .......................................................................................

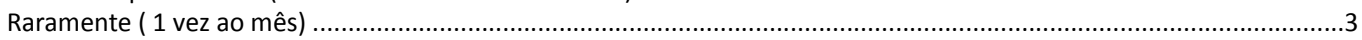

Ocasionalmente ( poucas vezes em cada mês) …………….................................................................................2

Frequentemente ( 2-3 vezes por semana) ……………........................................................................................

Quase diariamente ( 4 ou mais vezes por semana) ou não faz o bolus até depois de comer .............................................

Bolus após comer baseado na recomendação médica___

13- Se o (a)seu (sua) filho/filha espera comer MENOS do que está no seu plano alimentar, ele/ela muda a dose do bolus de insulina? Se sim, como?

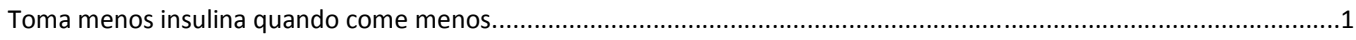

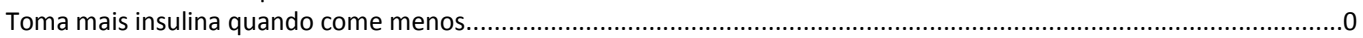

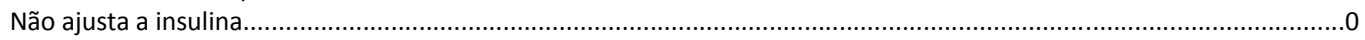

Monitorização do açúcar no sangue- teste de ponta de dedo

Algumas crianças fazem todos os seus testes de ponta de dedo, mas muitas crianças acham difícil em fazer todos os testes que os médicos e enfermeiros pedem. A seguir, eu vou lhe perguntar sobre os hábitos do (a)seu (sua) filho/filha em relação a fazer teste de ponta de dedo. Tente ser o mais honesto (a) e preciso (a) possível sobre os hábitos do (a)seu (sua) filho/filha em relação a fazer os teste de ponta de dedo nos últimos 3 meses.

14- Nos últimos 3 meses, quantas vezes ele/ela fez teste de ponta de dedo por dia?

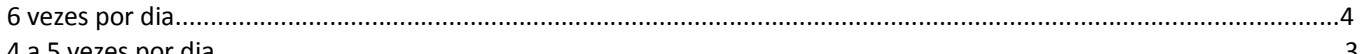

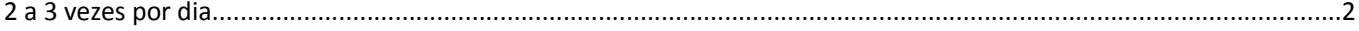

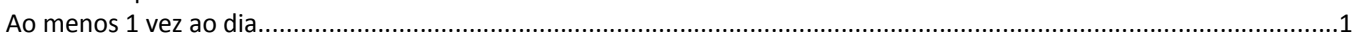

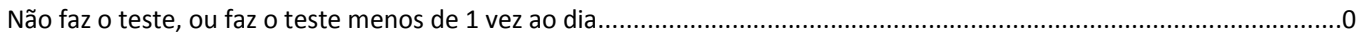

15- Com qual frequência o médico sugeriu que a ele/ela fizesse o teste de ponta de dedo?

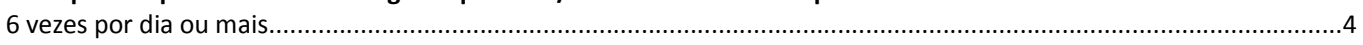

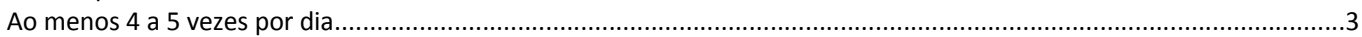

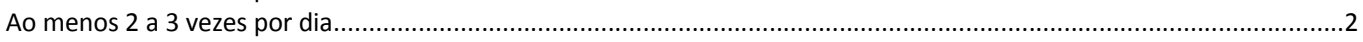

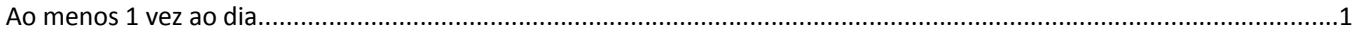

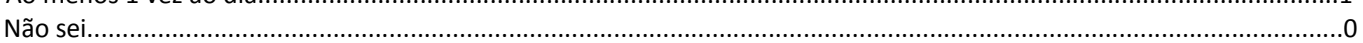

16- Quantas vezes ele/ela faz o teste de ponta de dedo (dentro de 30 minutos) antes da refeição?

Sempre faz o teste de ponta de dedo (30 minutos) antes de cada refeição..................................................................

Com frequência ( $75 \%$ das vezes u mais de metade das vezes) faz o teste de ponta de dedo (30 minutos) antes das

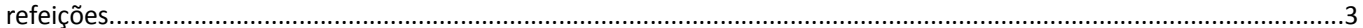

Às vezes ( $50 \%$ das vezes ou metade) faz o teste de ponta de dedo (30 minutos) antes das refeições .................................2 Raramente ( $25 \%$ das vezes ou menos de metade das vezes) faz o teste de ponta de dedo ( 30 minutos) antes das refeições

Nunca faz o teste (30 minutos) antes das refeições..

17- Quantas vezes ele/ela faz o teste de ponta de dedo 2 a 3 horas após a refeição?

Faz o teste 2 a 3horas após a refeição 4 vezes ou mais vezes por semana...................................................................

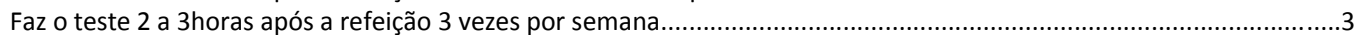

Faz o teste 2 a 3horas após a refeição 2 vezes por semana..........................................................................................

Faz o teste 2 a 3horas após a refeição 1 vez por semana.........................................................................................

Nunca faz o teste 2 a 3 horas após as refeições......................................................................................................

18- Quantas vezes ele/ela faz o teste de ponta de dedo 2 a 3 horas após atividade física intensa?

Sempre faz o teste de ponta de dedo 2 a 3 horas após o exercício

Com frequência (75\% das vezes u mais de metade das vezes) faz o teste de ponta de dedo 2-3 horas após o exercício 
Às vezes ( $50 \%$ das vezes ou metade) faz o teste de ponta de dedo 30 minutos 2-3 horas após o exercício Raramente ( $25 \%$ das vezes ou menos de metade das vezes) faz o teste de ponta de dedo 2-3 horas após o exercício Nunca faz o teste 2 a 3 horas após o exercício

19- Nos últimos 3 meses, quantas vezes ele/ela ajustou a sua dose de insulina, a alimentação, ou a atividade física quando os testes de ponta de dedo dele/dela estavam ficando altos?

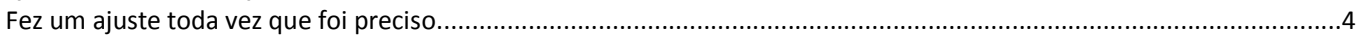

Com frequência fez um ajuste quando foi necessário ( $75 \%$ das vezes ou mais de metade das vezes) ..............................3

Às vezes fez um ajuste quando foi necessário ( $50 \%$ das vezes ou metade das vezes) ......................................................2

Raramente fez um ajuste quando foi necessário ( $25 \%$ das vezes ou menos de metade das vezes).................................

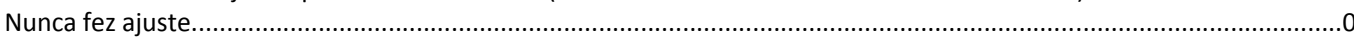

20- $O$ (a)seu (sua) filho/filha costuma fazer o teste para cetonas? Sim $\square \quad$ Não $\square$

Se ele/ela tem 2 resultados de ponta de dedo acima de 240 em sequência, quantas vezes ele/ela faz o teste de cetona na urina?

Não se lembra de ele/ela ter tido 2 testes acima de 240 em sequência...................................................................

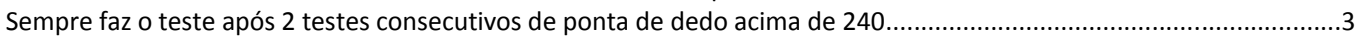

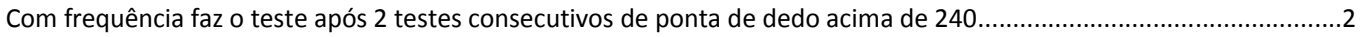

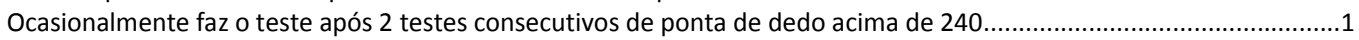

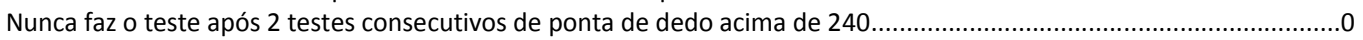

21- Quando o (a)seu (sua) filho/filha está doente, quantas vezes ele/ela faz um teste de cetona na urina? (Se responder "sempre", pergunte quantas vezes por dia?)

Sempre faz o teste várias vezes ao dia quando está doente

Sempre faz o teste uma vez ao dia quando está doente...

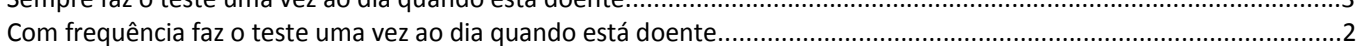

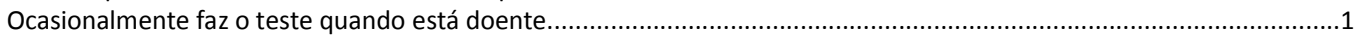

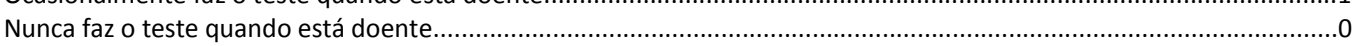

Insulina

Tomar injeções de insulina inclui medir as doses cuidadosamente, tomar as injeções na hora certa e talvez mudar a dose dependendo do resultado do teste de ponta de dedo. Tudo isso não é simples e requer um certo tempo que muitas crianças prefeririam gastar fazendo outras coisas Esta parte da entrevista é sobre os hábitos em relação as aplicações de insulina do (a)seu (sua) filho/filha. Tente ser totalmente honesto (a) quando você responder as perguntas.

22- Nos últimos 3 meses, quantas vezes o (a)seu (sua) filho/filha atrasou um bolus ou aplicação de insulina que ele/ela não deveria ter atrasado?

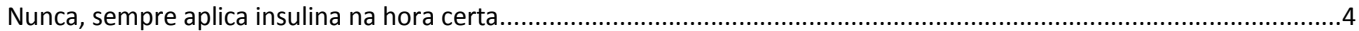

Atrasou 1 vez por mês, ou menos ( 1 a 3 vezes nos últimos 3 meses) ..........................................................................

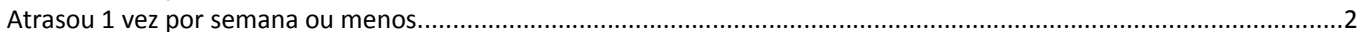

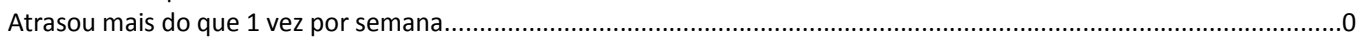

23- Nos últimos 3 meses, quantas vezes o (a)seu (sua) filho/filha aplicou MAIS insulina ou fez mais bolus do que deveria ter feito, ou, ele/ela alguma vez aplicou muita insulina?

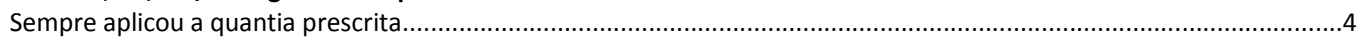

Aplicou mais do que a quantia prescrita (até 1 vez por mês nos últimos 3 meses).........................................................

Aplicou mais do que a quantia prescrita ( 1 a 2 vezes por mês nos últimos 3 meses) .......................................................

Aplicou mais do que a quantia prescrita ( 3 a 4 vezes por mês nos últimos 3 meses) .......................................................

Aplicou mais do que a quantia prescrita (mais de 4 vezes por mês nos últimos 3 meses)...........................................

24- Nos últimos 3 meses, quantas vezes o (a)seu (sua) filho/filha aplicou MENOS insulina ou fez MENOS bolus do que deveria ter feito, ou, ele/ela alguma vez aplicou pouca insulina?

Sempre aplicou a quantia prescrita

Aplicou menos do que a quantia prescrita (até 1 vez por mês nos últimos 3 meses).

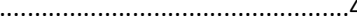

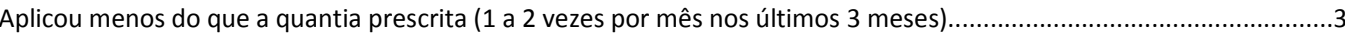

Aplicou menos do que a quantia prescrita ( 3 a 4 vezes por mês nos últimos 3 meses) ...................................................

Aplicou menos do que a quantia prescrita (mais de 4 vezes por mês nos últimos 3 meses)..........................................

25- Nos últimos 3 meses, quantas vezes o (a)seu (sua) filho/filha perdeu o bolus ou a aplicação de insulina porque ele/ela esqueceu ou estava muito ocupado, ou, falhou na administração da insulina basal porque a bomba não estava funcionando ou não estava inserida?

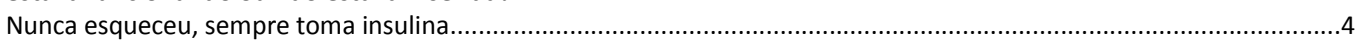

Esqueceu uma vez ao mês ou menos ( 1 a 2 vezes nos últimos 3 meses) ..................................................................

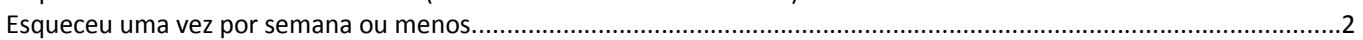

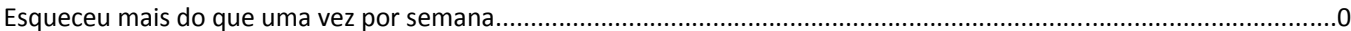




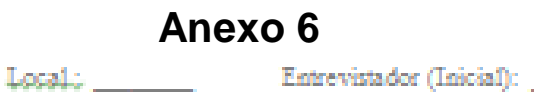

Ideatificaça do Famila: Data:

Participante: Mae Pai Ovaro cuidador Criança

Regime:Conveacional Flextre1

Idade da Criasc:

\section{Escore - DLABETES SELF-MANAGEMENT PROFILE}

\section{ATIVIDADE FISICA}

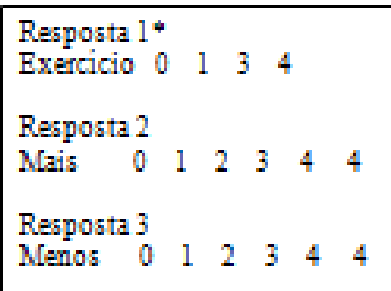

\begin{tabular}{|c|c|c|c|c|}
\hline \multicolumn{5}{|c|}{ HIPOGLICEMIIA } \\
\hline $\begin{array}{l}\text { Resposta } 4 \\
\text { Emerg } 0\end{array}$ & 1 & & & \\
\hline $\begin{array}{l}\text { Resposta } 5 \\
\text { Baixo } 0\end{array}$ & 1 & 2 & 3 & 4 \\
\hline Resposta 6 & & & & \\
\hline Tratam 0 & 1 & 2 & 3 & 4 \\
\hline $\begin{array}{l}\text { Resposta ? } \\
\text { Indentificaçäo }\end{array}$ & & 0 & 1 & 2 \\
\hline
\end{tabular}

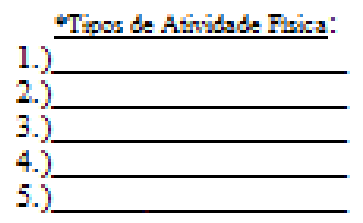

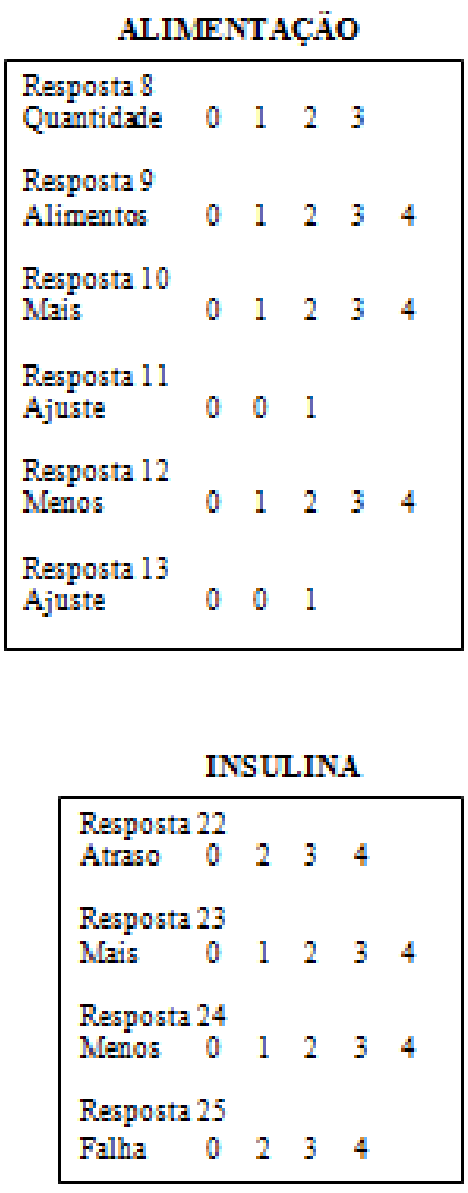

\section{MONTORIZACุÄO}

Resposta 14

$\begin{array}{llllll}\text { Freq } & 0 & 1 & 2 & 3 & 4\end{array}$

Resposta 15

$\begin{array}{llllll}\text { Dif. } & 0 & 1 & 2 & 3 & 4\end{array}$

Resposta 16

$\begin{array}{llllll}\text { Antes } & 0 & 1 & 2 & 3 & 4\end{array}$

Resposta 17

$\begin{array}{llllll}\text { Após } & 0 & 1 & 2 & 3 & 4\end{array}$

Resposta 18

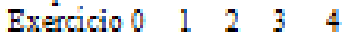

Resposta 19

Ajuste $\begin{array}{llllll}0 & 1 & 2 & 3 & 4\end{array}$

Resposta 20

$\begin{array}{llllll}\text { Alto } & 0 & 1 & 2 & 3 & 4\end{array}$

Resposta 21

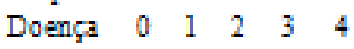

Teste de Cetonemia: Sim Nâo 
11 REFERÊNCIAS 
1. Alberti KGMM, Zimmet $\mathrm{PZ}$, for the WorldHealth Organization Consultation. Definition, diagnosis and classification of diabetes mellitus and its complications. Part 1: Diagnosis and classification of diabetes mellitus. Report of a WHO Consultation.Geneva: WHO; 1999.

2. American Diabetes Association. Classification and diagnosis of diabetes. Diabetes Care.2015;38 (Suppl. 1):S8-S162015)

3. The Expert Committee on the diagnosis and classification of diabetes mellitus. Report of the Expert Committee on the diagnosis and classification of diabetes mellitus. Diabetes Care. 2003 Jan;26 Suppl 1:S5-20.

4. International Diabetes Federation. IDF Diabetes, 7 ed. Brussels, Belgium: International Diabetes Federation, 2015. http://www.diabetesatlas.org. The global picture.pp50-64

5. Robinson N, Lloyd CE, Stevens LK. Social deprivation and mortality in adults with diabetes mellitus. Diabet Med. 1998;15:205-12.

6. Patterson C, Guariguata L, Dahlquist G, Soltész G, Ogle G, Silink M. Diabetes in the young - a global view and worldwide estimates of numbers of children with type 1 diabetes. Diabetes Res Clin Pract. 2013 Dec 1. pii: S0168-8227(13)00388-4. doi: 10.1016/j.diabres.2013.11.005.

7. Ferreira SR, Franco LJ, Vivolo MA, Negrato CA, Simoes AC, Ventureli CR. Population-based incidence of IDDM in the state of São Paulo, Brazil. Diabetes Care. 1993 May;16(5):701-4.

8. Negrato CA, Dias JP, Teixeira MF, Dias A, Salgado MH, Lauris JR, Montenegro RM Jr, Gomes MB, Jovanovic L. Temporal trends in incidence of Type 1 diabetes between 1986 and 2006 in Brazil. J Endocrinol Invest. 2010;33(6):373-7.

9. www.datasus.gov.br, acesso $14 / 01 / 15$

10. Diabetes Control Complications Trial Research Group. The effect of intensive treatment of diabetes on the development and progression of 
long-term complications in insulin-dependent diabetes mellitus. $\mathrm{N}$ Engl J Med. 1993;329:977-986

11. Harris $M$, Wysocki $T$, Sadler $M$, Wilkinson $K$ et al. Validation of $a$ structured Interview for the Assesment of Diabetes Self- Management. Diabetes Care.2000;23:1301-1304.

12. Lewin $A B$, Heidgerken AD, Geffken GR, Williams LB, Storch, EA, Gelfand KM, et al. The relation between family factors and metabolic control: the role of diabetes adherence. Journal of Pediatric Psychology. 2006; 31, 174-183.

13. American Diabetes Association (ADA). (2003). Economic costs of diabetes in the U.S. in 2002. Diabetes Care 2002;26, 917-932.

14. Icks A, Holl RW, Giani G. Economics in pediatric type 1 diabetes results from recently published studies. Experimental Clinical Endocrinology and Diabetes. 2007; 115, 448-454.

15. Clement S. Diabetes education in children and adolescents. Pediatric Diabetes. 2007;8:103-109.

16. American Association of Diabetes Educators. Standards for outcomes measurements of diabetes self-management education. The Diabetes Educator. 2003;29:804-816

17. Funnell MM, Brown TL, Childs BP, Haas LB, Hosey GM, Jensen B, Maryniuk M, Peyrot M, Piette JD, Reader D, Siminerio LM, Weinger K, Weiss MA. National standards for diabetes self-management education. Diabetes Care. 2008 Jan;31 Suppl 1:S97-104.

18. Tradução para o português e validação do instrumento Diabetes Quality of Life Measure (DQOL-Brasil) / Translation to portuguese and validation of the Diabetes Quality Of Life Measure (DQOL-Brazil).Ara Bras Endocrinol Metab. 2008;52(3):515-522.

19. Quittner AL, Modi AC, Lemanek K L, levers-Landis CE, Rapoff MA. Evidence-based assessment of adherence to medical treatments in pediatric psychology. Journal of Pediatric Psychology. 2008; 33, 916936. 
20. Schilling LS, Grey $M$, Knafl KA. A review of measures of selfmanagement of type 1 diabetes by youth and their parents. Diabetes Educ. 2002 Sep-Oct;28(5):796-80.

21. Schilling LS, Dixon JK, Knafl KA, Lynn MR, Murphy K.,Dumser S, Grey M. A new self-report reasure of the Self-management. Nurs Res. 2009; Jul-Aug;58(4):228-36.

22. Hanson CL, Henggeler SW, Burghen GA. Social competence and parental support as mediators of the link between stress and metabolical control in youths insulin-dependent diabetes mellitus .J Consult Clin Psycho. 1987; 57:644-651.

23. Diabetes Research in Children Network (Direct Net) Group. (2005). Diabetes self-management profilefor flexible insulin regimens: Crosssectional \&longitudinal analysis of psychometric properties in a pediatric sample. Diabetes Care. 2005; 28, 2034-2035.

24. lannotti RJ, Nasel R.N. Schneider SS, Haynie DL, Simons-Morton B, Sobel DO, Zeitzoff $L$ et al. Assessing regimen adherence of adolescents with type 1 diabetes. Diabetes Care. 2006; 29:2263

25. Lewin A. Brief report: Normative Data on a structured interview for diabetes adhrence in childhood. Journal of Pediatric Psychology. 2010; 35(2)pp 177-182.

26. Valenzuela, JM, Fernandez MC, Harris MA, Taylor C, La Greca, AM, Delamater, AM. Psycometric indings for a Spanish Translation of the Diabetes Self- Manegement Profile ( DSMP- Parent - Sp).Diabetes Care. 2010,33:3-8.

27. Wysocki T, Buckloh LM, Antal H, Lochrie A, Taylor A. Validation of a selfreport version of the diabetes self-management profile. Pediatr Diabetes. 2012 Aug;13(5):438-43.

28. Teló GH, Souza MS, Schaan BD. Cross-cultural adaptation and validation to Brazilian Portuguese of two measuring adherence instruments for patients with type 1 diabetes. Diabetology \& Metabolic Syndrome. 2014, 6:141 
29. Guillemin F, Bombardier C, Beaton D. Cross-cultural adaptation of healthrelated quality of life measures: literature review and proposed guidelines. J Clin Epidemiol. 1993;46:1417-32.

30. Bullinger $M$, Alonso J, Apolone $G$, Leplège $A$, Sullivan $M$, WoodDauphinee $S$, et al. Translating health status questionnaires and evaluating their quality: the IQOLA Project approach. International Quality of Life Assessment. J Clin Epidemiol. 1998;51:913-23

31. Varni JW. PedsQLTM Translation MethodologyTM. 1998-2007 [cited Sep 19 2000]. http://www.pedsql.org/translations.html

32. Cronbach LJ. Coefficient alpha and the internal structure of tests. Psychometrika. 16(3), 297-334, 1951

33. IBM Corp. Released 2011. IBM SPSS Statistics for Windows, Version 20.0. Armonk, NY: IBM Corp.

34. Shrivastava et al. Journal of Diabetes \& Metabolic Disorders. 2013, 12:14.

35. Rosenbauer J; Dost A; Karges B; Hungele A; Stahl A,; et al. Improved Metabolic Control in Children and Adolescents With Type 1 Diabetes: A trend analysis using prospective multicenter data from Germany and Austria. Diabetes Care 2012,31: 80-6.

36. ftp://ftp.ibge.gov.br/Trabalho_e_Rendimento/Pesquisa_Nacional_por_Am ostra_de_Domicilios_continua/Renda_domiciliar_per_capita_2014/Rend a_domiciliar_per_capita_2014.pdf

37. http://portal.acsp.com.br/assets/html/indicadores/indicadores iegv/iegv d olar.html

38. http://www.ibope.com.br/pt-br/noticias/Paginas/61-das-mulheres-estaono-mercado-de-trabalho.aspx

39. Cameron FJ, Amin R, de Beaufort C, Codner E, Acerini CL. ISPAD Clinical Practice Consensus Guidelines - 2014: Diabetes in adolescence. Pediatric Diabetes. 2014: 15 (Suppl. 20): 245-256

40. Danne T, Bangstad H-J, Deeb L, Jarosz-Chobot P, Mungaie L, Saboo B, Urakami T, Battelino T, Hanas R. Insulin treatment in children and adolescents with diabetes. Pediatric Diabetes. 2014: 15 (Suppl. 20): 115-134. 
41. Lange $K$, Swift $P$, Pankowska $E$, Danne $T$. Diabetes education in children and adolescents. Pediatric Diabetes. 2014: 15 (Suppl. 20): 77-85.

42. http://www.joslin.org/info/joslin-clinical-guidelines.html

43. Hallal PC, Bertoldi AD, Gonçalves H, Victora CG. Prevalence of sedentary lifestyle and associated factors in adolescents 10 to 12 years of age. Cad Saude Publica. 2006; 22: 1277-87.

44. Cabrera, TFC, Correia IFL, Santos, DOP, Francis Lopes Prado MTA. Silva, TDM et al. Analisys of the prevalence of overweight and obesity and the level of physical activity in children and adolescents. Journal of Human Growth and Development. 2014; 24(1): 67-66. 